\title{
Supporting Information for \\ Process Research and Impurity Control Strategy for Obeticholic Acid, a Farnesoid X Receptor Agonist
}

Wei-Dong Feng†, Song-Ming Zhuoł, Fu-Li Zhang†§*

†Collaborative Innovation Center of Yangze River Delta Region Green Pharmaceuticals, Zhejiang University of Technology, 18

Chaowang Road, Hangzhou 310014, China

$\ddagger$ Department of Pharmaceutial Engineering, China Pharmaceutical University, 24 Tongjiaxiang, Nanjing 210009, China

§Shanghai Institute of Pharmaceutical Industry, China State Institute of Pharmacetical Industry, 285 Gebaini Road, Pudong, Shanghai 201203, China

\section{AUTHOR INFORMATION}




\section{CONTENTS:}

(1) ${ }^{1} \mathrm{H}$ NMR, ${ }^{13} \mathrm{C}$ NMR, HRMS, and HPLC data of 2.

S-1, S-2, S-3, S-4

(2) ${ }^{1} \mathrm{H}$ NMR, ${ }^{13} \mathrm{C}$ NMR, HRMS and HPLC data of 6.

S-5, S-6, S-7, S-8

(3) ${ }^{1} \mathrm{H}$ NMR and ${ }^{13} \mathrm{C}$ NMR data of $\mathbf{6 a}$.

S-9, S-10

(4) ${ }^{1} \mathrm{H}$ NMR and ${ }^{13} \mathrm{C}$ NMR data of 7.

S-11, S-12

(5) ${ }^{1} \mathrm{H}$ NMR and ${ }^{13} \mathrm{C}$ NMR data of $\mathbf{7 a}$.

S-13, S-14, S-15

(6) ${ }^{1} \mathrm{H}$ NMR, ${ }^{13} \mathrm{C}$ NMR, HRMS and HPLC data of 8.

S-16, S-17, S-18, S-19

(7) ${ }^{1} \mathrm{H}$ NMR, ${ }^{13} \mathrm{C}$ NMR, HRMS and HPLC data of 9.

$\mathrm{S}-20, \mathrm{~S}-21, \mathrm{~S}-22, \mathrm{~S}-23$

(8) ${ }^{1} \mathrm{H}$ NMR, ${ }^{13} \mathrm{C}$ NMR and HRMS data of 9a.

S-24, S-25, S-26

(9) ${ }^{1} \mathrm{H}$ NMR, ${ }^{13} \mathrm{C}$ NMR, HRMS and HPLC data of $\mathbf{1 0}$.

S-27, S-28, S-29, S-30

(10) ${ }^{1} \mathrm{H}$ NMR, ${ }^{13} \mathrm{C}$ NMR, HRMS and content assay data of 1 (OCA).

S-31, S-32, S-33, S-34

(11) Content assay data of the original drugs from Intercept Pharmaceuticals Inc.

S-35

(12) ${ }^{1} \mathrm{H}$ NMR, ${ }^{13} \mathrm{C}$ NMR and HRMS data of Imp-1.

S-36, S-37, S-38

(13) ${ }^{1} \mathrm{H}$ NMR, ${ }^{13} \mathrm{C}$ NMR and HRMS data of Imp-2.

S-39, S-40, S-41

(14) ${ }^{1} \mathrm{H}$ NMR, ${ }^{13} \mathrm{C}$ NMR and HRMS data of Imp-3.

S-42, S-43, S-44

(15) ${ }^{1} \mathrm{H}$ NMR, ${ }^{13} \mathrm{C}$ NMR and HRMS data of Imp-4.

S-45, S-46, S-47

(16) ${ }^{1} \mathrm{H}$ NMR, ${ }^{13} \mathrm{C}$ NMR and HRMS data of Imp-5.

S-48, S-49, S-50

(17) ${ }^{1} \mathrm{H}$ NMR, ${ }^{13} \mathrm{C}$ NMR and HRMS data of Imp-6.

S-51, S-52, S-53

(18) ${ }^{1} \mathrm{H}$ NMR, ${ }^{13} \mathrm{C}$ NMR and HRMS data of Imp-7.

S-54, S-55, S-56

(19) ${ }^{1} \mathrm{H} N M R,{ }^{13} \mathrm{C}$ NMR and HRMS data of Imp-8.

S-57, S-58, S-59

(20) ${ }^{1} \mathrm{H}$ NMR, ${ }^{13} \mathrm{C}$ NMR and HRMS data of Imp-9.

S-60, S-61, S-62 
(21) ${ }^{1} \mathrm{H}$ NMR, ${ }^{13} \mathrm{C}$ NMR and HRMS data of Imp-10.

S-63, S-64, S-65

(22) ${ }^{1} \mathrm{H}$ NMR, ${ }^{13} \mathrm{C}$ NMR and HRMS data of Imp-11.

S-66, S-67, S-68

(23) ${ }^{1} \mathrm{H}$ NMR, ${ }^{13} \mathrm{C}$ NMR and HRMS data of Imp-12.

S-69, S-70, S-71

(24) ${ }^{1} \mathrm{H}$ NMR, ${ }^{13} \mathrm{C}$ NMR and HRMS data of Imp-13.

S-72, S-73, S-74

(25) ${ }^{1} \mathrm{H}$ NMR, ${ }^{13} \mathrm{C}$ NMR and HRMS data of Imp-14.

S-75, S-76, S-77 


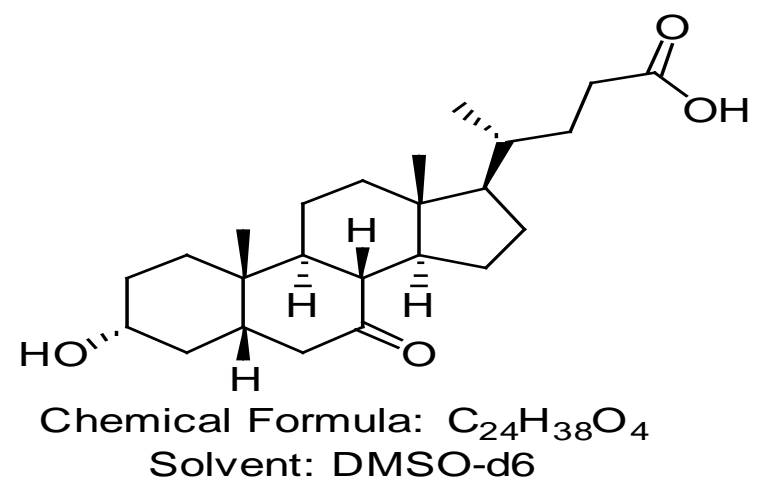

Solvent: DMSO-d6
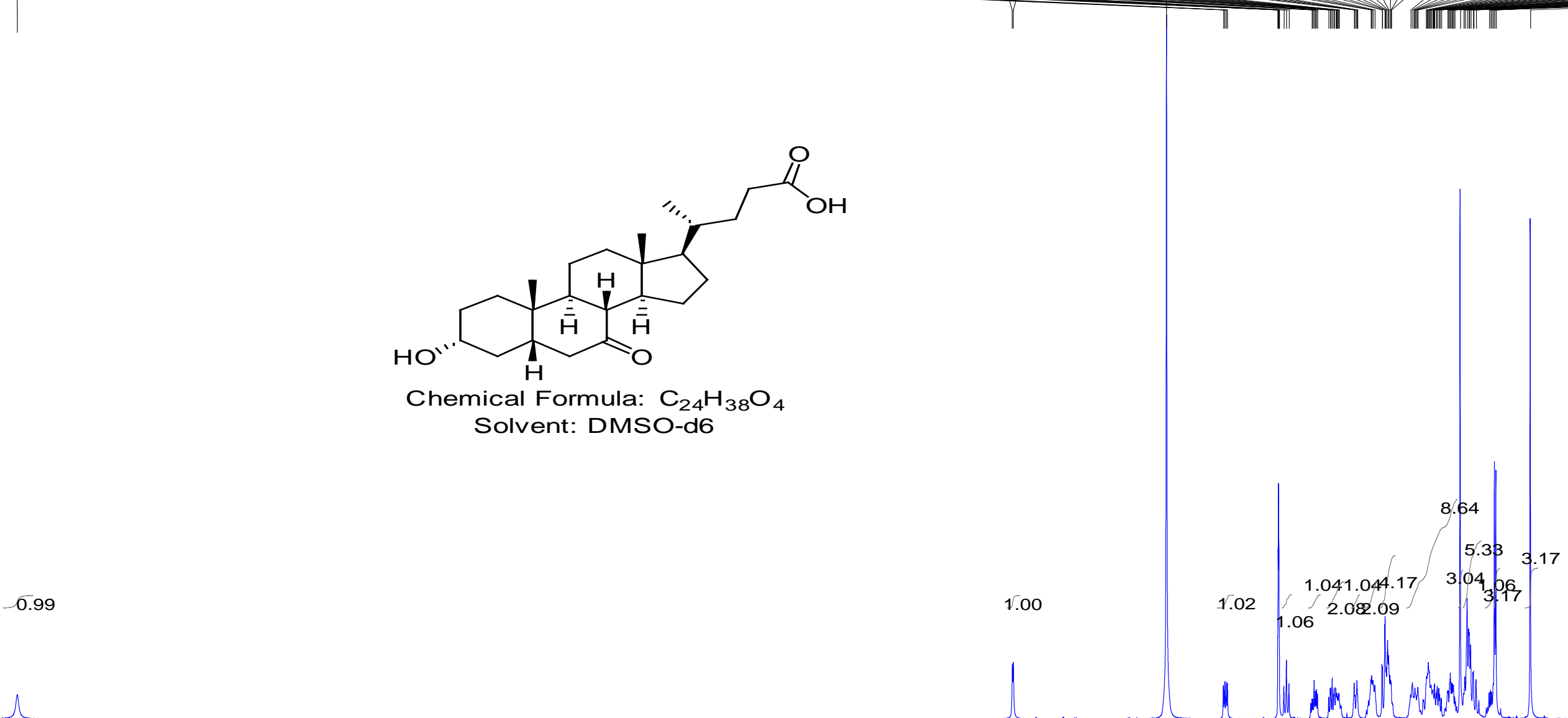

12

10

8

6

4

2

PPM

${ }^{1} \mathrm{H}$ NMR (400 MHz, DMSO-d ${ }_{6}$ ) $\delta 11.96$ (br, 1H), 4.50 (d, $\left.J=2.8 \mathrm{~Hz}, 1 \mathrm{H}\right), 2.90$ (dd, $\left.J=4.0 \mathrm{~Hz}, 8 \mathrm{~Hz}, 1 \mathrm{H}\right), 2.44$ (t, $J=4 \mathrm{~Hz}, 8.0 \mathrm{~Hz}, 1 \mathrm{H}$ ), 2.21-2.26 (m, 1H), 2.03-2.13 (m, 2H), 1.92 (dt, $J=2.4$ Hz, 8.8 Hz, 1H), 1.78-1.84 (m, 2H), 1.65-1.73 (m, 4H), 1.00-1.51 (m, 14 H), 1.14 (s, 3H), 0.89-0.94 (m, 1H), 0.88 (d, $J=4.0 \mathrm{~Hz}, 3 \mathrm{H}), 0.61$ (s, 3H).

\section{S-1. ${ }^{1} \mathrm{H}$ NMR spectrum of compound 2}



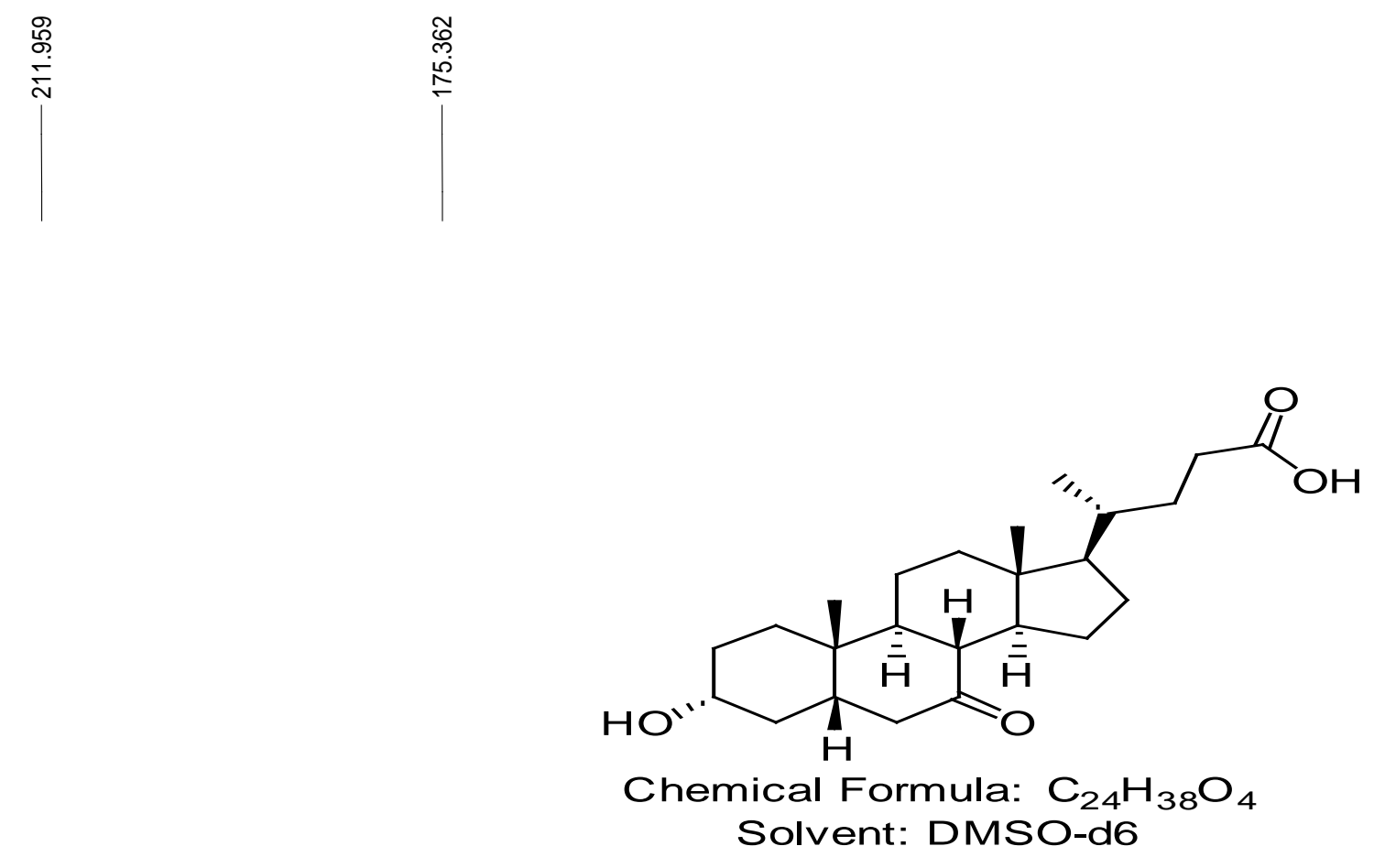

${ }^{13}$ C NMR (100 MHz, DMSO-d $\left.\mathrm{d}_{6}\right) \delta$ 211.96, 175.36, 69.56, 54.79, 49.26, 49.04, 45.86, 45.54, 42.64, 39.05, 37.90, 35.24, 35.22, 34.34, 31.20, 31.19, 30.31, 28.33, 24.88, 23.27, 21.70, 18.71, 12.37.

\section{S-2. ${ }^{13} \mathrm{C}$ NMR spectrum of compound 2}




\section{Mass Spectrum SmartFormula Report}

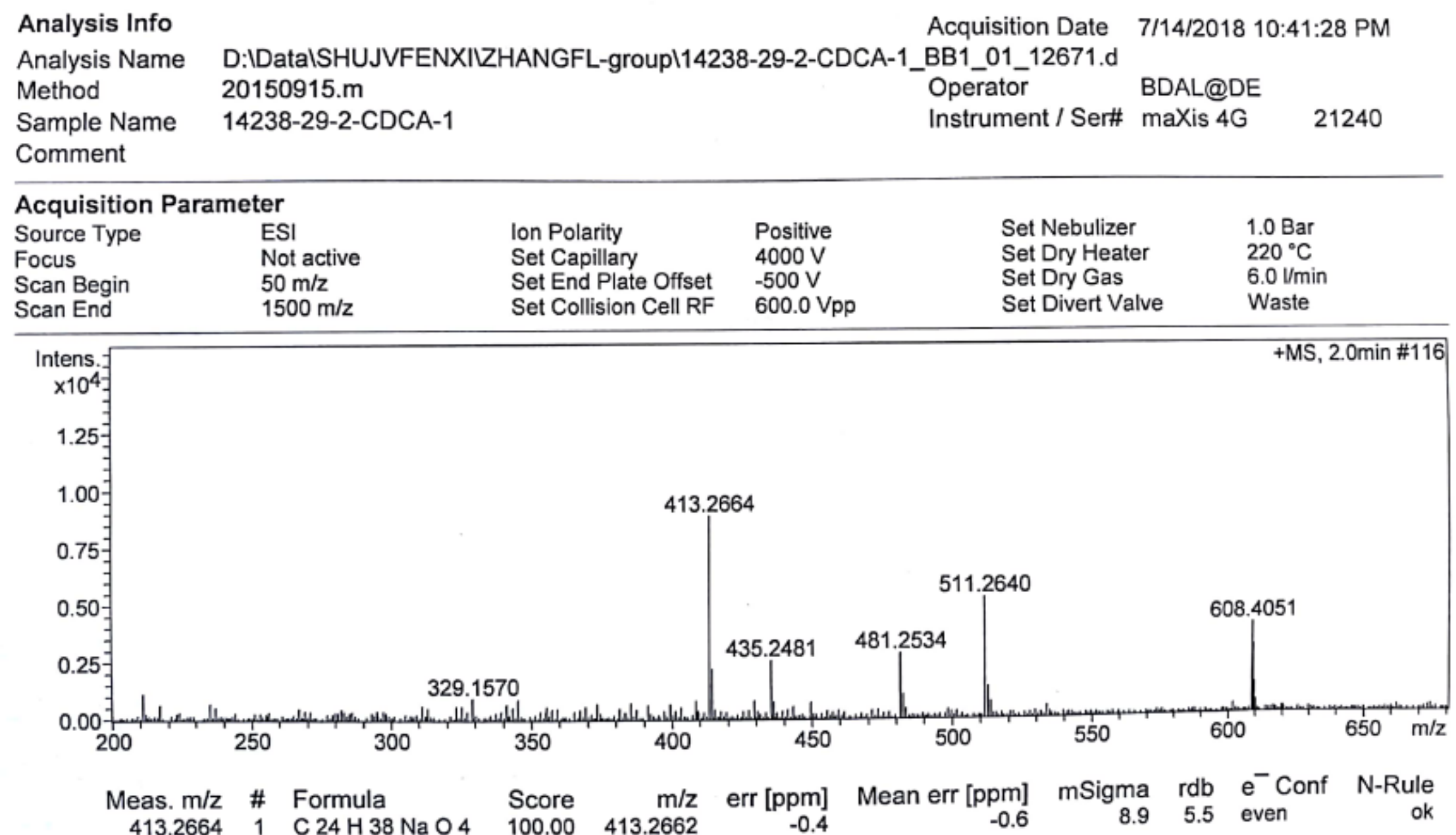

HRMS m/z [M+Na] ${ }^{+}$Calcd for $\mathrm{C}_{24} \mathrm{H}_{38} \mathrm{NaO}_{4}$ : 413.2668; found: 413.2664

\section{S-3. HRMS spectrum of compound 2}




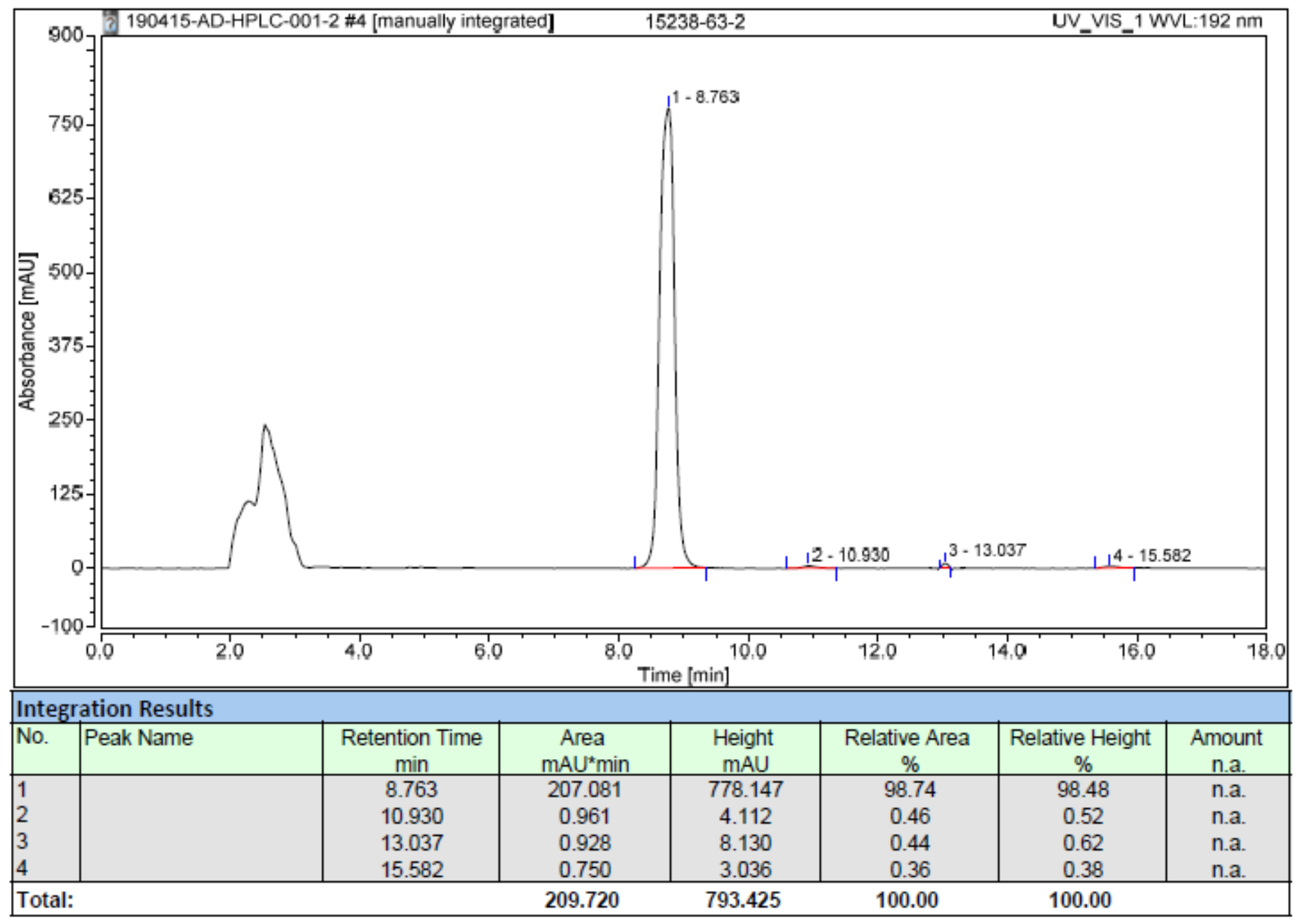

S-4. HPLC chromatogram of compound 2 


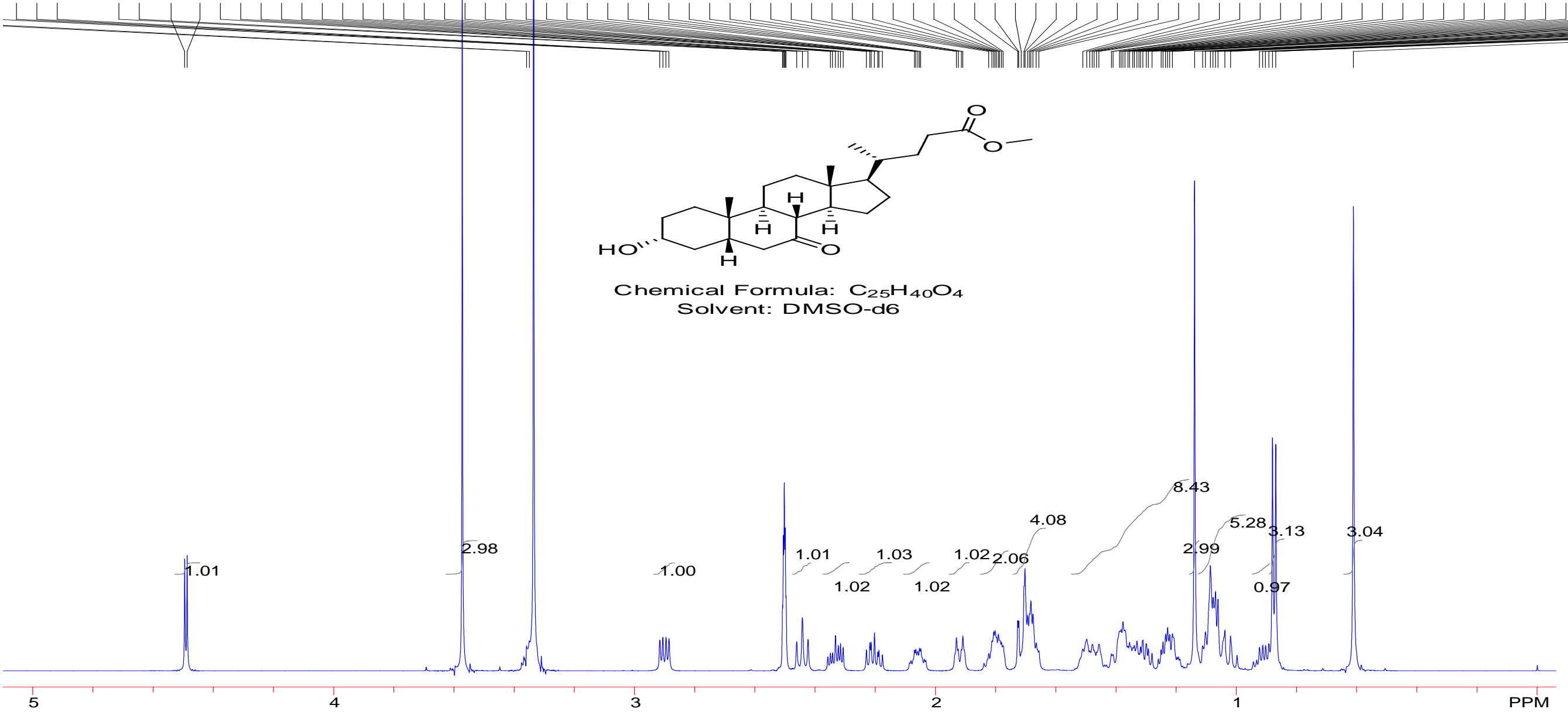

${ }^{1} \mathrm{H}$ NMR (400 MHz, DMSO-d 6 ) $\delta 4.49$ (d, $J=3.2 \mathrm{~Hz}, 1 \mathrm{H}$ ), 3.57 (s, 3H), 2.90 (dd, $\left.J=4 \mathrm{~Hz}, 8.4 \mathrm{~Hz}, 1 \mathrm{H}\right), 2.44(\mathrm{t}, J=7.6 \mathrm{~Hz}, 1 \mathrm{H}), 2.31-2.35$ (m, 1H), 2.18-2.23 (m, 1H), 2.03-2.09 (m, 1H), 1.92 (dt, $J=2.4$ Hz, 6.4 Hz, 1H), 1.78-1.84 (m, 2H), 1.66-1.73 (m, 4H), 1.00-1.51 (m, 14H), 1.14 (s, 3H), 0.89-0.94 (m, 1H), 0.87 (d, $J=4.4 \mathrm{~Hz}, 3 \mathrm{H}), 0.61$ (s, 3H). 
|

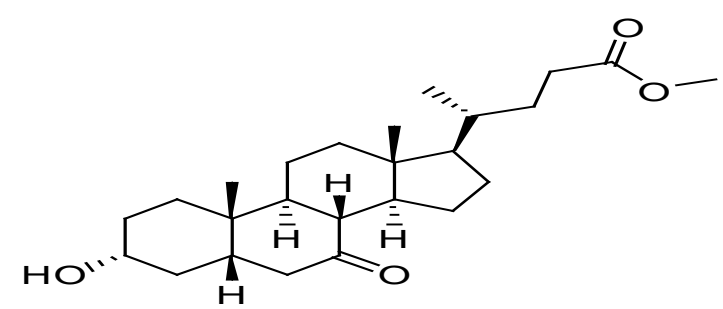

Chemical Formula: $\mathrm{C}_{25} \mathrm{H}_{40} \mathrm{O}_{4}$ Solvent: DMSO-d6

${ }^{13} \mathrm{C}$ NMR $\left(100 \mathrm{MHz}, \mathrm{DMSO}-\mathrm{d}_{6}\right) \delta$ 211.94, 174.21, 69.55, 54.69, 51.69, 49.26, 49.05, 45.85, 45.54, 42.65, 39.03, 37.89, 35.24, 35.19, 34.33, $31.11,30.83,30.30,28.31,24.87,23.27,21.68,18.66,12.35$.

\section{S-6. ${ }^{13} \mathrm{C}$ NMR spectrum of compound 6}




\section{Mass Spectrum SmartFormula Report}

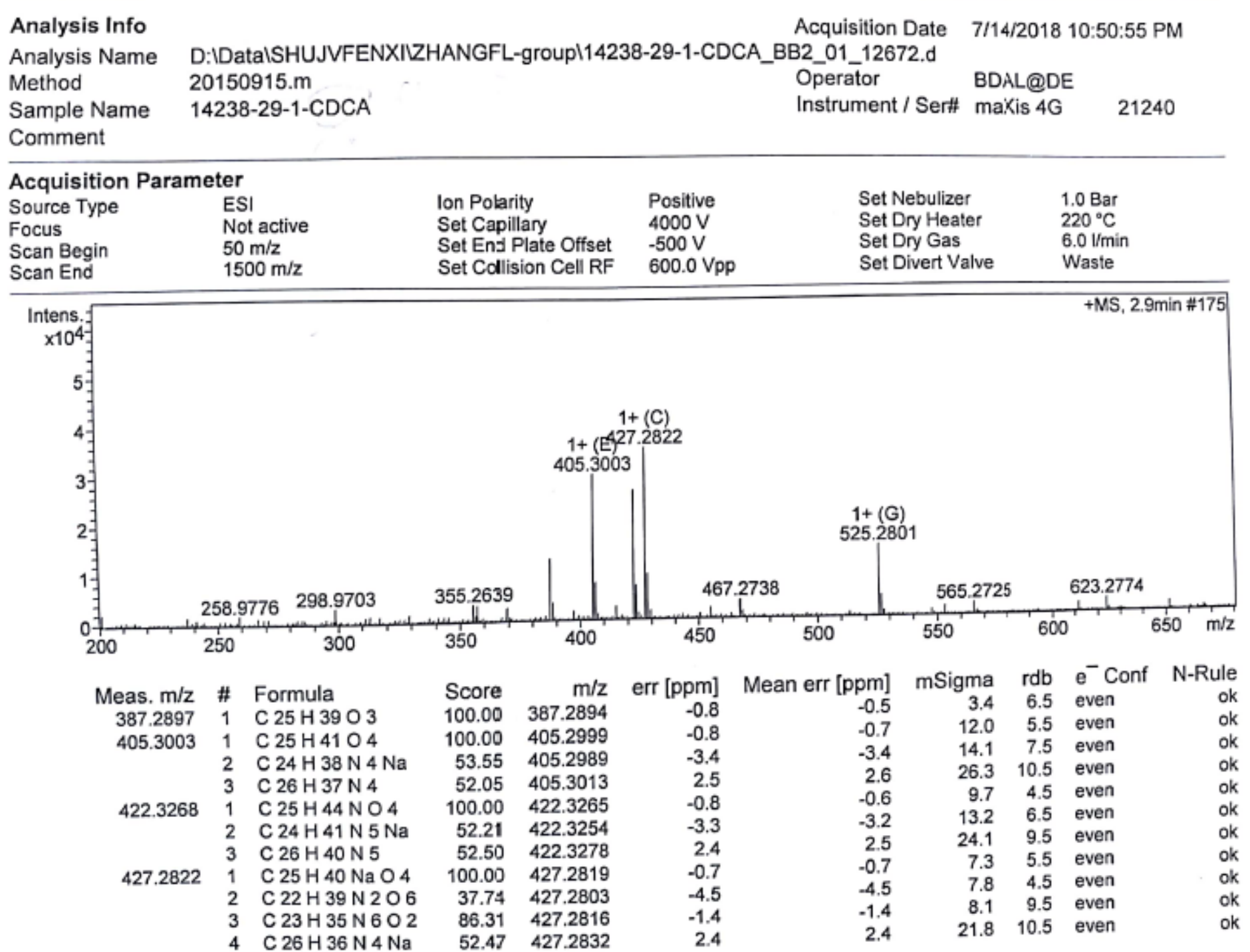

HRMS $m / z$ [M+Na] $]^{+}$Calcd for $\mathrm{C}_{25} \mathrm{H}_{40} \mathrm{NaO}_{4}$ : 427.2824; found: 427.2822.

\section{S-7. HRMS spectrum of compound 6}




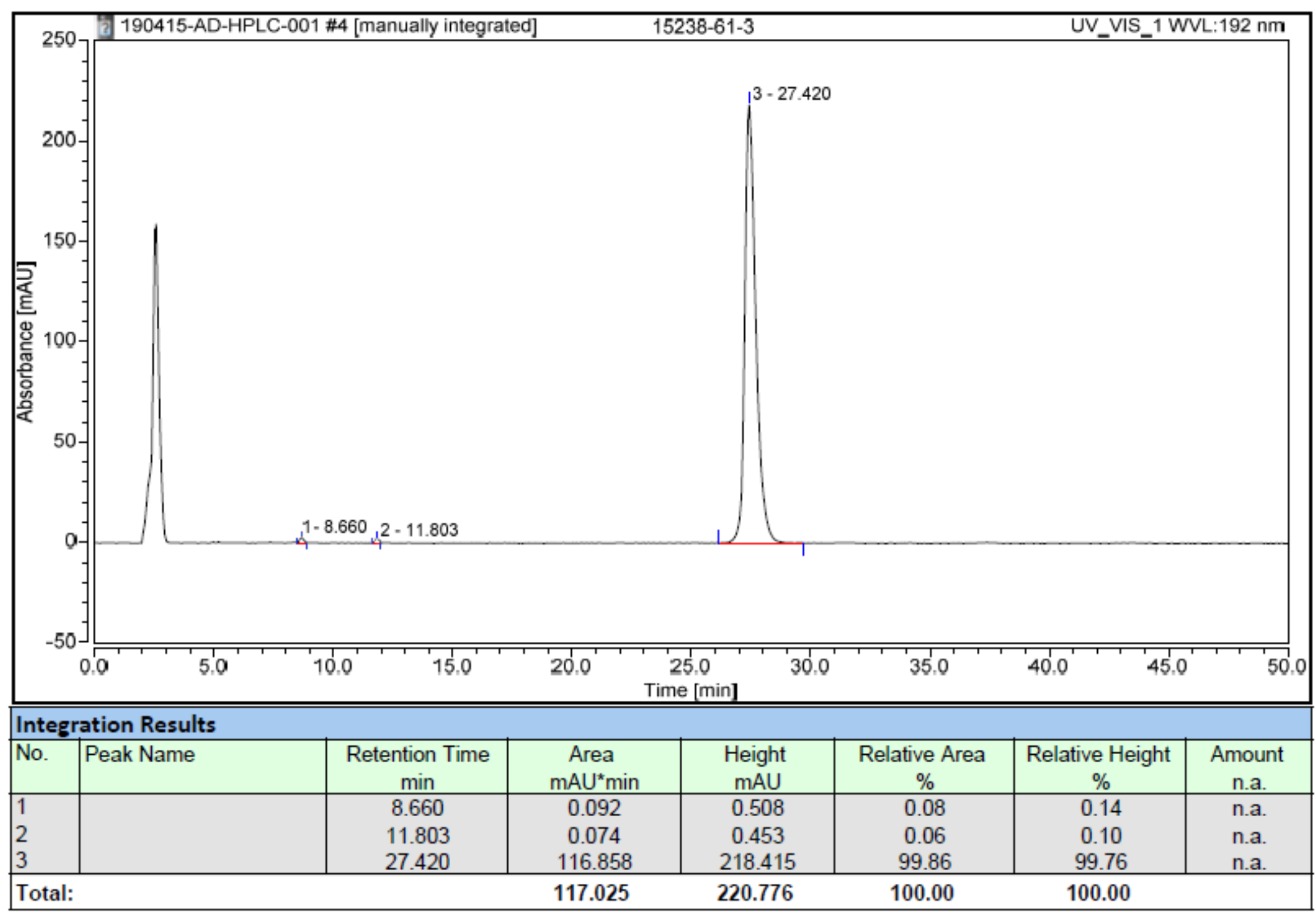

S-8. HPLC chromatogram of compound 6 


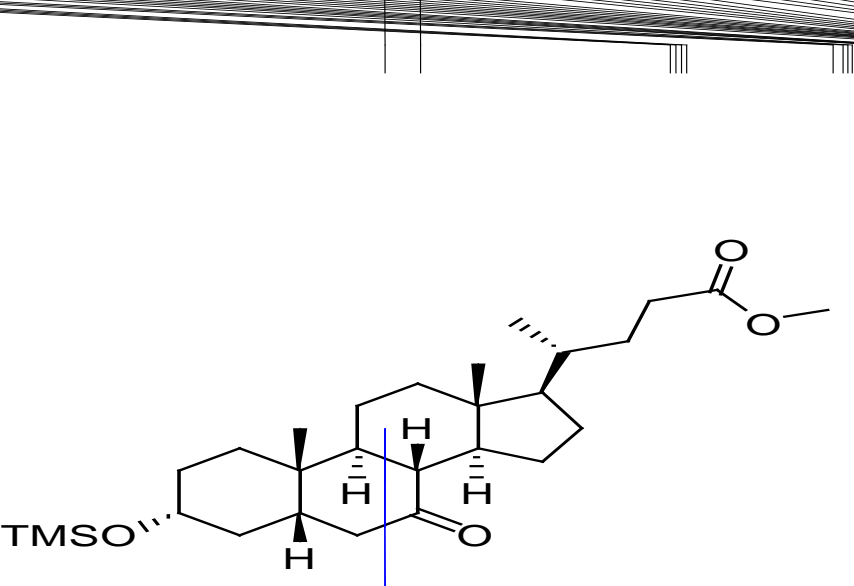

Chemical Formula: $\mathrm{C}_{28} \mathrm{H}_{48} \mathrm{O}_{4} \mathrm{Si}$ Solvent: $\mathrm{CDCl}_{3}$

$$
7
$$

$+1+1$

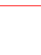

5

4

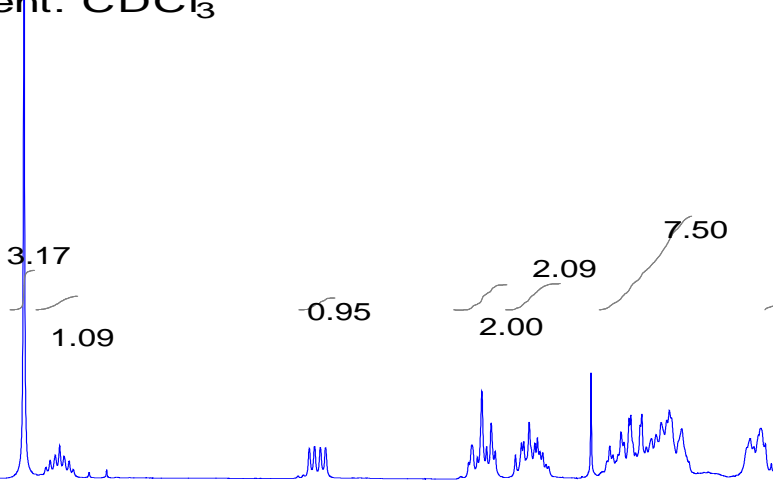

1

O PPM

${ }^{1} \mathrm{H}$ NMR (400 MHz, $\mathrm{CDCl}_{3}$ ) $\delta 3.65$ (s, 3H), 3.51-3.59 (s, 1H), 2.81 (dd, $\left.J=6 \mathrm{~Hz}, 12.8 \mathrm{~Hz}, 1 \mathrm{H}\right), 2.31-2.37$ (m, $\left.2 \mathrm{H}\right), 2.15-2.25$ (m, $\left.2 \mathrm{H}\right)$, 1.75-1.99 (m, 7H), 1.23-1.59 (m, 9H), 1.17 (s, 3H), 1.05-1.15 (m, 4H), 0.93-0.97 (m, 1H), 0.91 (d, J = 3.6 Hz, 3H), 0.64 (s, $3 \mathrm{H}), 0.08$ (s, $9 \mathrm{H})$. 

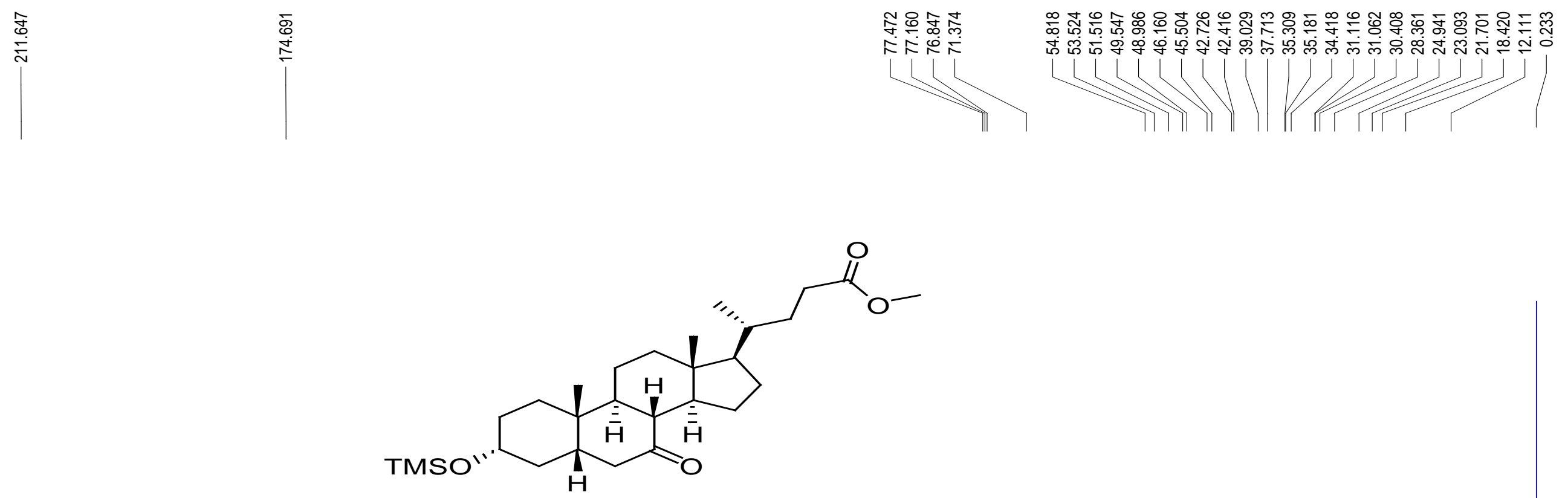

Chemical Formula: $\mathrm{C}_{28} \mathrm{H}_{48} \mathrm{O}_{4} \mathrm{Si}$ Solvent: $\mathrm{CDCl}_{3}$

${ }^{13} \mathrm{C}$ NMR $\left(100 \mathrm{MHz}, \mathrm{CDCl}_{3}\right) \delta$ 211.65, 174.69, 71.37, 54.82, 51.52, 49.55, 48.99, 46.16, 45.50, 42.73, 42.42, 39.03, 37.71, 35.31, 35.18, 34.42, 31.12, 31.06, 30.41, 28.36, 24.94, 23.09, 21.70, 18.42, 12.11, 0.23.

\section{S-10. ${ }^{13} \mathrm{C}$ NMR spectrum of compound $6 a$}




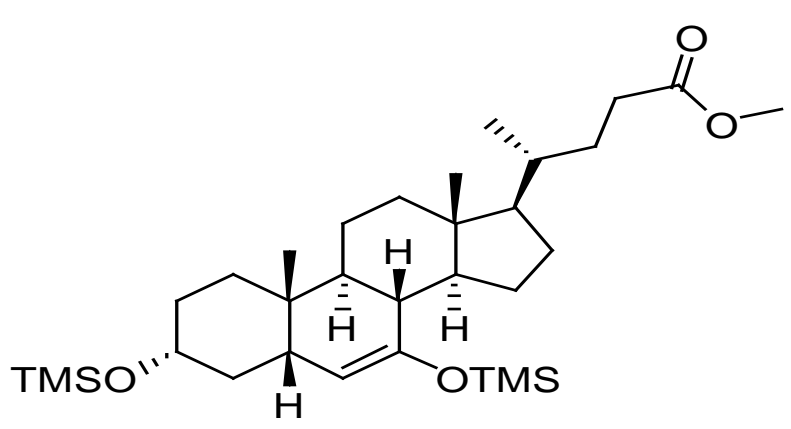

Chemical Formula: $\mathrm{C}_{31} \mathrm{H}_{56} \mathrm{O}_{4} \mathrm{Si}_{2}$ Solvent: $\mathrm{CDCl}_{3}$

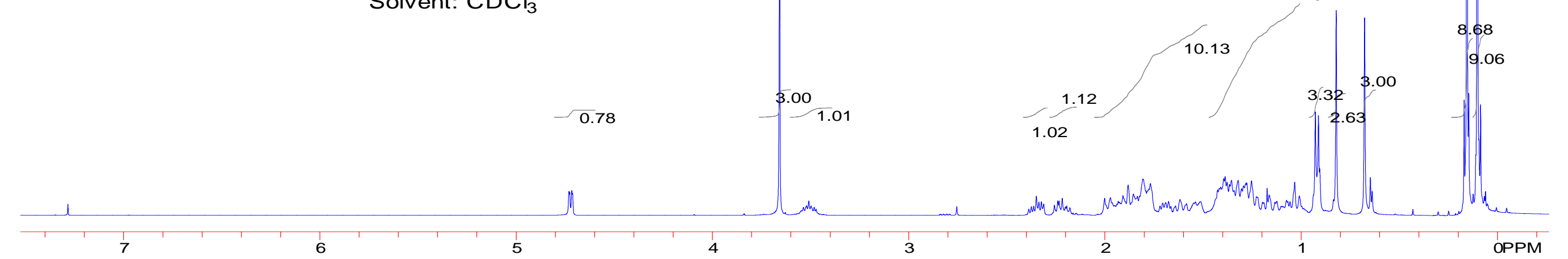

${ }^{1} \mathrm{H}$ NMR (400 MHz, $\mathrm{CDCl}_{3}$ ) $\delta 4.72$ (dd, $\left.J=1.6 \mathrm{~Hz}, 6 \mathrm{~Hz}, 1 \mathrm{H}\right), 3.66$ (s, 3H), 3.47-3.55 (m, 1H), 2.31-2.39 (m, 1H), 2.18-2.26 (m, 1H), 1.51-2.00 (m, 10H), 0.99-1.44 (m, 12 H), 0.92 (d, $J=6.4 \mathrm{~Hz}, 3 \mathrm{H}), 0.61$ (s, 3H), 0.68 (s, 3H), 0.16 (s, 9H), 0.10 (s, 9H).

\section{S-11. ${ }^{1} \mathrm{H}$ NMR spectrum of compound 7}



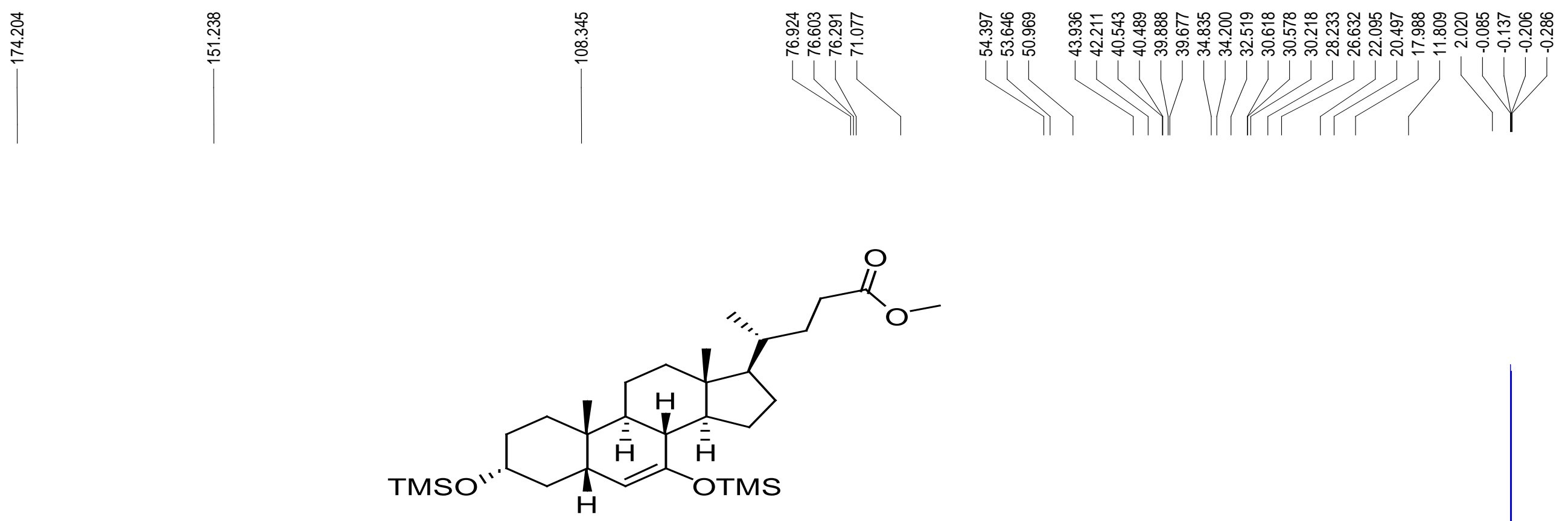

Chemical Formula: $\mathrm{C}_{31} \mathrm{H}_{56} \mathrm{O}_{4} \mathrm{Si}_{2}$ Solvent: $\mathrm{CDCl}_{3}$

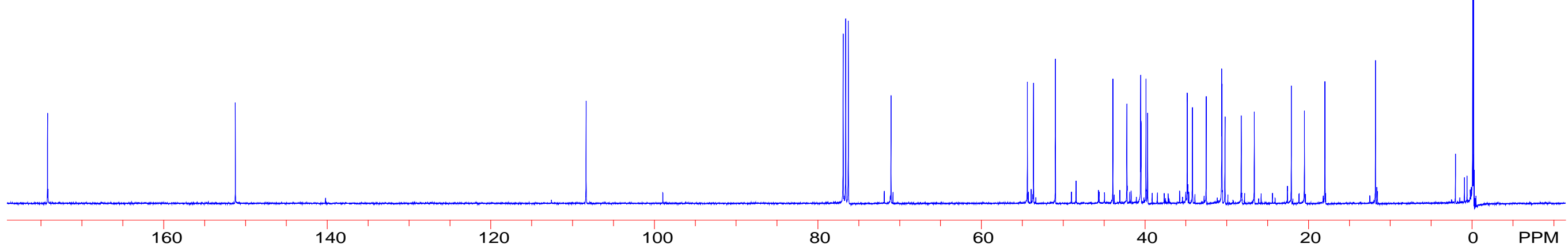

${ }^{13} \mathrm{C}$ NMR $\left(100 \mathrm{MHz}, \mathrm{CDCl}_{3}\right) \delta 174.76,151.80,108.90,71.63,54.95,54.20,51.53,44.49,42.77,41.10,41.05,40.45,40.23,35.39,34.76$, 33.08, 31.18, 31.14, 30.78, 28.79, 27.19, 22.65, 21.05, 18.55, 12.37, 0.47, 0.35 .

\section{S-12. ${ }^{13} \mathrm{C}$ NMR spectrum of compound 7}



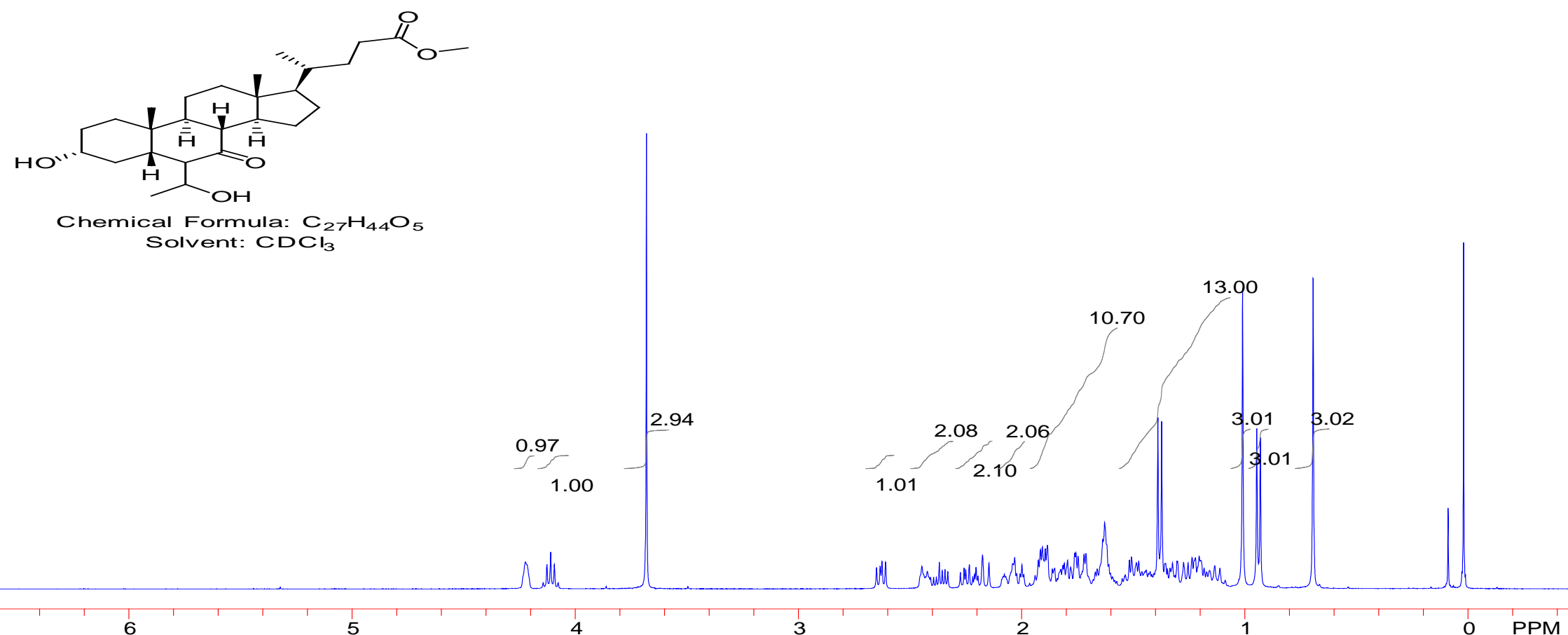

${ }^{1} \mathrm{H}$ NMR (400 MHz, $\mathrm{CDCl}_{3}$ ) $\delta$ 4.20-4.25 (m, 1H), 4.08-4.14 (m, 1H), 3.68 (s, 3H), 2.61-2.65 (m, 1H), 2.33-2.45 (m, $\left.2 \mathrm{H}\right), 2.15-2.28$ (m, $\left.2 \mathrm{H}\right)$, 1.99-2.08 (m, 2H), 1.57-1.94 (m, 10H), 1.09-1.55 (m, 13H), 1.01 (s, 3H), 0.94 (d, J = 6 Hz, 3H), 0.69 (s, 3H).

\section{S-13. ${ }^{1}$ H NMR spectrum of compound 7 a}




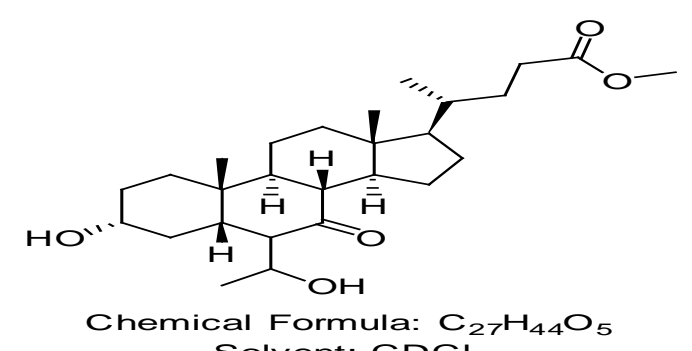

Solvent: $\mathrm{CDCl}_{3}$

${ }^{13} \mathrm{C}$ NMR $\left(100 \mathrm{MHz}, \mathrm{CDCl}_{3}\right) \quad \delta 215.71,174.67,68.05,66.21,55.04,54.99,51.50,50.50,48.80,48.66,42.94,39.73,37.96,35.35,34.13$, $31.87,31.07,30.99,28.94,28.29,24.50,24.21,24.07,23.23,18.72,18.32,12.09$.

\section{S-14. ${ }^{13}$ C NMR spectrum of compound 7a}




\section{Mass Spectrum SmartFormula Report}

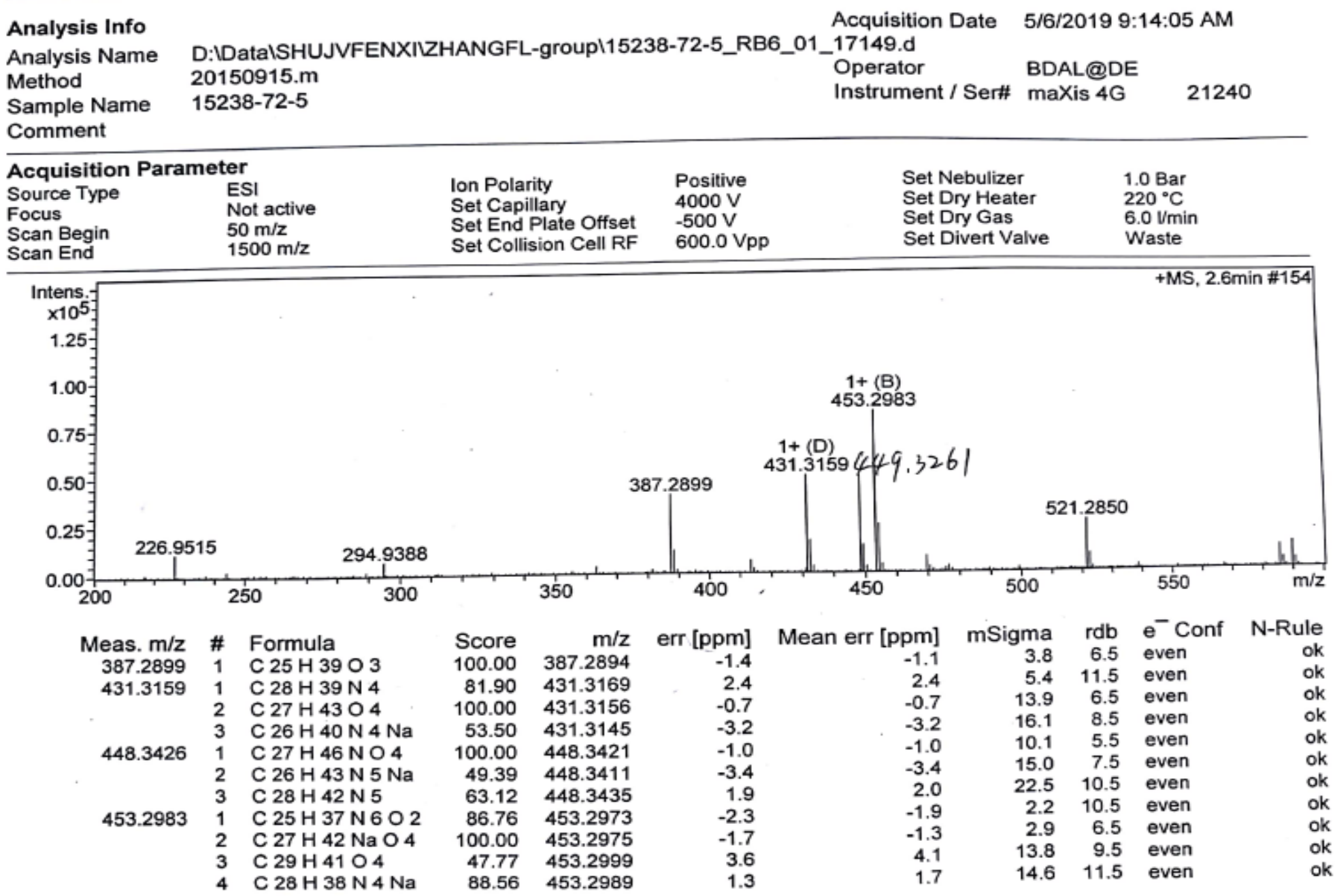

HRMS m/z [M+Na] $]^{+}$Calcd for $\mathrm{C}_{27} \mathrm{H}_{45} \mathrm{O}_{5}$ : 449.3267; found: 449.3261 . 

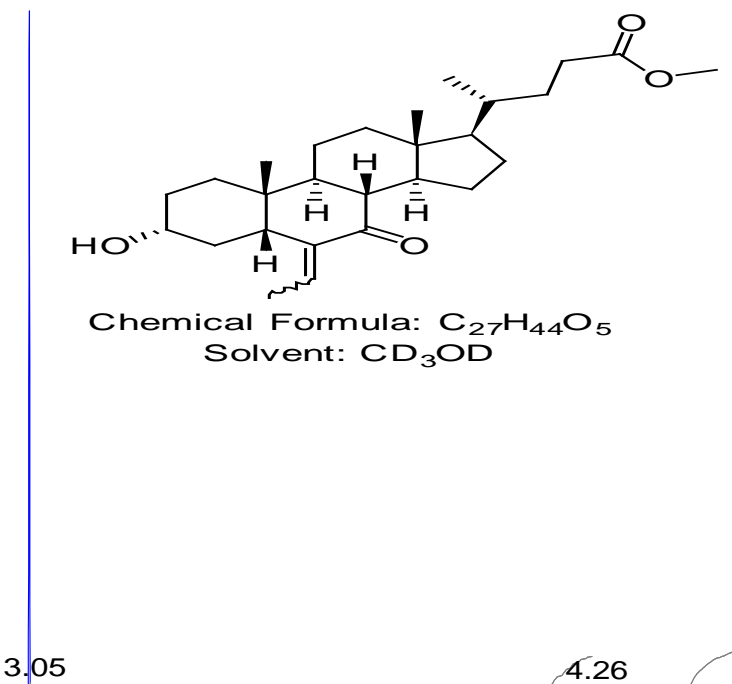

1.00
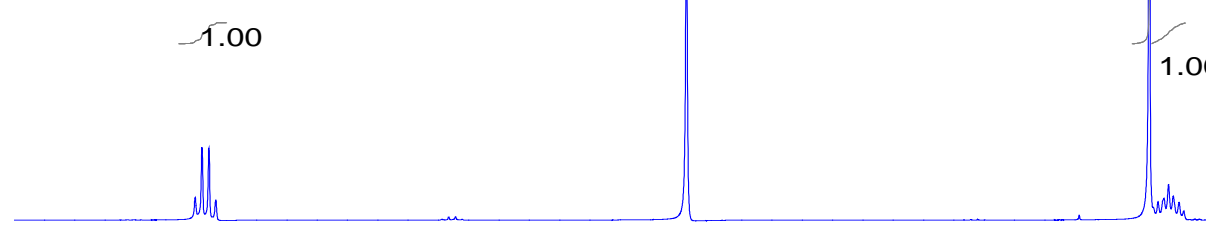

1.00

4.26

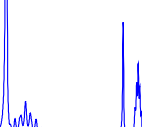

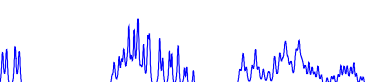

OPPM

${ }^{1} \mathrm{H}$ NMR $\left(400 \mathrm{MHz}, \mathrm{CD}_{3} \mathrm{OD}\right) \delta 6.11(\mathrm{q}, J=6.8 \mathrm{~Hz}, 14 \mathrm{~Hz}, 1 \mathrm{H}), 3.67$ (s, 3H), 3.58-3.66 (m, 1H), $2.70(\mathrm{dd}, J=4 \mathrm{~Hz}, 12.8 \mathrm{~Hz}, 1 \mathrm{H})$, 2.23-2.43 (m, 4H), 1.10-2.11 (m, 24H), 1.06 (s, 3H), 0.98 (d, J = 6.4 Hz, 3H), 0.71 (s, 3H).

\section{S-16. ${ }^{1} \mathrm{H}$ NMR spectrum of compound 8}




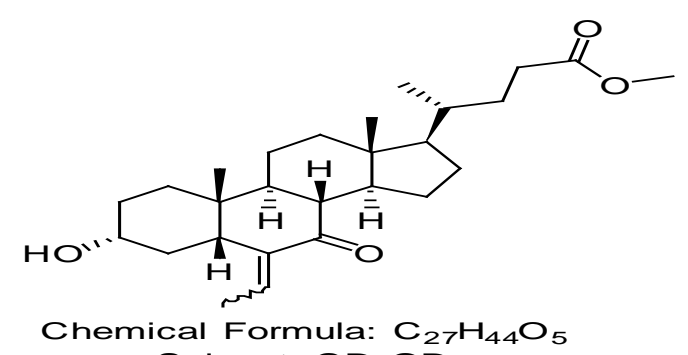

Solvent: $\mathrm{CD}_{3} \mathrm{OD}$

${ }^{13} \mathrm{C}$ NMR $\left(100 \mathrm{MHz}, \mathrm{CD}_{3} \mathrm{OD}\right) \quad \delta 205.63,174.49,143.51,128.53,69.10,54.07,50.17,50.15,48.30,45.01,42.85,38.87,38.41,36.53$, 34.70, 33.93, 33.57, 30.41, 30.01, 28.63, 27.57, 25.17, 21.41, 20.60, 17.08, 10.92, 10.65. 


\section{Mass Spectrum SmartFormula Report}

\begin{tabular}{|c|c|c|c|c|c|c|c|c|c|}
\hline $\begin{array}{l}\text { Analysis Info } \\
\text { Analysis Name } \\
\text { Method } \\
\text { Sample Name } \\
\text { Comment }\end{array}$ & $\begin{array}{l}\text { D:IDatalSHUJVFENX } \\
20150915 . \mathrm{m} \\
15238-72-4\end{array}$ & HANG & L-group \15 & 38-72-4_RC5 & $\begin{array}{l}\text { Acquisitio } \\
\text { 01_17146.d } \\
\text { Operator } \\
\text { Instrumer }\end{array}$ & $\begin{array}{ll}\text { Date } & 5 / \\
& B \\
\text { / Ser\# } & m\end{array}$ & $\begin{array}{l}\text { DAL@ } \\
\text { aXis 4 }\end{array}$ & 3:09:05 & 240 \\
\hline $\begin{array}{l}\text { Acquisition Para } \\
\text { Source Type } \\
\text { Focus } \\
\text { Scan Begin } \\
\text { Scan End }\end{array}$ & $\begin{array}{l}\text { Imeter } \\
\text { ESI } \\
\text { Not active } \\
50 \mathrm{~m} / \mathrm{z} \\
1500 \mathrm{~m} / \mathrm{z}\end{array}$ & $\begin{array}{l}\text { lon Pola } \\
\text { Set Cap } \\
\text { Set End } \\
\text { Set Coll }\end{array}$ & $\begin{array}{l}\text { rity } \\
\text { illary } \\
\text { Plate Offse } \\
\text { ision Cell RF }\end{array}$ & $\begin{array}{l}\text { Positive } \\
4000 \mathrm{~V} \\
-500 \mathrm{~V} \\
600.0 \mathrm{Vpp}\end{array}$ & $\begin{array}{l}\text { Set } \\
\text { Set } \\
\text { Set } \\
\text { Set }\end{array}$ & $\begin{array}{l}\text { Vebulizer } \\
\text { Pry Heater } \\
\text { Jyy Gas } \\
\text { Divert Valve }\end{array}$ & & $\begin{array}{l}1.0 \mathrm{Bar} \\
220^{\circ} \mathrm{C} \\
6.0 \mathrm{l} / \mathrm{min} \\
\text { Waste }\end{array}$ & \\
\hline $\begin{array}{r}\text { Intens. } \\
\times 10^{4}- \\
8-1\end{array}$ & & & 38 & 431 & $\begin{array}{l}1.3161 \\
453.2980\end{array}$ & & 21.2857 & $+M S, 2$. & $\min \# 152$ \\
\hline 200 & 250 & & 350 & 400 & 450 & 500 & & 550 & $\mathrm{~m} / \mathrm{z}$ \\
\hline $\begin{array}{r}\text { Meas. } \mathrm{m} / \mathrm{z} \\
431.3161\end{array}$ & 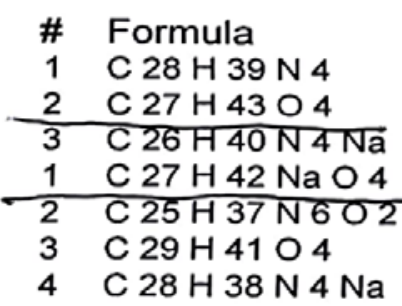 & $\begin{array}{r}\text { Score } \\
96.67 \\
100.00 \\
52.37 \\
100.00 \\
85.53 \\
33.47 \\
64.94\end{array}$ & $\begin{array}{r}\mathrm{m} / \mathrm{z} \\
431.3169 \\
431.3156 \\
431.3145 \\
453.2975 \\
453.2973 \\
453.2999 \\
453.2989\end{array}$ & $\begin{array}{rr}\text { err [ppm] } & \text { M } \\
1.8 & \\
-1.3 & \\
-3.7 & -1.0 \\
-1.7 & \\
4.3 & 1.9\end{array}$ & $\begin{array}{r}\text { lean err [ppm] } \\
2.0 \\
-1.1 \\
-3.6 \\
-1.0 \\
-1.6 \\
4.3 \\
2.0\end{array}$ & $\begin{array}{r}\text { mSigma } \\
4.9 \\
10.2 \\
11.3 \\
3.5 \\
4.4 \\
14.7 \\
16.0\end{array}$ & $\begin{array}{r}r d b \\
11.5 \\
6.5 \\
8.5 \\
6.5 \\
10.5 \\
9.5 \\
11.5\end{array}$ & $\begin{array}{l}e^{-} \text {Conf } \\
\text { even } \\
\text { even } \\
\text { even } \\
\text { even } \\
\text { even } \\
\text { even } \\
\text { even }\end{array}$ & $\begin{array}{r}\text { N-Rule } \\
\text { ok } \\
\text { ok } \\
\text { ok } \\
\text { ok } \\
\text { ok } \\
\text { ok } \\
\text { ok }\end{array}$ \\
\hline
\end{tabular}

HRMS m/z [M+H] $]^{+}$Calcd for $\mathrm{C}_{27} \mathrm{H}_{43} \mathrm{O}_{4}$ : 431.3136; found: 431.3161 .

\section{S-18. HRMS spectrum of compound 8}




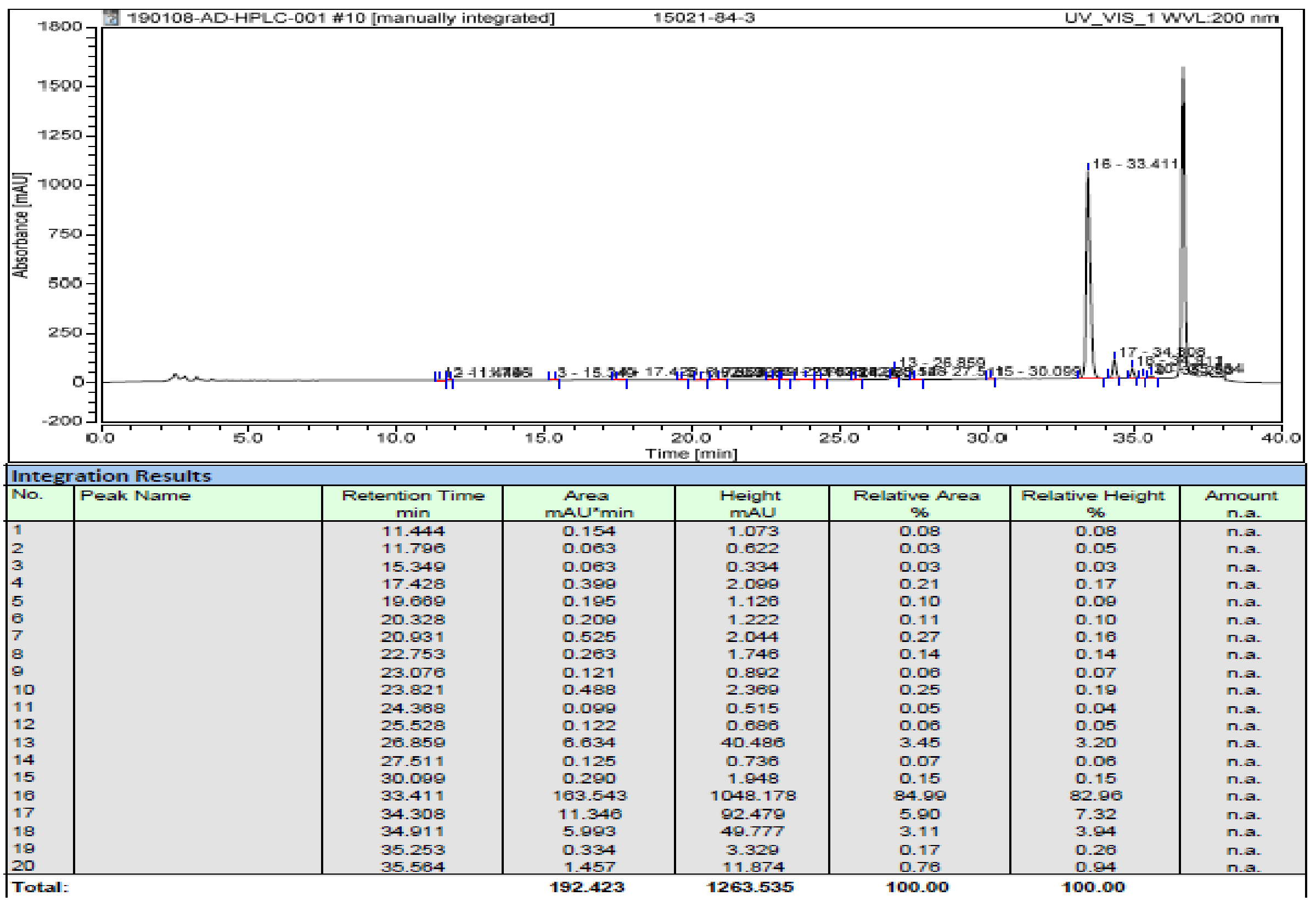

S-19. HPLC chromatogram of compound 8 (HPLC purity of cis and trans of $8>90 \%$ ) 


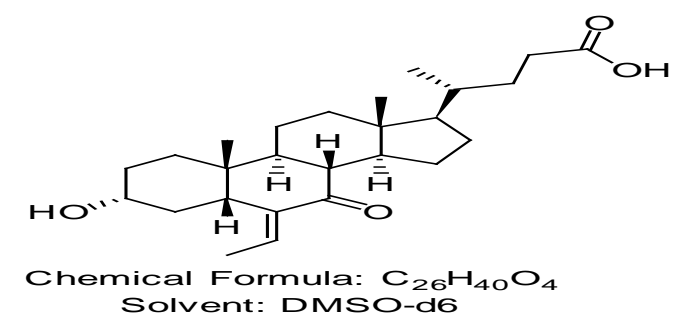

Solvent: DMSO-d6

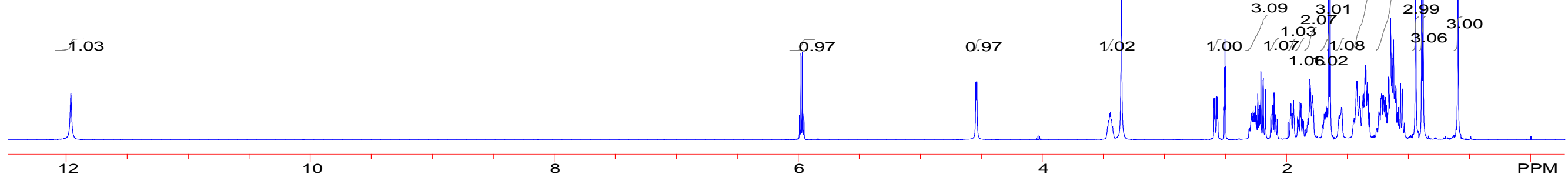

${ }^{1} \mathrm{H}$ NMR (400 MHz, DMSO-d6) $\delta 11.96$ (s, 1H), 5.97 (q, $J=4.8$ Hz, $\left.9.6 \mathrm{~Hz}, 1 \mathrm{H}\right), 4.54$ (d, $\left.J=2.8 \mathrm{~Hz}, 1 \mathrm{H}\right), 3.42-3.47$ (m, $\left.1 \mathrm{H}\right), 2.58$ (dd, $J=$ 2.8 Hz, 8.4 Hz, 1H), 2.17-2.30 (m, 3H), 2.08-2.13 (m, 1H), 1.95 (dt, $J=2$ Hz, 8.4 Hz, 1H), 1.86-1.91 (m, 1H), 1.78-1.83 (m, 2H), $1.66-1.71$ (m, 1H), 1.65 (d, $J=4.8 \mathrm{~Hz}, 3 \mathrm{H}), 1.55-1.57$ (m, 1H), 1.32-1.45 (m, 5H), 1.04-1.27 (m, 8H), 0.94 (s, 3H), 0.89 (d, $J=4 \mathrm{~Hz}, 3 \mathrm{H}), 0.60$ (s, $3 \mathrm{H})$.

\section{S-20. ${ }^{1} \mathrm{H}$ NMR spectrum of compound 9}




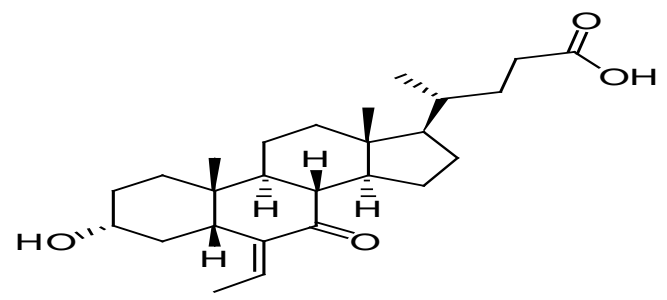

Chemical Formula: $\mathrm{C}_{26} \mathrm{H}_{40} \mathrm{O}_{4}$ Solvent: DMSO-d6

${ }^{13} \mathrm{C}$ NMR (100 MHz, DMSO-d6) $\delta$ 204.16, 175.35, 144.15, 128.88, 69.04, 54.49, 50.71, 48.64, 45.35, 43.53, 39.06, 38.94, 38.02, 35.20, 34.67, 34.50, 31.20, 30.06, 28.46, 26.13, 23.07, 21.33, 18.77, 12.80, 12.33.

\section{S-21. ${ }^{13} \mathrm{C}$ NMR spectrum of compound 9}




\section{Mass Spectrum SmartFormula Report}

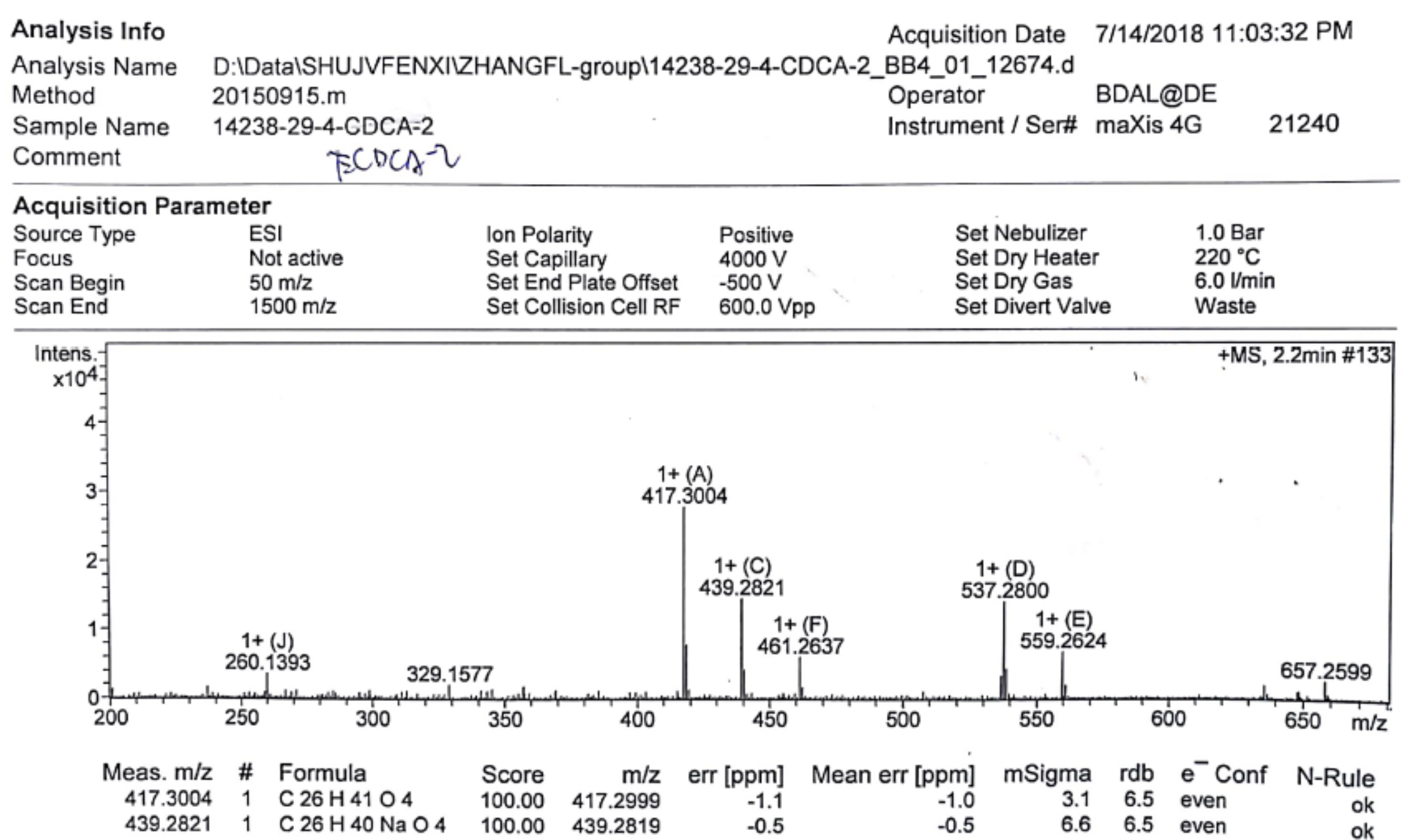

HRMS m/z $[\mathrm{M}+\mathrm{H}]^{+}$Calcd for $\mathrm{C}_{26} \mathrm{H}_{41} \mathrm{O}_{4}$ : 417.3005; found: 417.3004 .

\section{S-22. HRMS spectrum of compound 9}




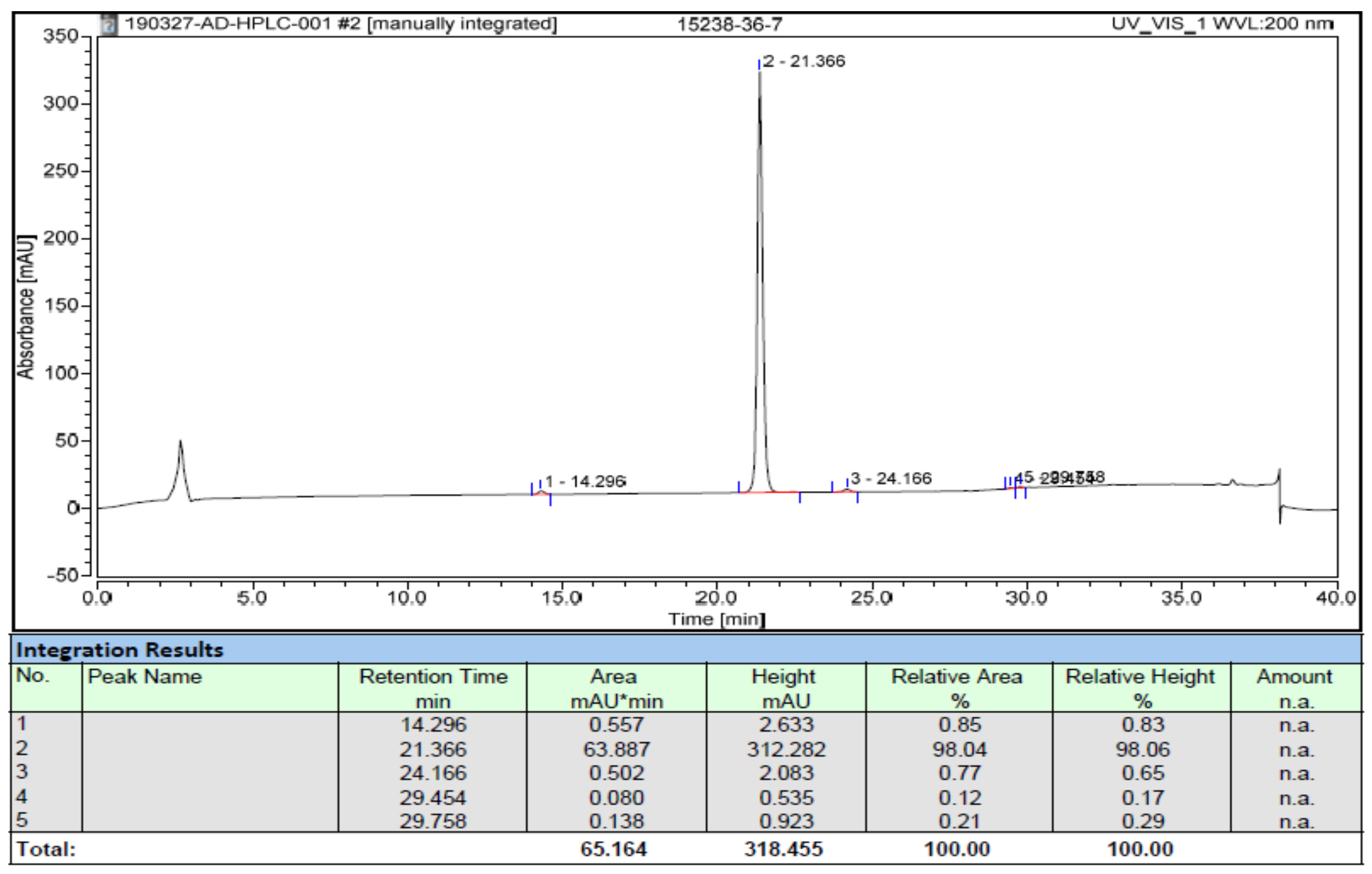

S-23. HPLC chromatogram of compound 9 

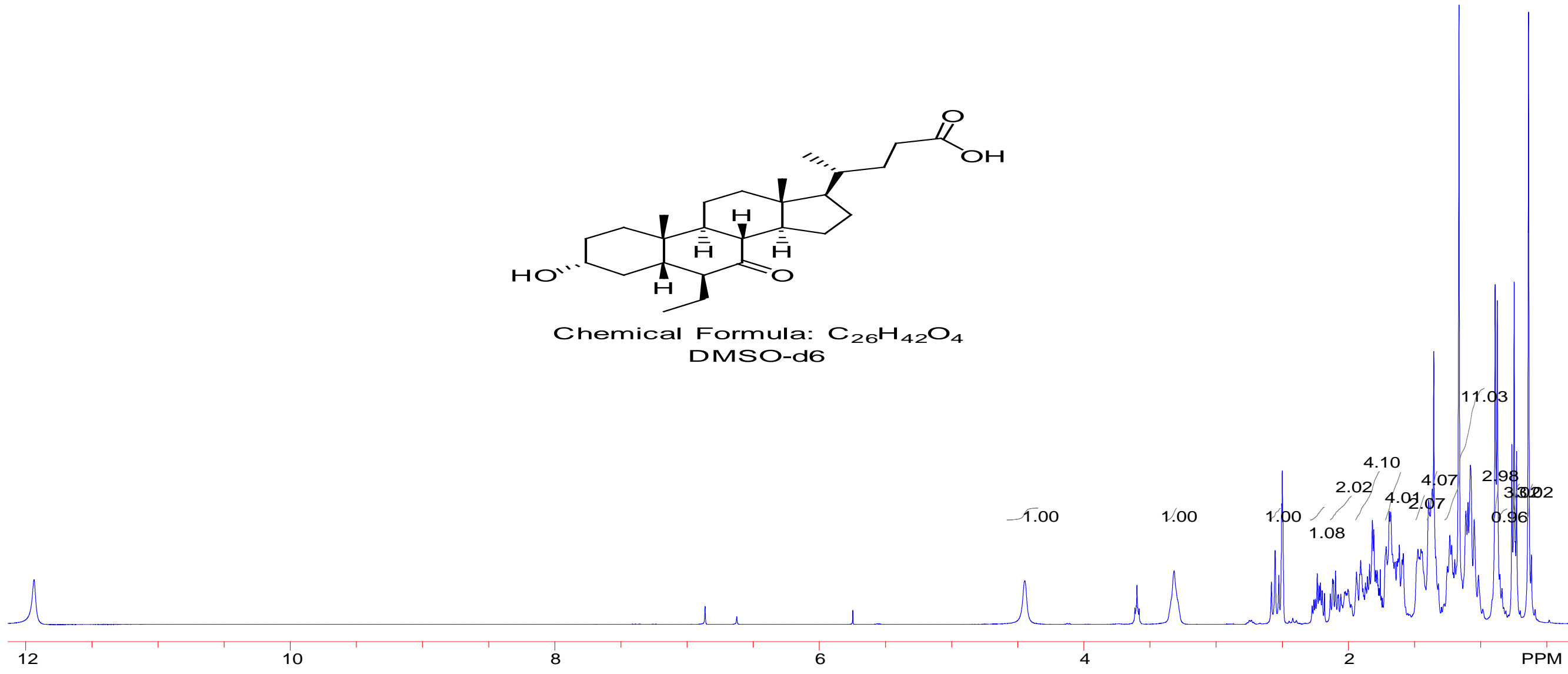

${ }^{1} \mathrm{H}$ NMR (400 MHz, DMSO-d6) $\delta 11.94$ (br, 1H), 4.45 (br, 1H), 3.24-3.37 (m, 1H), 2.55 (t, $J=11.2$ Hz, 1H), 2.18-2.27 (m, 1H), $1.98-2.14$ (m, 2H), 1.74-1.94 (m, 4H), 1.57-1.71 (m, 4H), 1.44-1.47 (m, 2H), 1.32-1.39 (m, 4H), 1.01-1.27 (m, 11H), $0.88(\mathrm{~d}, J=6.4 \mathrm{~Hz}, 3 \mathrm{H})$, 0.80-0.85 (m, 1H), $0.75(\mathrm{t}, J=7.2 \mathrm{~Hz}, 3 \mathrm{H}), 0.63(\mathrm{~s}, 3 \mathrm{H})$.

\section{S-24. ${ }^{1} \mathrm{H}$ NMR spectrum of compound 9a}



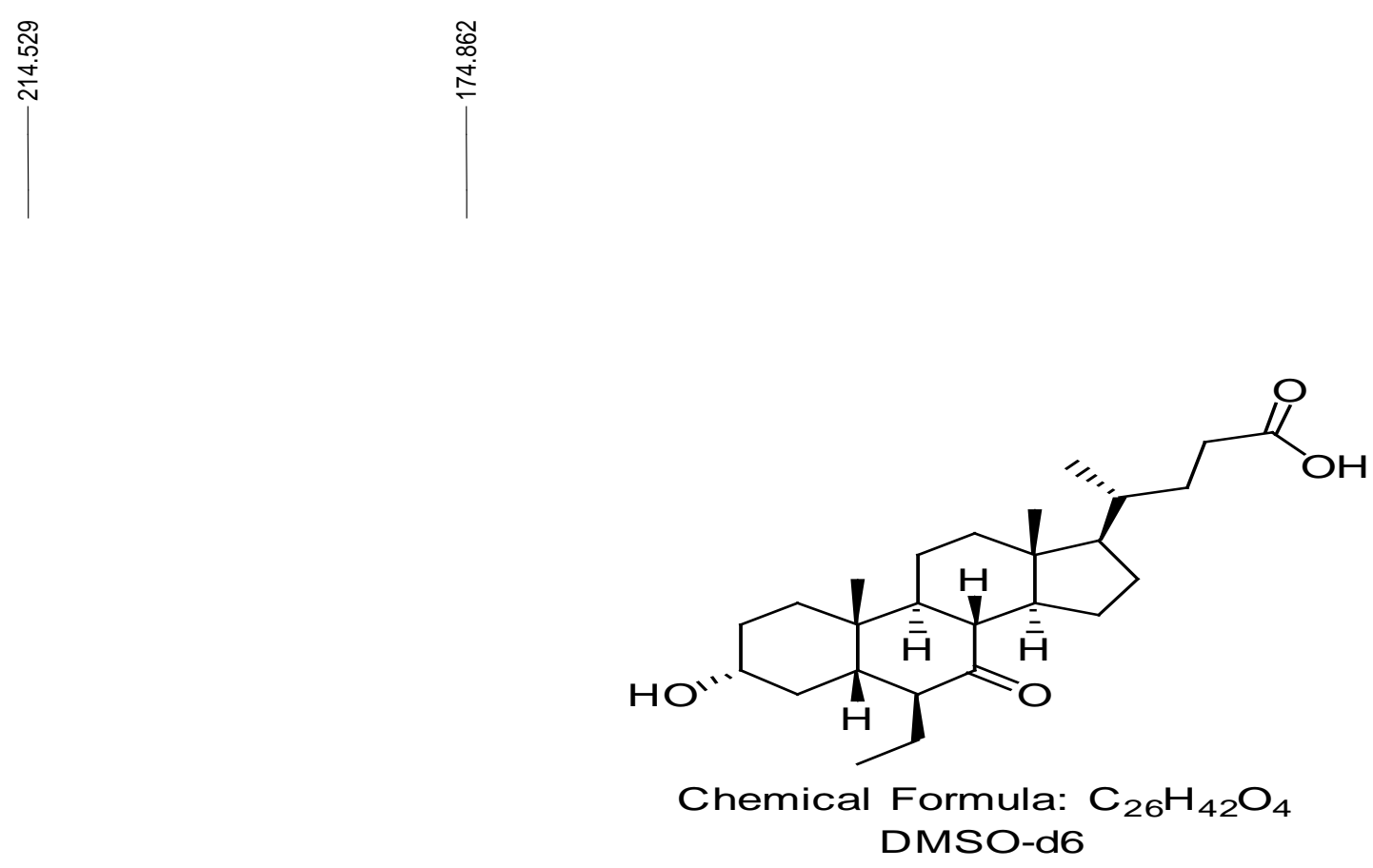

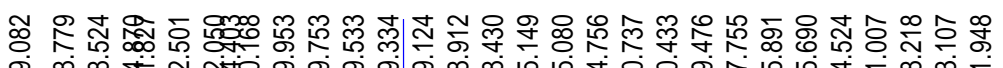

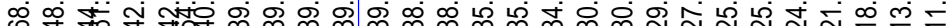
(16) [

${ }^{13} \mathrm{C}$ NMR (100 MHz, DMSO-d6) $\delta$ 214.53, 174.86, 68.78, 61.83, 54.40, 49.08, 48.52, 44.87, 42.50, 42.05, 38.43, 35.15, 35.08, 34.76, 30.74, 30.43, 29.48, 27.76, 25.89, 25.69, 24.52, 21.01, 18.22, 13.11, 11.95 .

\section{S-25. ${ }^{13} \mathrm{C}$ NMR spectrum of compound 9a}




\section{Mass Spectrum SmartFormula Report}

Analysis Info

Analysis Name Method

Sample Name

Comment
Acquisition Date

D:IDataISHUJVFENXILZHANGFL-groupl14237-12-1_BB6_01_12676.d 20150915.m

14237-12-1

Operator

Instrument/Ser\# maXis 4G

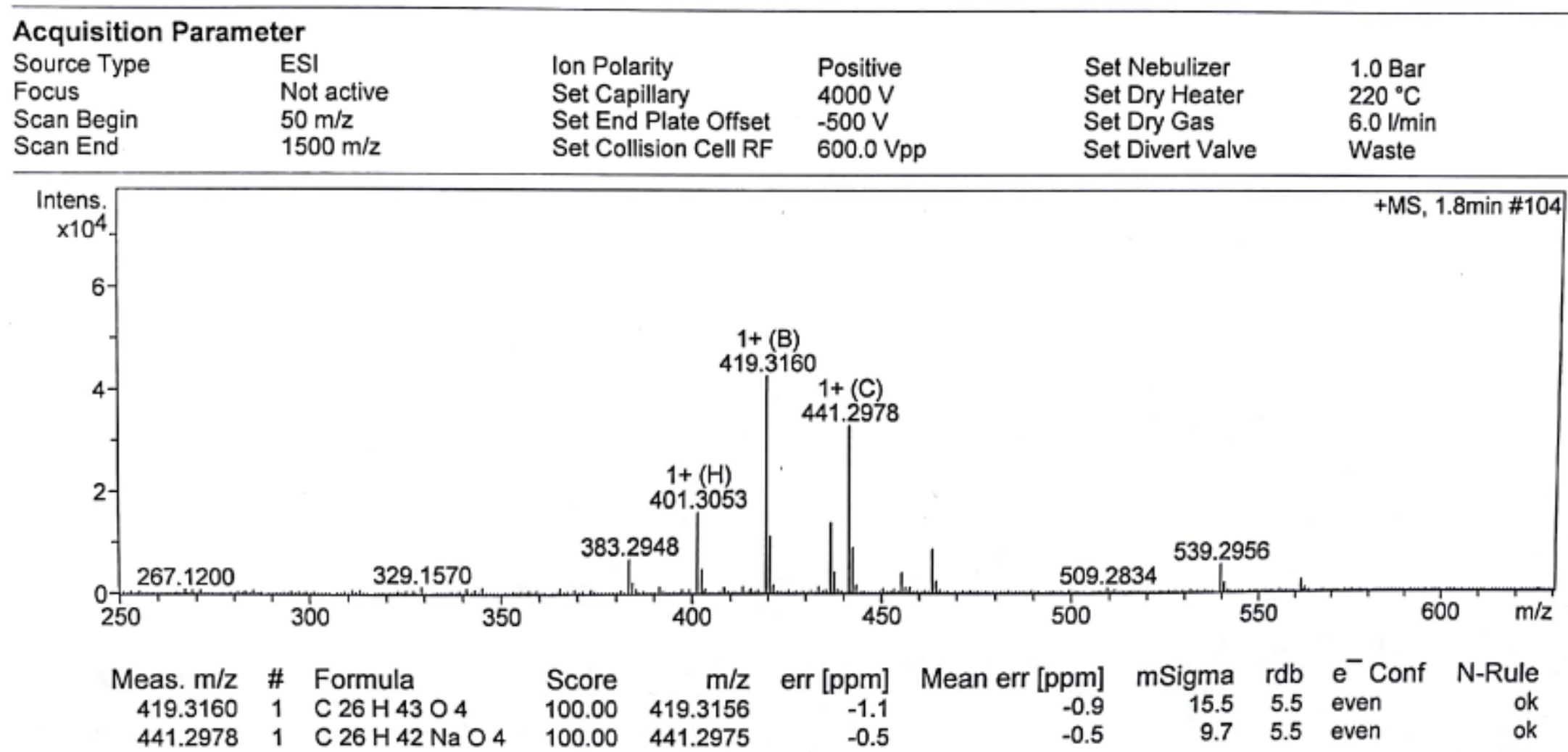

HRMS m/z [M+H] $]^{+}$Calcd for $\mathrm{C}_{26} \mathrm{H}_{43} \mathrm{O}_{4}$ : 419.3161; found: 419.3160 . 


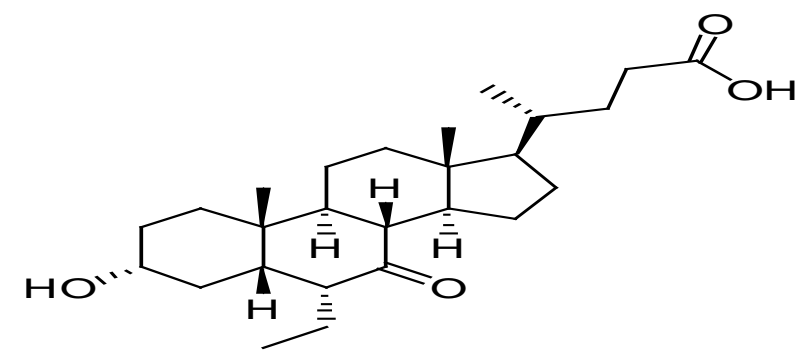

Chemical Formula: $\mathrm{C}_{26} \mathrm{H}_{42} \mathrm{O}_{4}$ DMSO-d6

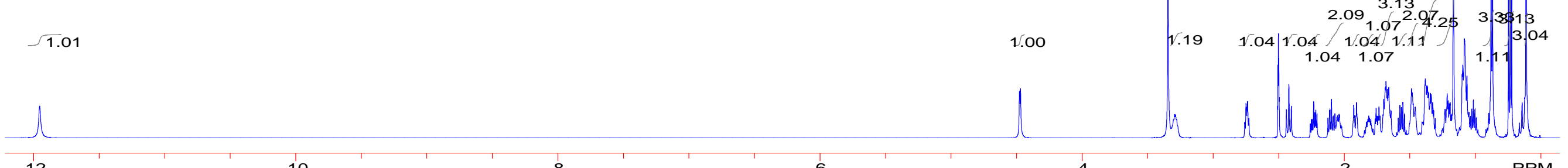

${ }^{1} \mathrm{H}$ NMR (400 MHz, DMSO-d6) $\delta 11.95$ (br, 1H), 4.47 (d, $\left.J=3.2 \mathrm{~Hz}, 1 \mathrm{H}\right), 3.25-3.32$ (m, 1H), 2.74 (q, $\left.J=4.0 \mathrm{~Hz}, 8.8 \mathrm{~Hz}, 1 \mathrm{H}\right), 2.42$ (t, $J=$ 7.6 Hz, 1H), 2.21-2.26 (m, 1H), 2.02-2.13 (m, 2H), 1.92 (dt, $J=2.0 \mathrm{~Hz}, 6.4 \mathrm{~Hz}, 1 \mathrm{H}), 1.78-1.85(\mathrm{~m}, 1 \mathrm{H}), 1.73-1.77$ (m, 1H), 1.65-1.71 (m, 3H), 1.53-1.60 (m, 1H), 1.46-1.49 (m, 2H), 1.31-1.43 (m, 4H), 1.17 (s, 3H), 0.98-1.27 (m, 8H), 0.90-0.92 (m, 1H), 0.88 (d, $J=4.4 \mathrm{~Hz}, 3 \mathrm{H})$, $0.74(\mathrm{t}, J=4.8 \mathrm{~Hz}, 3 \mathrm{H}), 0.62(\mathrm{~s}, 3 \mathrm{H})$. 


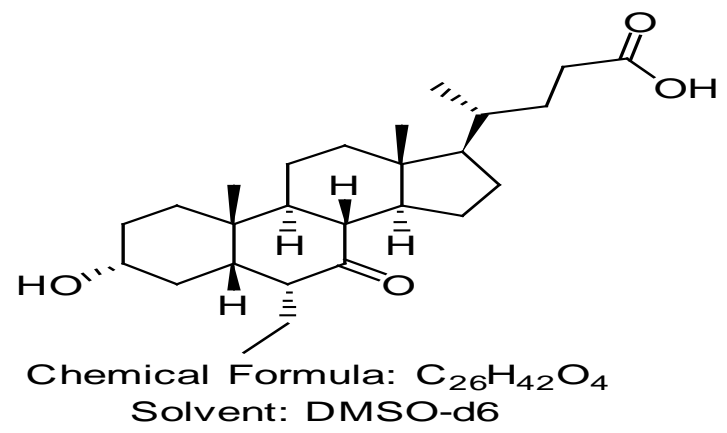

${ }^{13}$ C NMR (100 MHz, DMSO-d6) $\delta$ 212.69, 175.35, 69.73, 54.83, 51.54, 50.41, 49.48, 49.34, 43.66, 42.67, 39.09, 35.80, 35.21, 34.42, 32.16, 31.18, 30.20, 28.35, 24.70, 23.72, 21.88, 19.08, 18.70, 12.40, 12.33. HRMS m/z [M+H] Calcd for $\mathrm{C}_{26} \mathrm{H}_{43} \mathrm{O}_{4}$ : 419.3163; found: 419.3157. 


\section{Mass Spectrum SmartFormula Report}

Analysis Info

Analysis Name

Method

Sample Name

Comment
Acquisition Date 7/14/2018 11:09:25 PM

D:IDataISHUJVFENXIIZHANGFL-group|14238-29-5-ECDCA-3_BB5_01_12675.d

20150915.m

Operator BDAL@DE

Instrument / Ser\# maXis 4G

21240

\begin{tabular}{llllll}
\hline Acquisition Parameter & & & & \\
Source Type & ESI & Ion Polarity & Positive & Set Nebulizer & 1.0 Bar \\
Focus & Not active & Set Capillary & $4000 \mathrm{~V}$ & Set Dry Heater & $220^{\circ} \mathrm{C}$ \\
Scan Begin & $50 \mathrm{~m} / \mathrm{z}$ & Set End Plate Offset & $-500 \mathrm{~V}$ & Set Dry Gas & 6.0 Vmin \\
Scan End & $1500 \mathrm{~m} / \mathrm{z}$ & Set Collision Cell RF & $600.0 \mathrm{Vpp}$ & Set Divert Valve & Waste \\
\hline
\end{tabular}

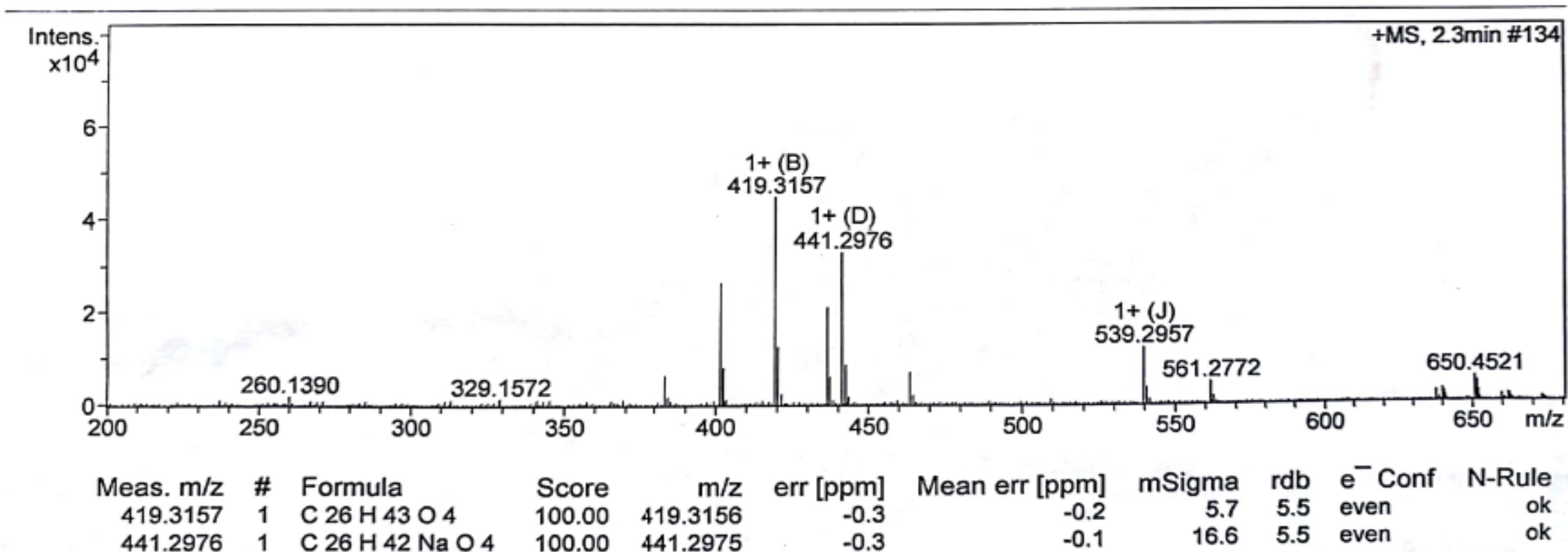

HRMS m/z [M+H] ${ }^{+}$Calcd for $\mathrm{C}_{26} \mathrm{H}_{43} \mathrm{O}_{4}$ : 419.3161; found: 419.3157 . 


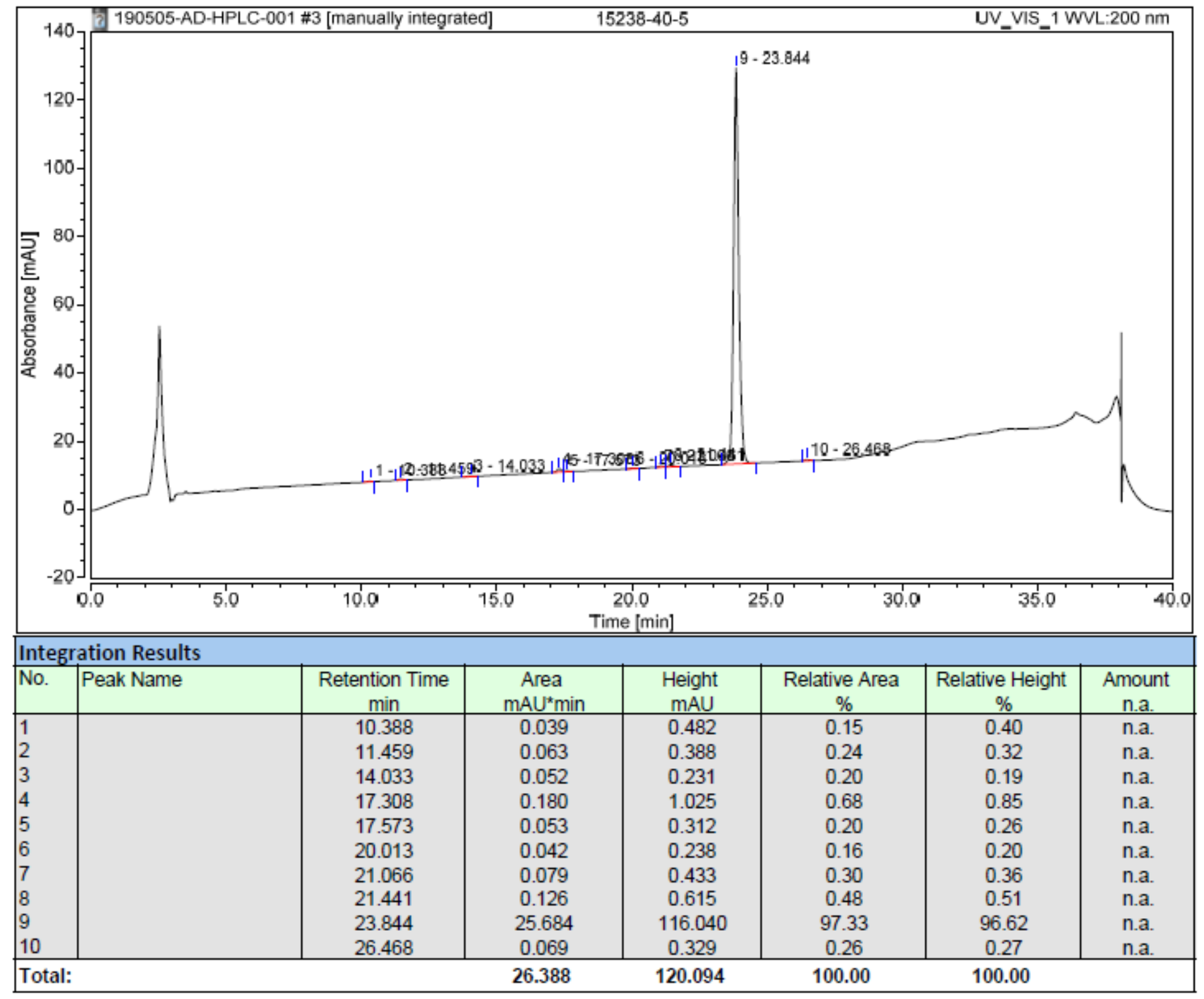

S-30. HPLC chromatogram of compound 10 


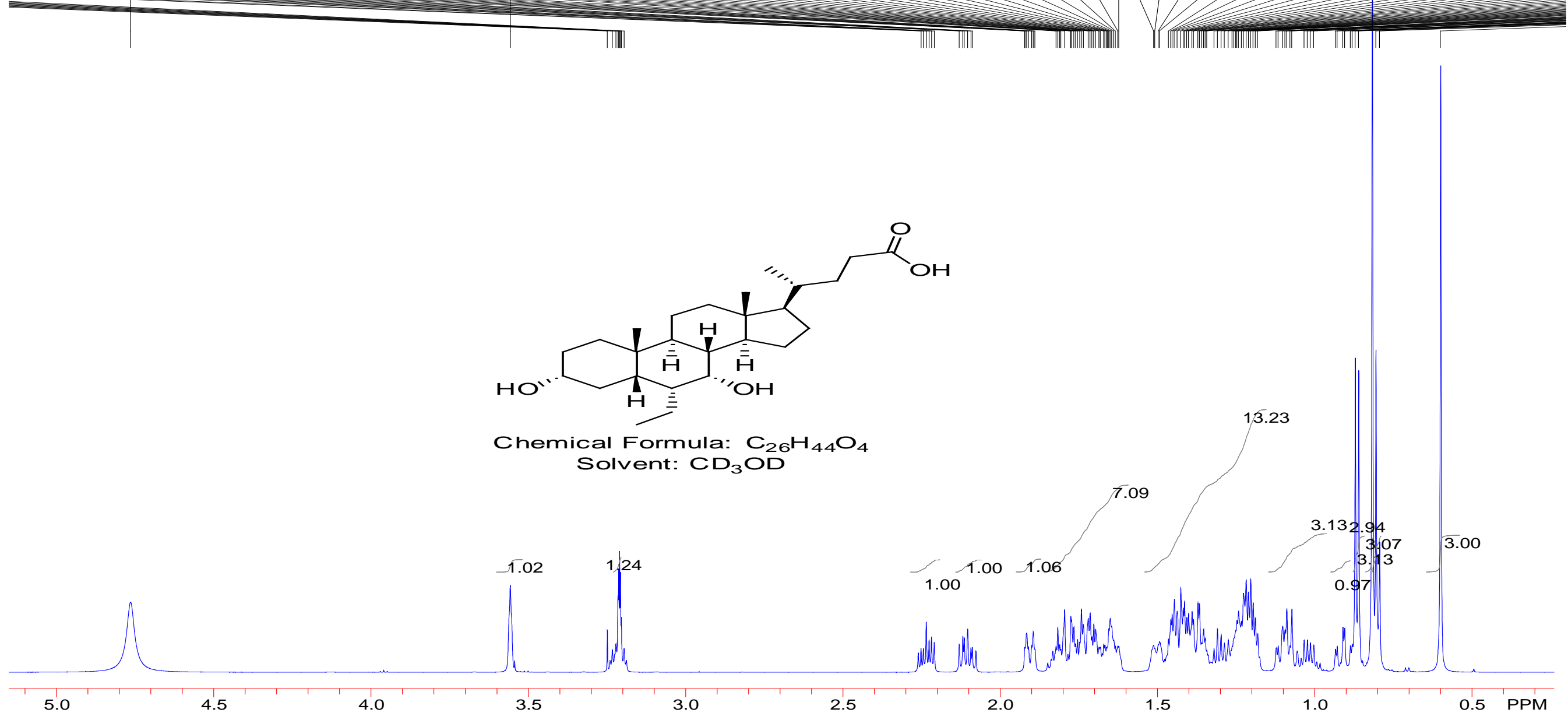

${ }^{1} \mathrm{H}$ NMR (400 MHz, CD $\left.\mathrm{OD}\right) \delta$ 3.55-3.57 (m, 1H), 3.18-3.24 (m, 1H), 2.21-2.26 (m, 1H), 2.07-2.12 (m, $\left.1 \mathrm{H}\right), 1.90(\mathrm{dt}, J=2.4 \mathrm{~Hz}, 8.4 \mathrm{~Hz}$ 1H), 1.62-1.85 (m, 7H), 1.18-1.51 (m, 13H), 0.97-1.12 (m, 3H), 0.88-0.93 (m, 1H), 0.87 (d, $J=4.0 \mathrm{~Hz}, 3 \mathrm{H}), 0.82(\mathrm{~s}, 3 \mathrm{H}), 0.81(\mathrm{t}, J=4.8 \mathrm{~Hz}$, 3H), $0.60(\mathrm{~s}, 3 \mathrm{H})$. 

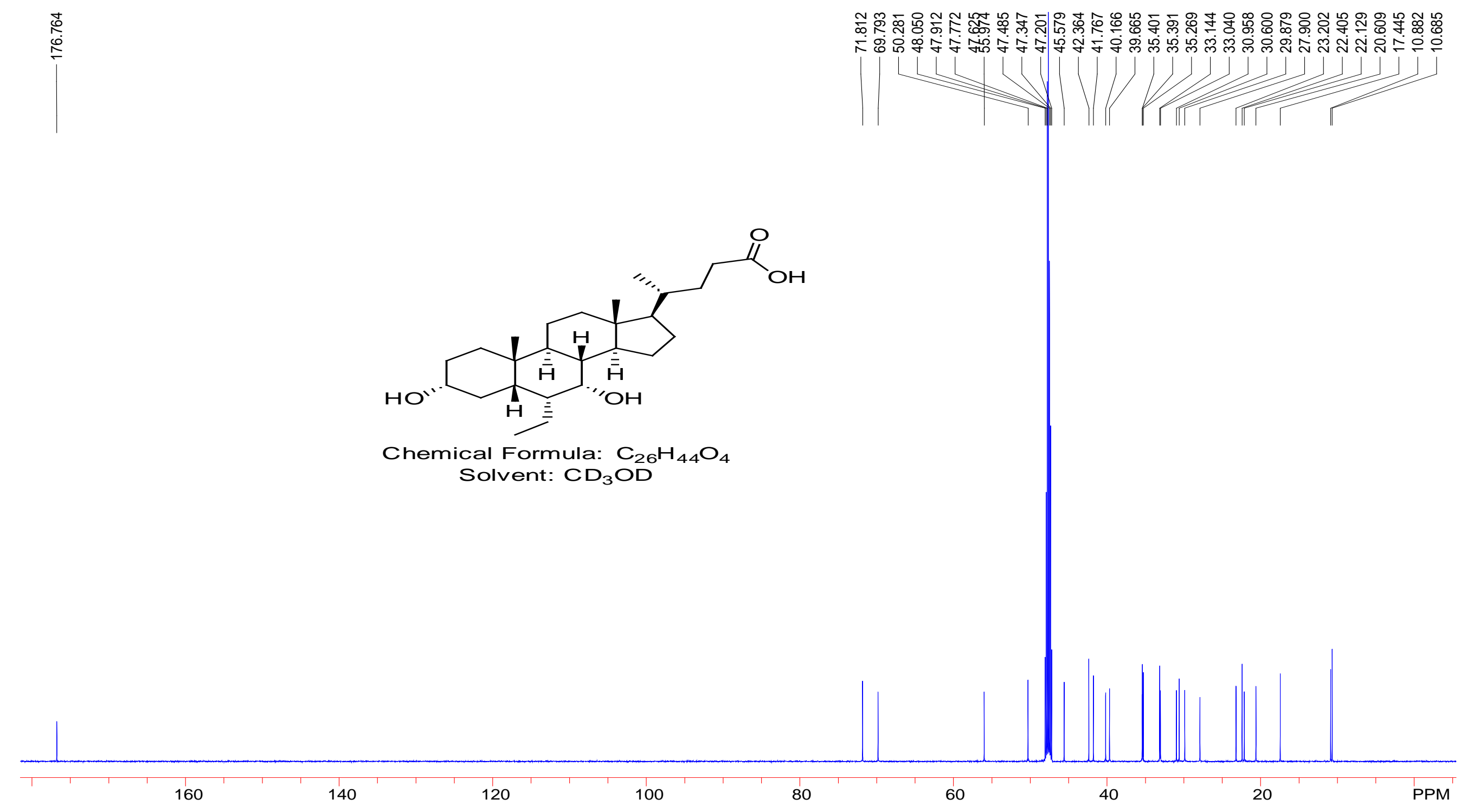

${ }^{13} \mathrm{C}$ NMR (100 MHz, CD 3 OD) $\delta$ 176.76, 71.81, 69.79, 55.97, 50.28, 45.58, 42.36, 41.77, 40.17, 39.67, 35.40, 35.39, 35.27, 33.14, 33.04, $30.96,30.60,29.88,27.90,23.20,22.41,22.13,20.61,17.45,10.88,10.69$. 


\section{Mass Spectrum SmartFormula Report}

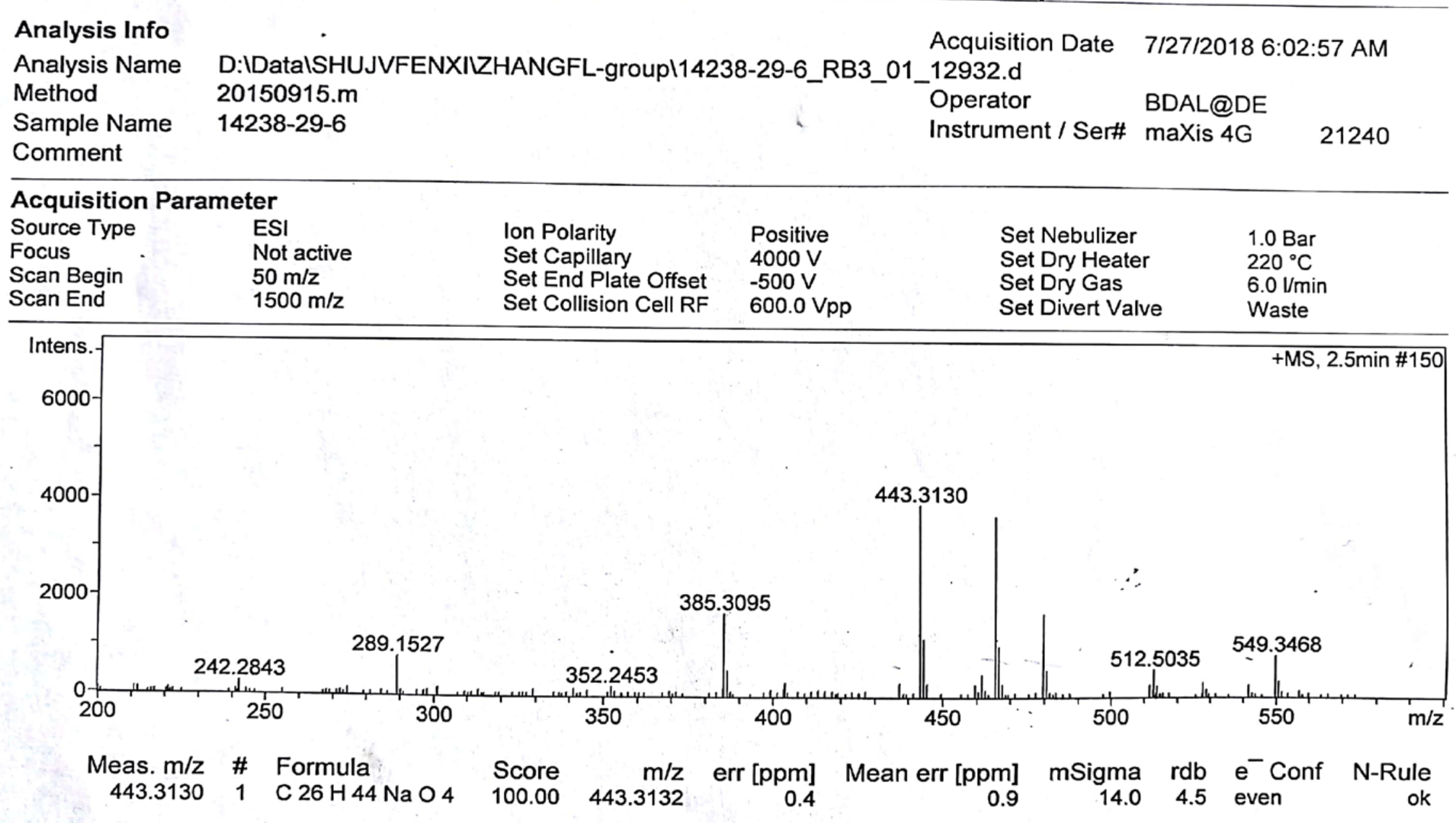

HRMS m/z [M+Na] $]^{+}$Calcd for $\mathrm{C}_{26} \mathrm{H}_{44} \mathrm{NaO}_{4}$ : 443.3137; found: 443.3130 .

S-33. HRMS spectrum of compound 1 (OCA) 


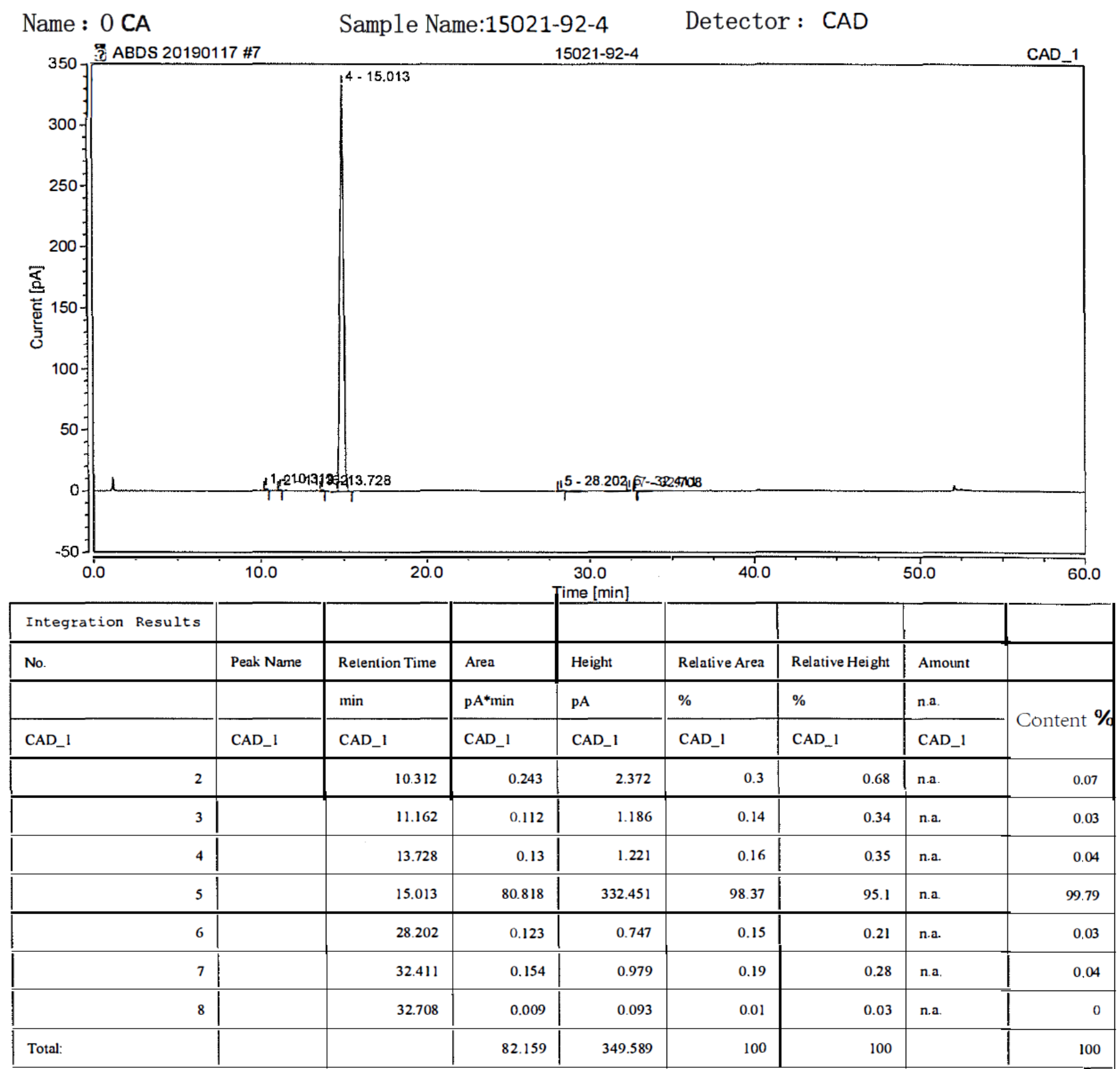

S-34. Content assay of compound 1 (OCA) 


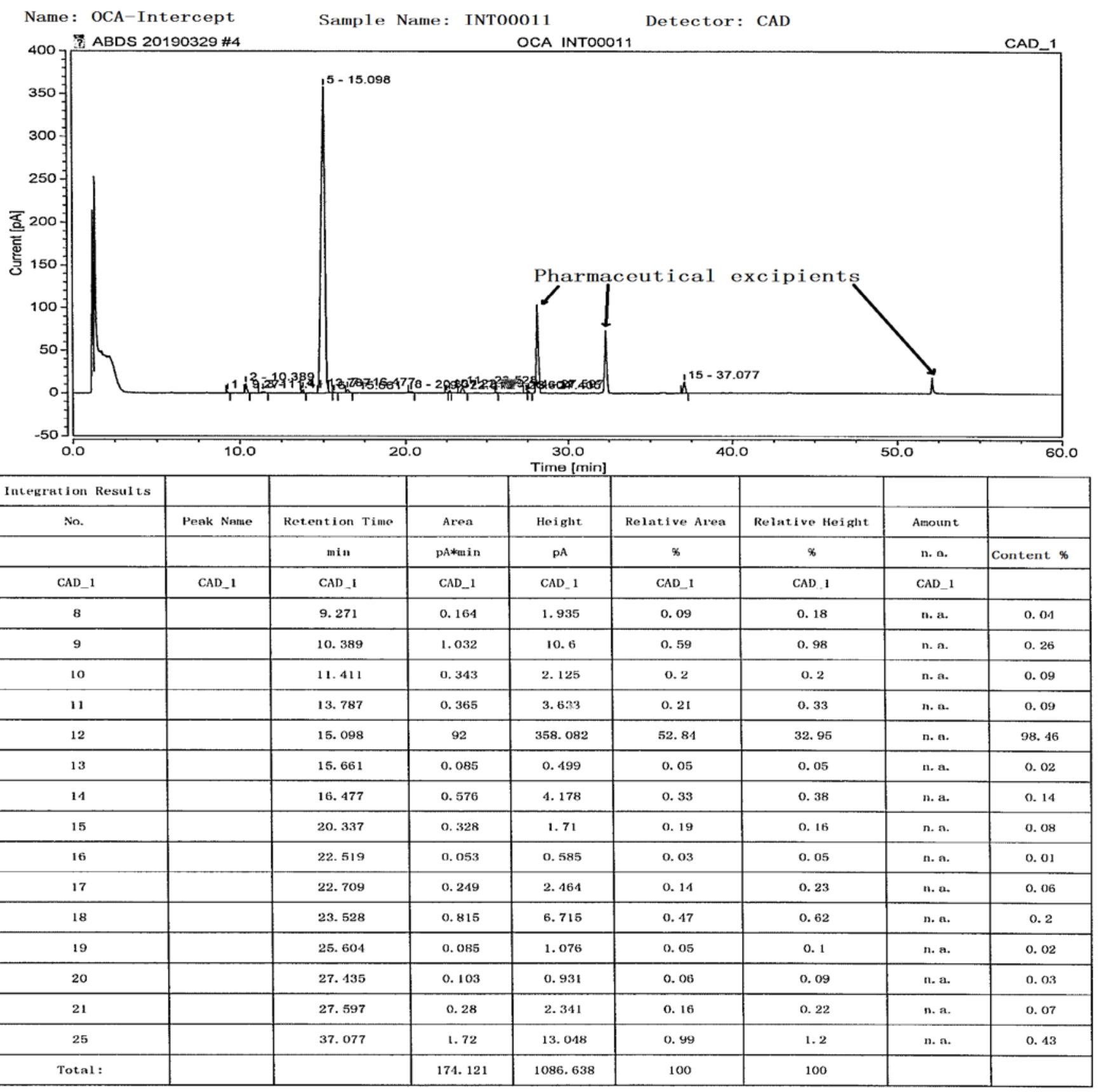

S-35. Content assay data of the original drugs from Intercept Pharmaceuticals Inc. 


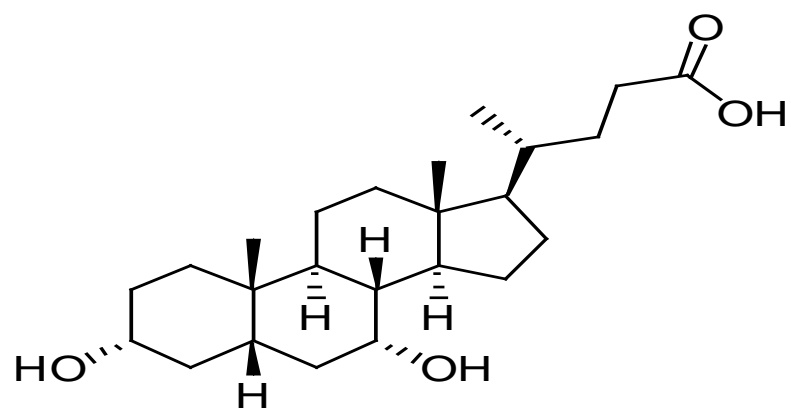

Chemical Formula: $\mathrm{C}_{24} \mathrm{H}_{40} \mathrm{O}_{4}$ DMSO-d6
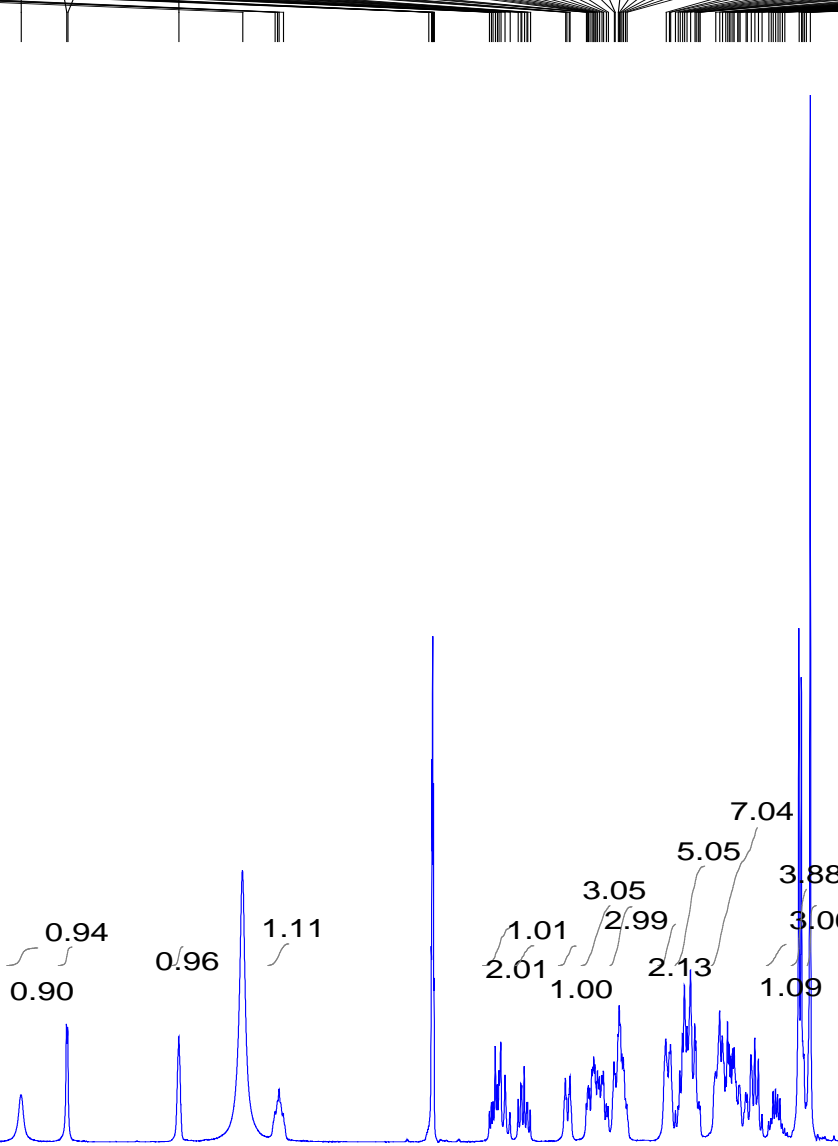

${ }^{1} \mathrm{H}$ NMR (400 MHz, DMSO-d6) $\delta 11.97$ (br, 1H), 4.32 (br, 1H), 4.12(d, $\left.J=2.0 \mathrm{~Hz}, 1 \mathrm{H}\right), 3.62$ (m, 1H), 3.16-3.20 (m, $\left.1 \mathrm{H}\right), 2.16-2.25$ (m, 2H), 2.07-2.13 (m, 1H), 1.91(dt, $J=2.4 \mathrm{~Hz}, 8.4 \mathrm{~Hz}, 1 \mathrm{H}), 1.73-1.82$ (m, 3H), 1.65-1.70 (m, 3H), $1.45-1.47$ (m, $2 \mathrm{H}), 1.32-1.43$ (m, 5H), 1.05-1.28 (m, 7H), 0.94-1.02 (m, 1H), 0.88 (d, $J=4.4$ Hz, 3H), 0.86-0.88 (m, 1H), 0.84 (s, 3H), 0.60 (s, 3H).

\section{S-36. ${ }^{1} \mathrm{H}$ NMR spectrum of Imp-1}




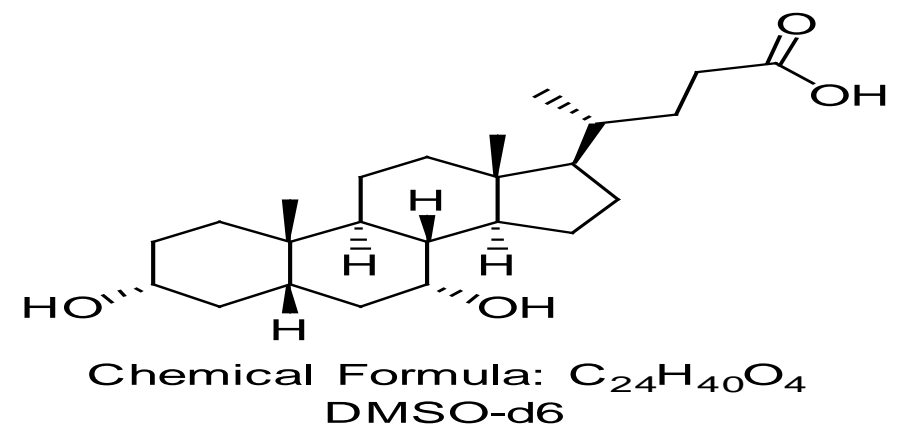

$$
\text { DMSO-d6 }
$$

${ }^{13} \mathrm{C}$ NMR (100 MHz, DMSO-d6) $\delta$ 175.40, 70.80, 66.63, 56.01, 50.48, 42.40, 41.88, 35.79, 35.43, 35.30, 35.22, 32.75, 31.24, 31.20, 31.04, 28.27, 23.64, 23.20, 20.73, 18.65, 12.14 . 


\section{Mass Spectrum SmartFormula Report}

Analysis Info

Analysis Name

Method

Sample Name

Comment
D:IDatalSHUJVFENXILZHANGFL-groupl14238-29-1-CDCA_RA8_01_12940.d 20150915.m

14238-29-1-CDCA
Acquisition Date

7/27/2018 7:34:25 AM

Operator BDAL@DE

Instrument / Ser\# maXis 4G

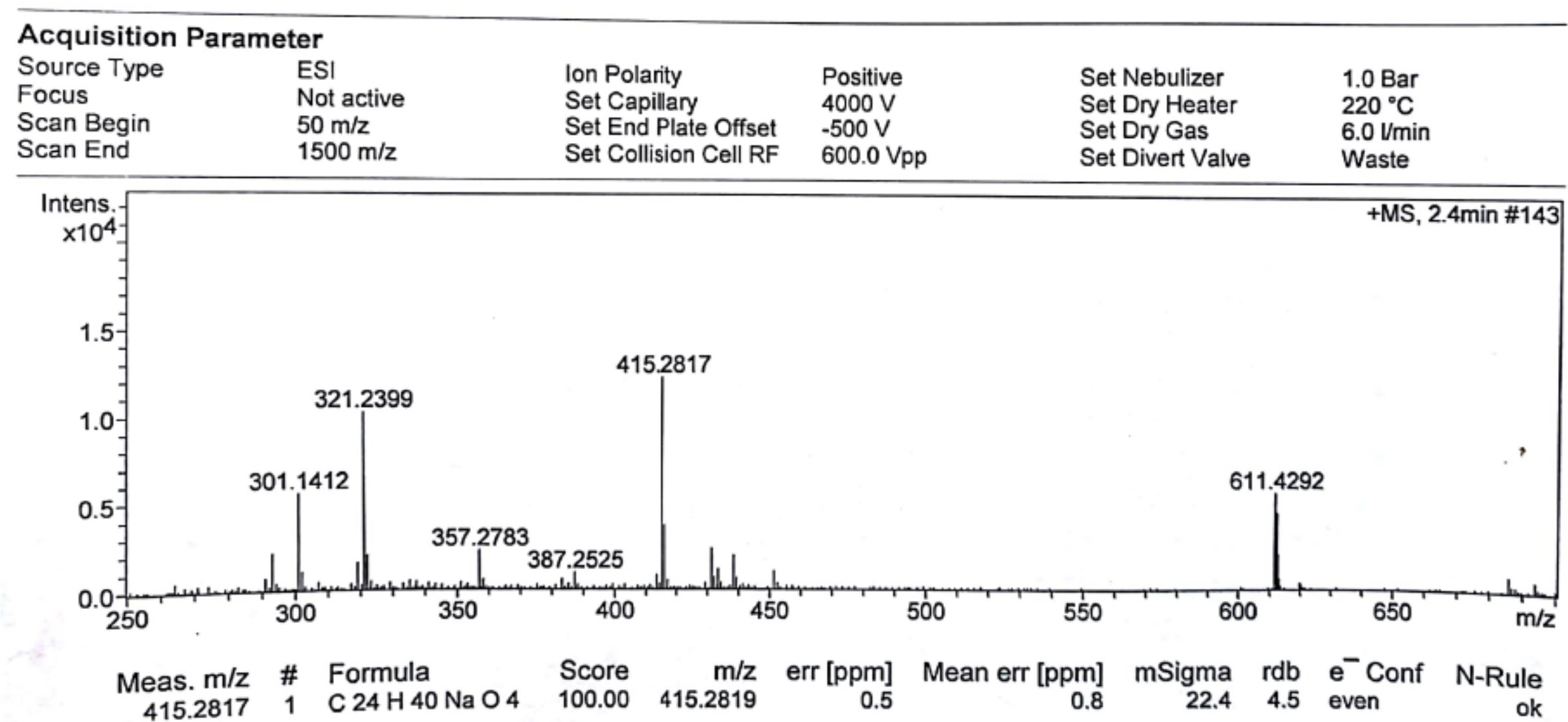

HRMS m/z [M+Na] ${ }^{+}$Calcd for $\mathrm{C}_{24} \mathrm{H}_{40} \mathrm{NaO}_{4}$ : 415.2824; found: 415.2817 .

\section{S-38. HRMS spectrum of Imp-1}




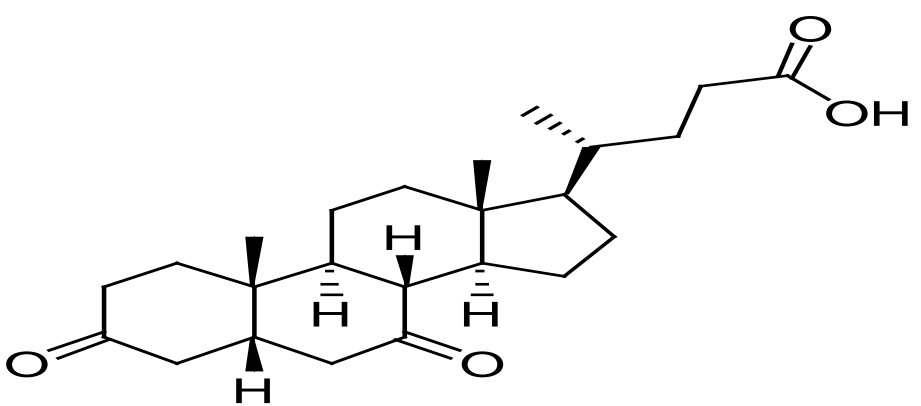

Chemical Formula: $\mathrm{C}_{24} \mathrm{H}_{36} \mathrm{O}_{4}$ Solvent: $\mathrm{CDCl}_{3}$

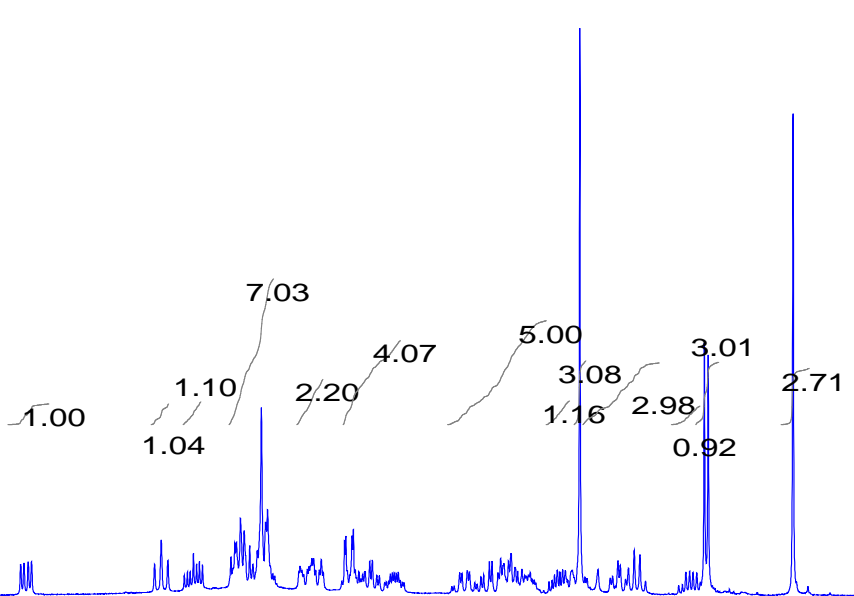

7

${ }^{1} \mathrm{H}$ NMR (400 MHz, $\left.\mathrm{CDCl}_{3}\right) \delta 2.88(\mathrm{dd}, J=3.6 \mathrm{~Hz}, 8.4 \mathrm{~Hz}, 1 \mathrm{H}), 2.50(\mathrm{t}, J=7.6 \mathrm{~Hz}, 1 \mathrm{H}), 2.38-2.43(\mathrm{~m}, 1 \mathrm{H}), 2.18-2.30(\mathrm{~m}, 7 \mathrm{H}), 2.04-2.11$ (m, 2H), 1.82-1.98 (m, 4H), 1.43-1.67 (m, 5H), 1.33-1.39 (m, 1H), $1.31(\mathrm{~s}, 3 \mathrm{H}), 1.12-1.29(\mathrm{~m}, 3 \mathrm{H}), 0.96-1.00(\mathrm{~m}, 1 \mathrm{H}), 0.95(\mathrm{~d}, J=4 \mathrm{~Hz}$ 3H), $0.70(\mathrm{~s}, 3 \mathrm{H})$.

\section{S-39. ${ }^{1} \mathrm{H}$ NMR spectrum of Imp-2}




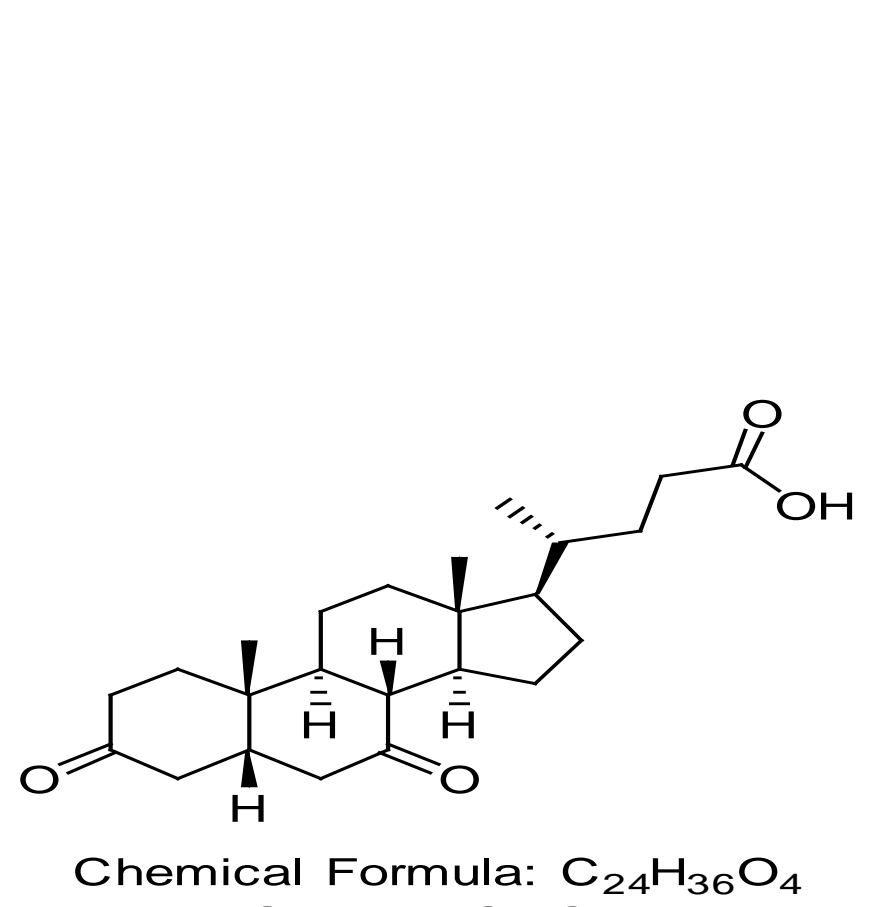
Solvent: $\mathrm{CDCl}_{3}$

${ }^{13}$ C NMR (100 MHz, DMSO-d6) $\delta$ 211.19, 210.29, 54.79, 49.57, 48.84, 47.78, 45.02, 42.93, 42.83, 42.68, 38.76, 36.76, 35.43, 35.17, 30.72, 30.56, 28.25, 24.76, 22.45, 22.12, 18.34, 12.10 . 
Mass Spectrum SmartFormula Report

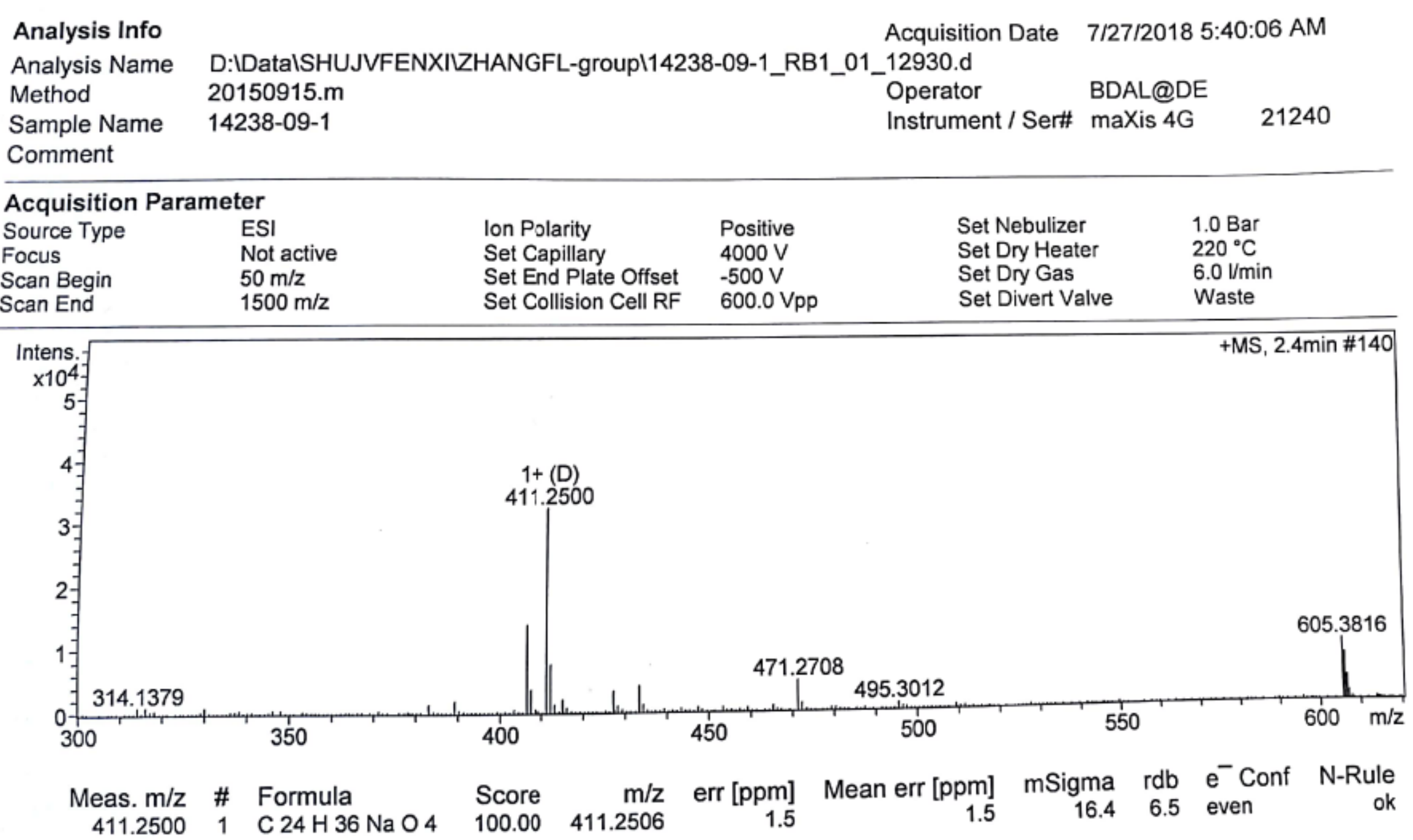

HRMS m/z [M+Na] $]^{+}$Calcd for $\mathrm{C}_{24} \mathrm{H}_{36} \mathrm{NaO}_{4}$ : 411.2511; found: 411.2500 .

\section{S-41. HRMS spectrum of Imp-2}




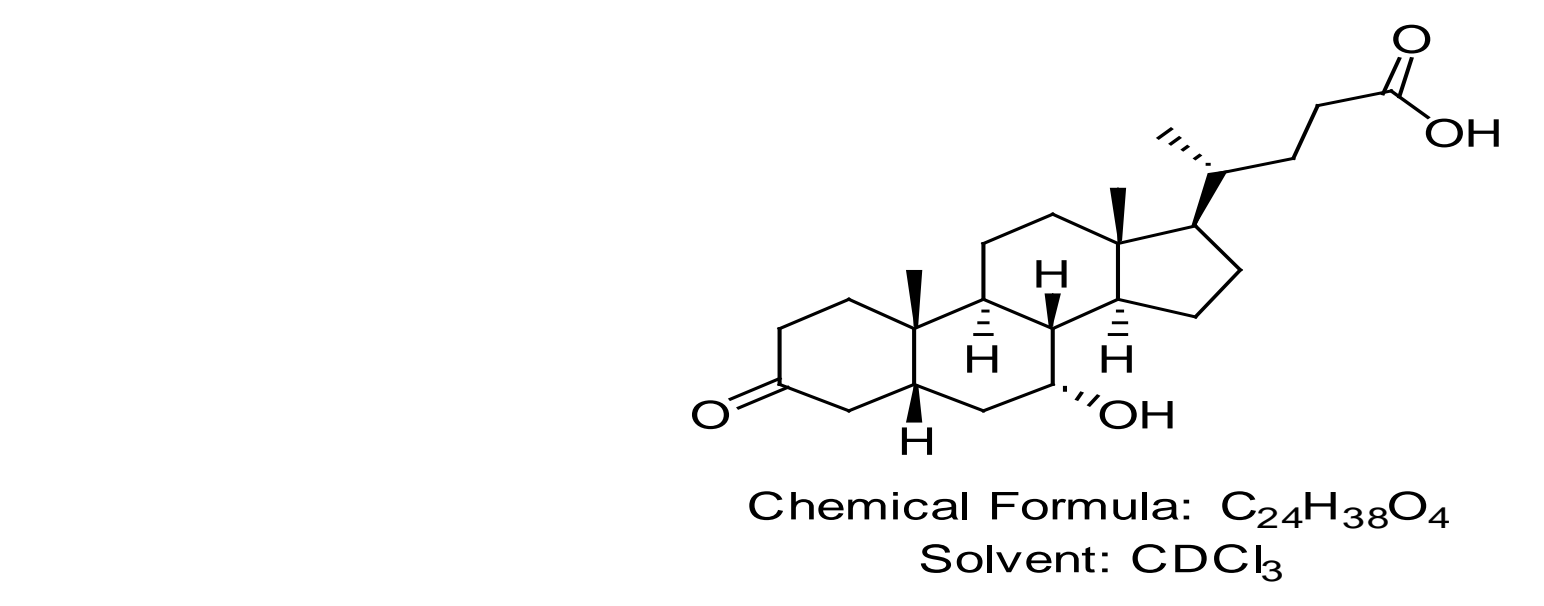

Chemical Formula: $\mathrm{C}_{24} \mathrm{H}_{38} \mathrm{O}_{4}$ Solvent: $\mathrm{CDCl}_{3}$

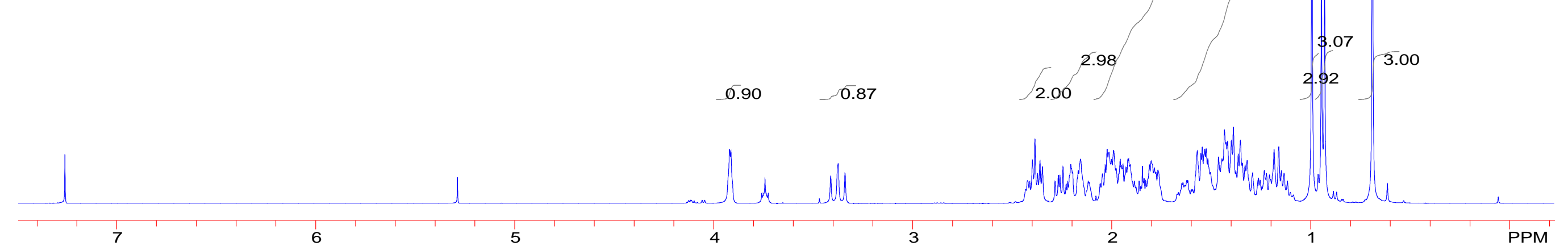

${ }^{1} \mathrm{H}$ NMR (400 MHz, CDCl3) $\delta 3.92$ (q, $\left.J=2.4 \mathrm{~Hz}, 1 \mathrm{H}\right), 3.38$ (t, $\left.J=14.8 \mathrm{~Hz}, 1 \mathrm{H}\right), 2.35-2.43(\mathrm{~m}, 2 \mathrm{H}), 2.11-2.28$ (m, 3H), 1.77-2.06 (m, 7H), 1.10-1.67 (m, 13H), 0.99 (s, 3H), 0.94 (d, $J=6.8 \mathrm{~Hz}, 3 \mathrm{H}), 0.69$ (s, 3H).

\section{S-42. ${ }^{1} \mathrm{H}$ NMR spectrum of Imp-3}




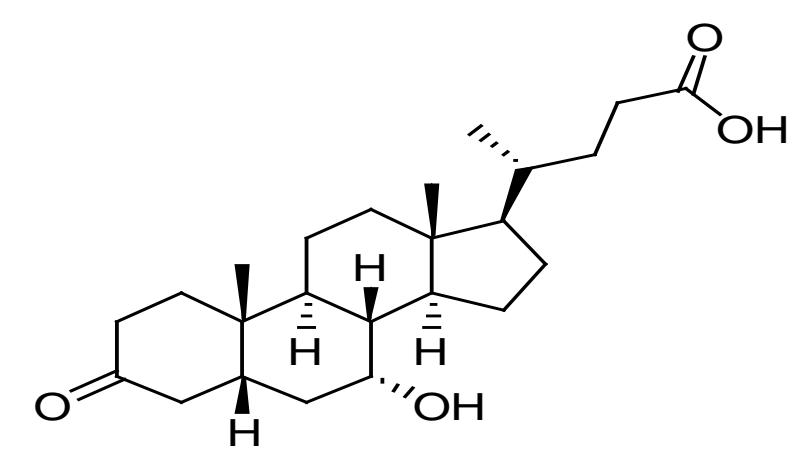

Chemical Formula: $\mathrm{C}_{24} \mathrm{H}_{38} \mathrm{O}_{4}$ Solvent: $\mathrm{CDCl}_{3}$

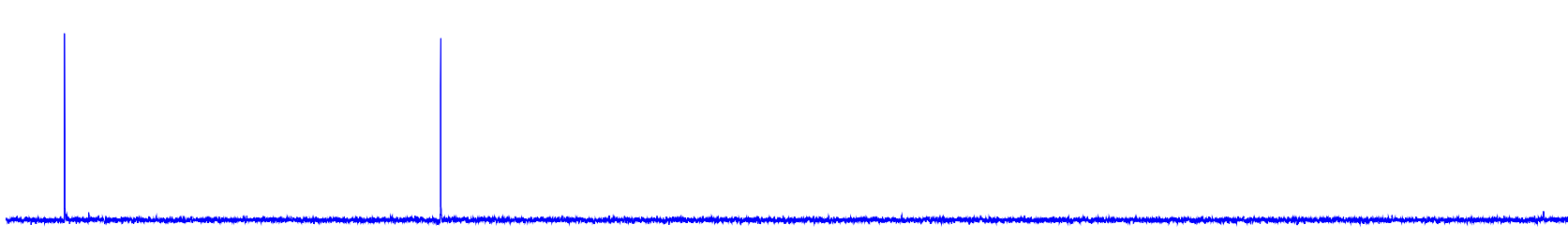

${ }^{13} \mathrm{C}$ NMR $\left(100 \mathrm{MHz}, \mathrm{CDCl}_{3}\right) \delta$ 213.70, 179.82, 68.62, 55.91, 50.41, 45.71, 43.29, 42.87, 39.64, 39.48, 37.06, 36.92, 35.46, 35.43, 33.97, 33.41, 31.12, 30.89, 28.25, 23.79, 22.05, 21.10, 18.38, 11.92.

\section{S-43. ${ }^{13} \mathrm{C}$ NMR spectrum of Imp-3}




\section{Mass Spectrum SmartFormula Report}

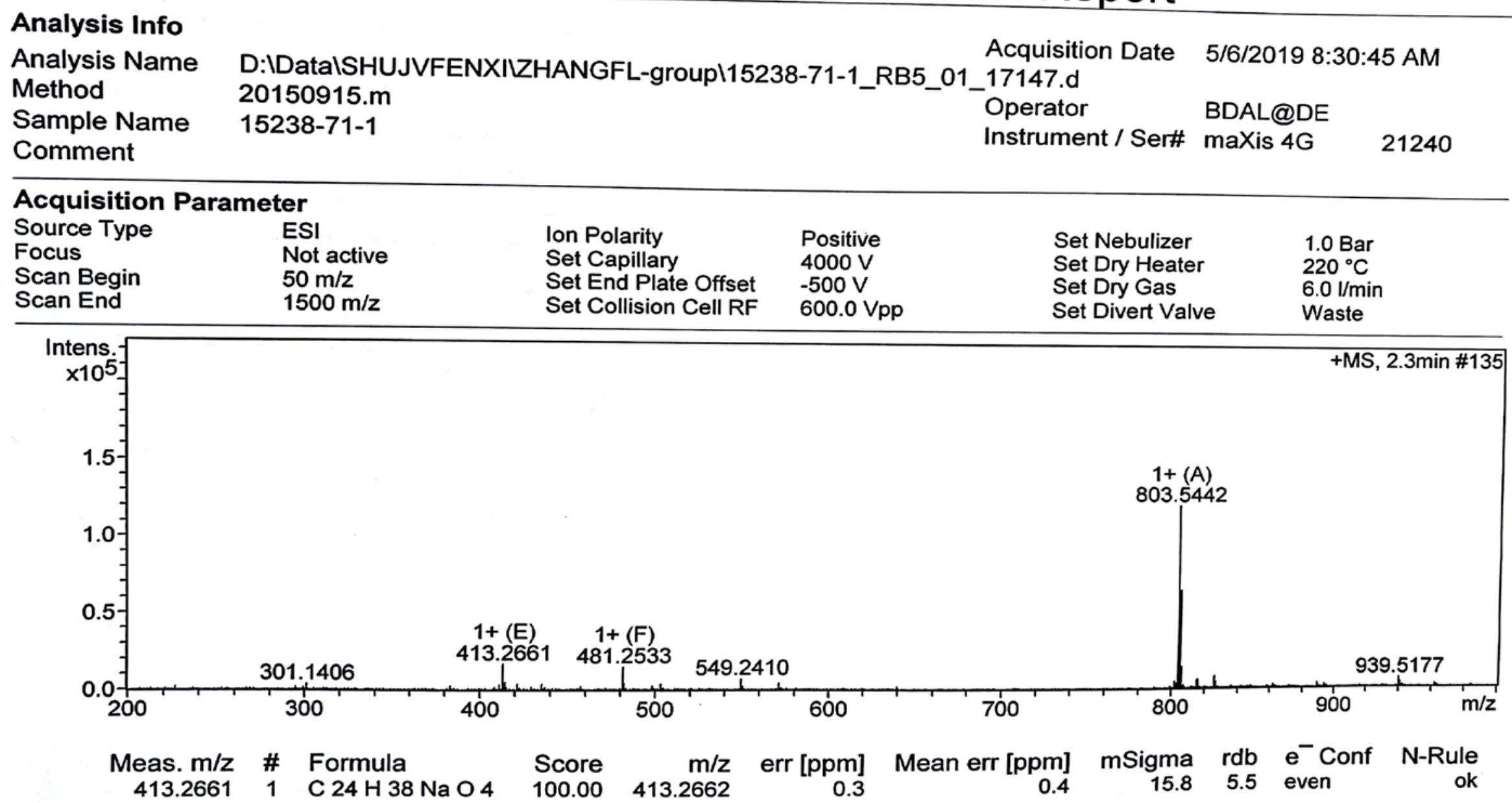

HRMS m/z [M+Na] $]^{+}$Calcd for $\mathrm{C}_{24} \mathrm{H}_{38} \mathrm{NaO}_{4}$ : 413.2668; found: 413.2661 .

\section{S-44. HRMS spectrum of Imp-3}




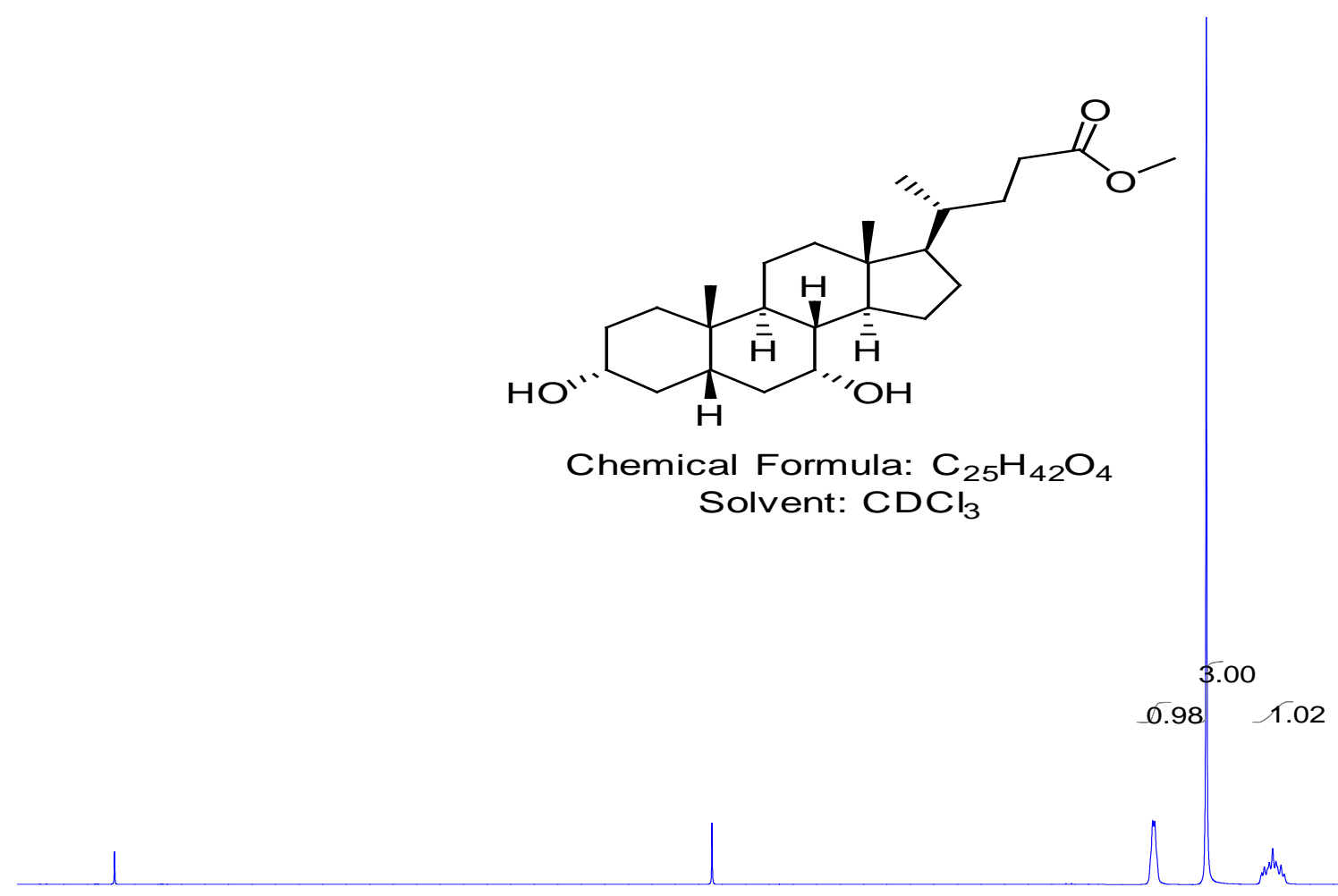

7

6

5

4

3

2

1

${ }^{1} \mathrm{H}$ NMR (400 MHz, CDCl $)$ ) 3.82-3.83 (m, 1H), 3.65 (s, 3H), 3.39-3.47 (m, 1H), 2.18-2.30 (m, 7H), 2.29-2.38 (m, 1H), 2.17-2.26 (m, 4H), 1.61-1.98 (m, 7H), 1.19-1.53 (m, 13H), 0.96-1.00 (m, 1H), 0.91 (d, $J=6.4 \mathrm{~Hz}, 3 \mathrm{H}), 0.65$ (s, 3H).

\section{S-45. ${ }^{1} \mathrm{H}$ NMR spectrum of Imp-4}




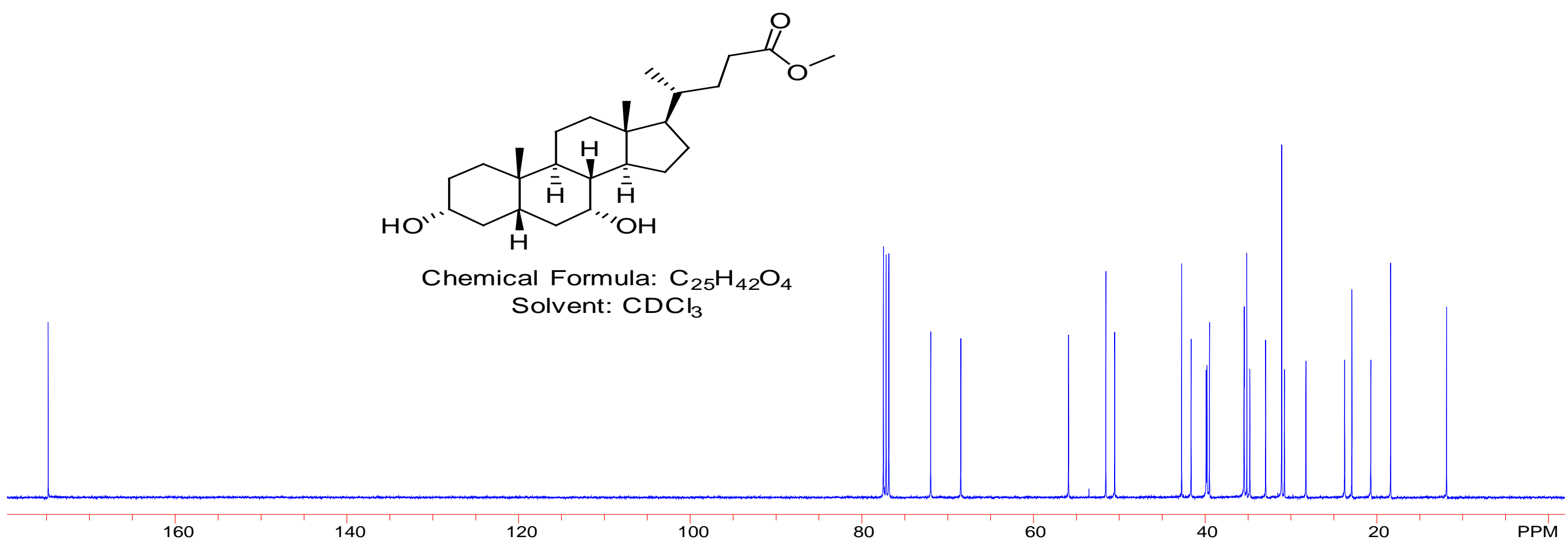

${ }^{13} \mathrm{C}$ NMR $\left(100 \mathrm{MHz}, \mathrm{CDCl}_{3}\right) \delta 174.81,71.97,68.46,55.91,51.56,50.52,42.72,41.62,39.86,39.75,39.48,35.45,35.43,35.12,34.77$, 32.93, 31.06, 30.74, 28.24, 23.73, 22.88, 20.69, 18.36, 11.83.

\section{S-46. ${ }^{13} \mathrm{C}$ NMR spectrum of Imp-4}




\section{Mass Spectrum SmartFormula Report}

\begin{tabular}{|c|c|c|c|}
\hline Analysis Info & & Acquisition Date & $5 / 31 / 20193: 21: 58$ AM \\
\hline Analysis Name & D:IDatalSHUJVFENXIZZHANGFL-groupl15596-11-1_GE3_01_ & 17533.d & \\
\hline Method & 20150915.m & Operator & BDAL@DE \\
\hline $\begin{array}{l}\text { Sample Name } \\
\text { Comment }\end{array}$ & $15596-11-1$ & Instrument / Ser\# & $\operatorname{maXis} 4 G$ \\
\hline
\end{tabular}

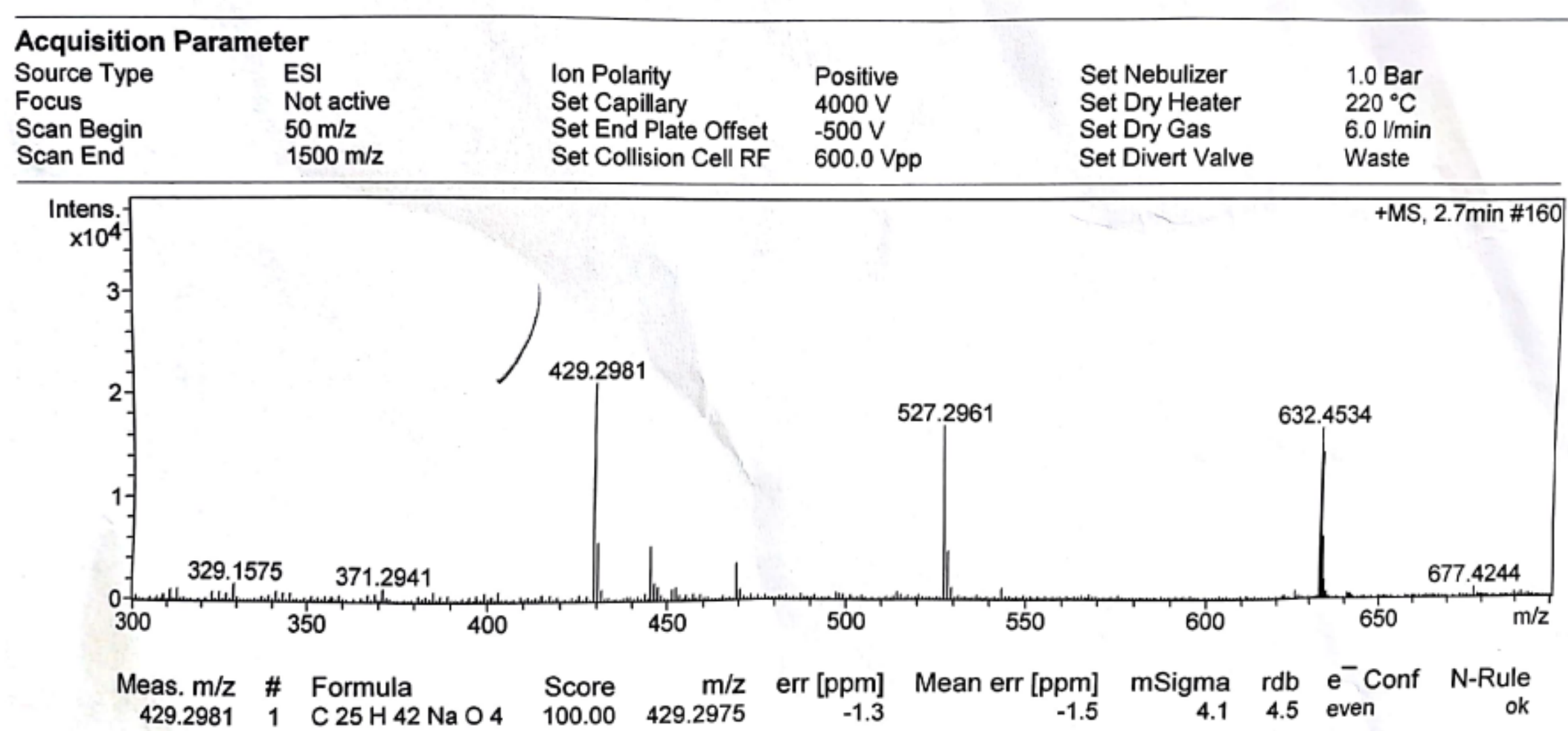

HRMS m/z [M+Na] ${ }^{+}$Calcd for $\mathrm{C}_{25} \mathrm{H}_{42} \mathrm{NaO}_{4}$ : 429.2981; found: 429.2981 . 

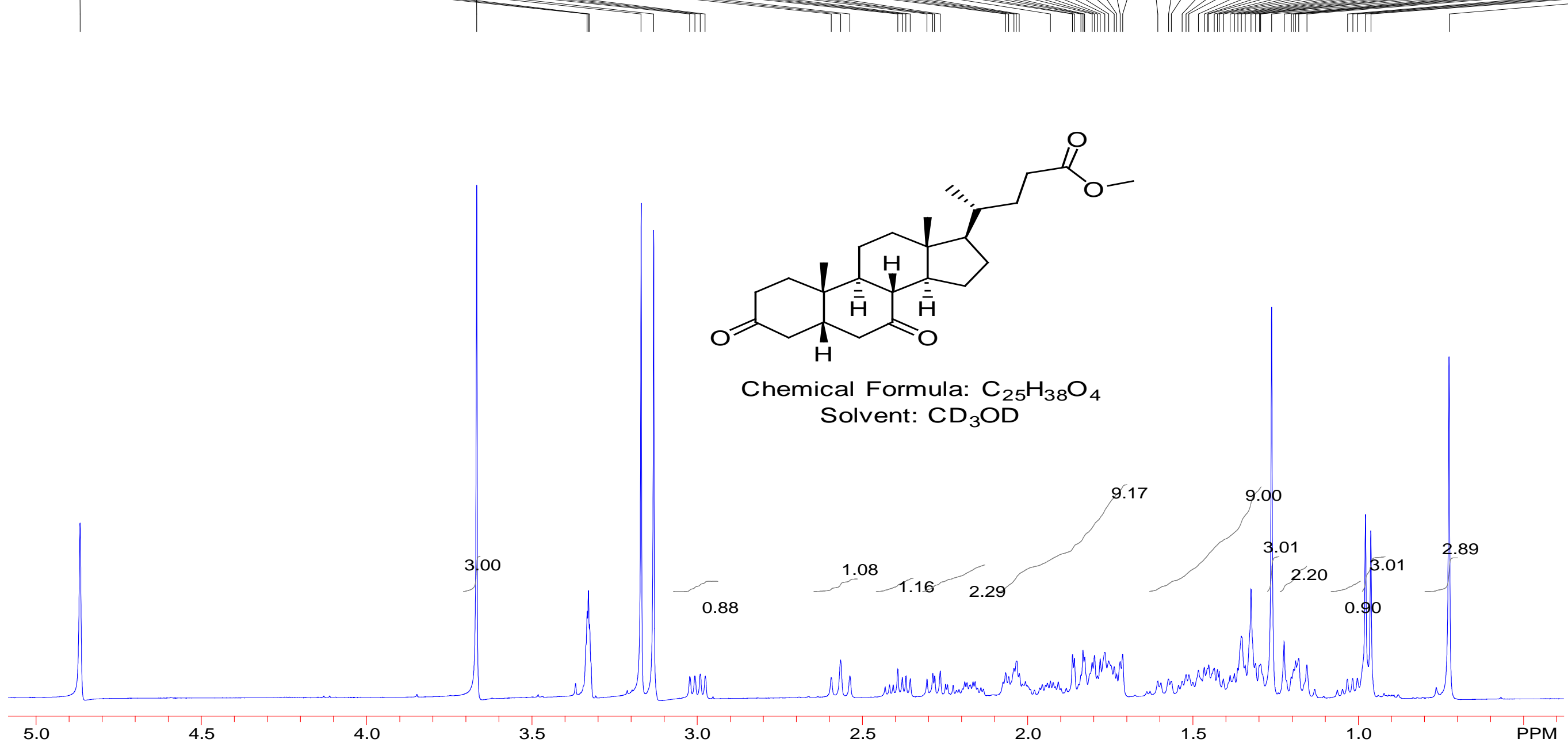

${ }^{1} \mathrm{H}$ NMR (400 MHz, CD $\left.\mathrm{CD}_{3} \mathrm{OD}\right) \delta 3.67$ (s, 3H), 2.99 (dd, $\left.J=6.0 \mathrm{~Hz}, 12.4 \mathrm{~Hz}, 1 \mathrm{H}\right), 2.57$ (t, $\left.J=11.6 \mathrm{~Hz}, 1 \mathrm{H}\right), 2.36-2.43(\mathrm{~m}, 1 \mathrm{H}), 2.13-2.31(\mathrm{~m}$, 2H), 1.71-2.08 (m, 9H), 1.30-1.61 (m, 9H), 1.26 (s, 3H), 1.16-1.22 (m, 2H), 1.00-1.06 (m, 1H), 0.97 (d, J = 6.4 Hz, 3H), 0.73 (s, 3H).

\section{S-48. ${ }^{1} \mathrm{H}$ NMR spectrum of Imp-5}




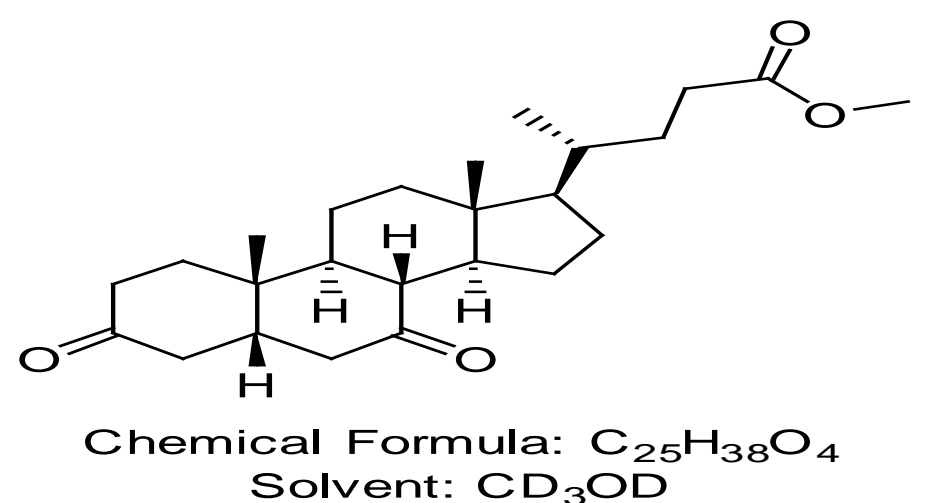

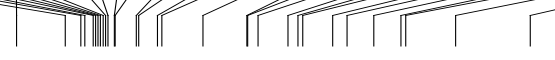

${ }^{13} \mathrm{C}$ NMR $\left(100 \mathrm{MHz}, \mathrm{CD}_{3} \mathrm{OD}\right) \delta$ 213.29, 174.53, 99.71, 54.31, 50.15, 45.98, 45.92, 44.11, 43.89, 42.31, 41.95, 38.44, 34.70, 34.66, 33.76, 31.21, 30.37, 29.98, 27.42, 26.18, 23.89, 21.60, 21.19, 16.96, 10.62.

\section{S-49. ${ }^{13} \mathrm{C}$ NMR spectrum of Imp-5}




\section{Mass Spectrum SmartFormula Report}

Analysis Info

Analysis Name

Method

Sample Name

Comment
Acquisition Date

D:IDatalSHUJVFENXIUZHANGFL-groupl15238-72-3_RC2 01_17143.d 20150915.m

$15238-72-3$

Operator

Instrument/ SerH maXis 4

BDAL@DE

maXis $4 \mathrm{G}$

21240

\begin{tabular}{llllll}
\hline \multicolumn{2}{l}{ Acquisition Parameter } & & & & \\
Source Type & ESI & lon Polarity & Positive & Set Nebulizer & 1.0 Bar \\
Focus & Not active & Set Capillary & $4000 \mathrm{~V}$ & Set Dry Heater & $220^{\circ} \mathrm{C}$ \\
Scan Begin & $50 \mathrm{~m} / \mathrm{z}$ & Set End Plate Offset & $-500 \mathrm{~V}$ & Set Dry Gas & 6.0 Vmin \\
Scan End & $1500 \mathrm{~m} / \mathrm{z}$ & Set Collision Cell RF & $600.0 \mathrm{Vpp}$ & Set Divert Valve & Waste \\
\hline
\end{tabular}

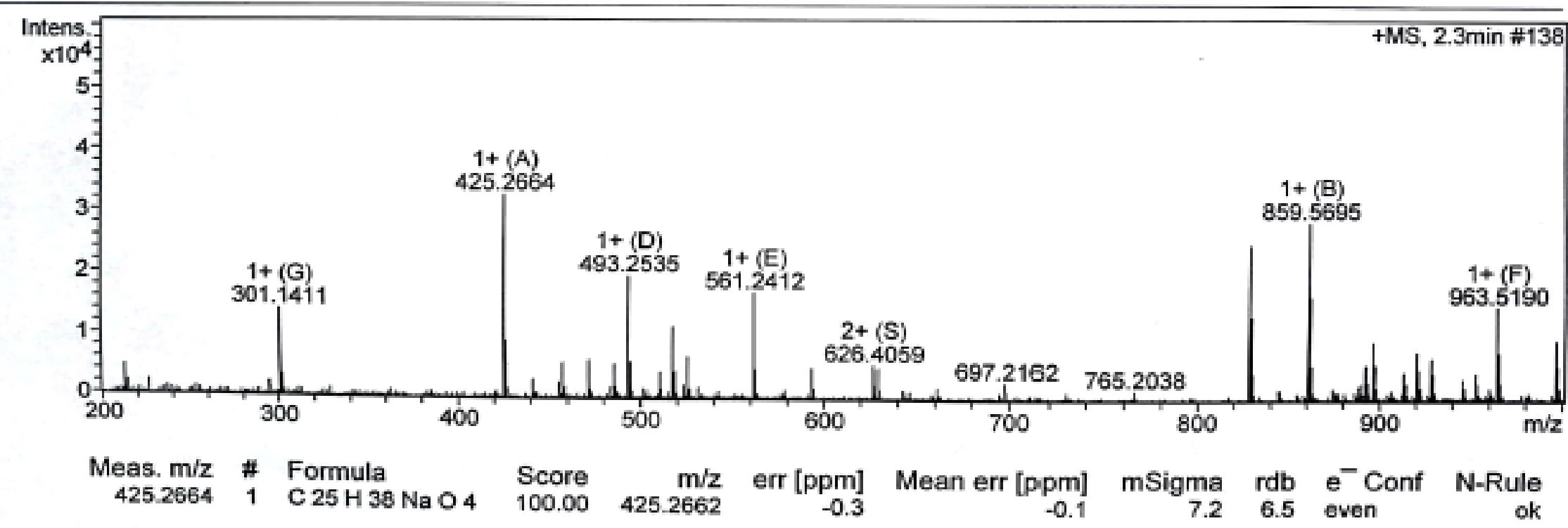

HRMS m/z [M+Na] $]^{+}$Calcd for $\mathrm{C}_{25} \mathrm{H}_{38} \mathrm{NaO}_{4}$ : 425.2668; found: 425.2664 .

\section{S-50. HRMS spectrum of Imp-5}




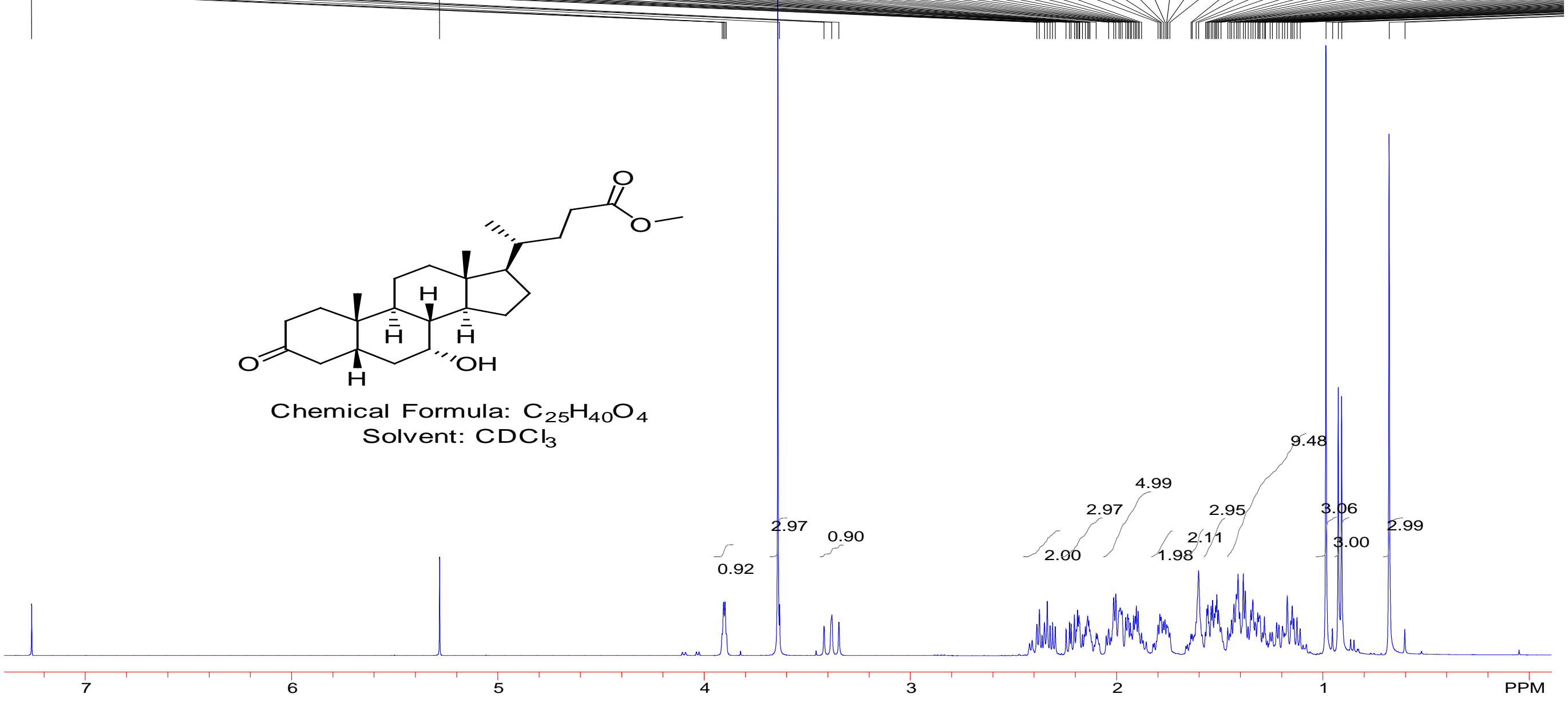

${ }^{1} \mathrm{H}$ NMR (400 MHz, CDCl3) $\delta 3.90$ (q, $J=2.8 \mathrm{~Hz}, 1 \mathrm{H}$ ), 3.64 (s, 3H), 3.38 (t, $\left.J=15.2 \mathrm{~Hz}, 1 \mathrm{H}\right), 2.30-2.42$ (m, 2H), $2.08-2.25$ (m, 3H), 1.86-2.05 (m, 5H), 1.74-1.82 (m, 2H), 1.59-1.66 (m, 2H), 1.48-1.57 (m, 3H), 1.08-1.46 (m, 9H), 0.99 (s, 3H), 0.92 (d, J = 6.4 Hz, 3H), 0.68 (s, 3H).

\section{S-51. ${ }^{1} \mathrm{H}$ NMR spectrum of Imp-6}




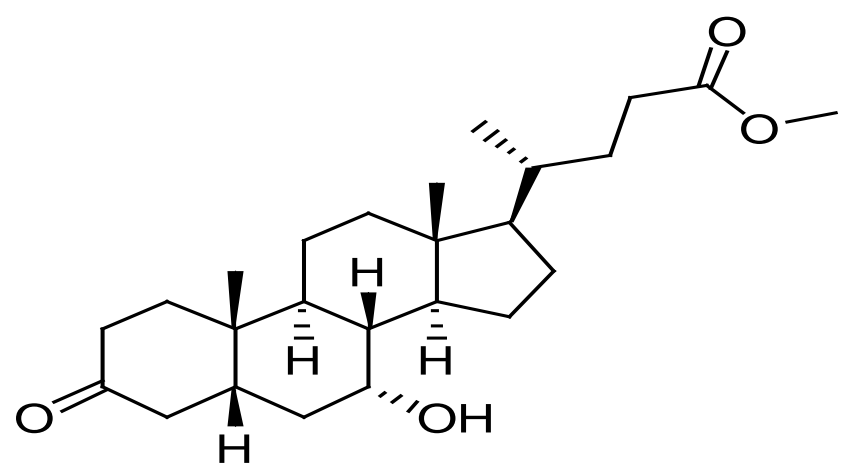

Chemical Formula: $\mathrm{C}_{25} \mathrm{H}_{40} \mathrm{O}_{4}$ Solvent: $\mathrm{CDCl}_{3}$

${ }^{13} \mathrm{C}$ NMR $\left(100 \mathrm{MHz}, \mathrm{CDCl}_{3}\right) \delta$ 213.37, 174.82, 68.52, 55.91, 51.61, 50.42, 45.73, 43.32, 42.83, 39.62, 39.48, 37.07, 36.93, 35.45, 35.42, 34.01, 33.38, 28.24, 23.78, 22.04, 21.09, 18.38, 11.89 . 


\section{Mass Spectrum SmartFormula Report}

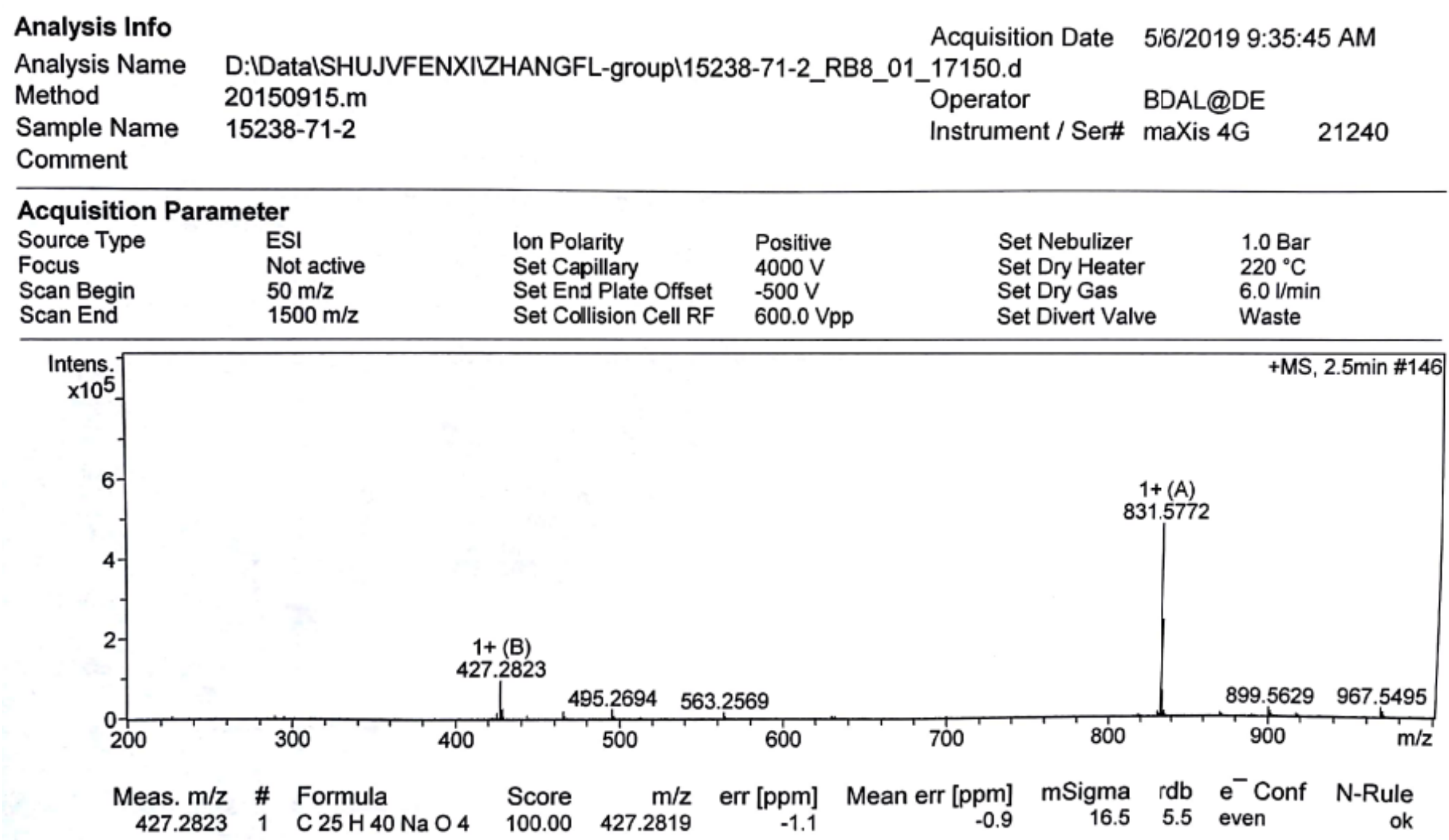

HRMS m/z [M+Na] $]^{+}$Calcd for $\mathrm{C}_{25} \mathrm{H}_{40} \mathrm{NaO}_{4}$ : 427.2824; found: 427.2823.

S-53. HRMS spectrum of Imp-6 


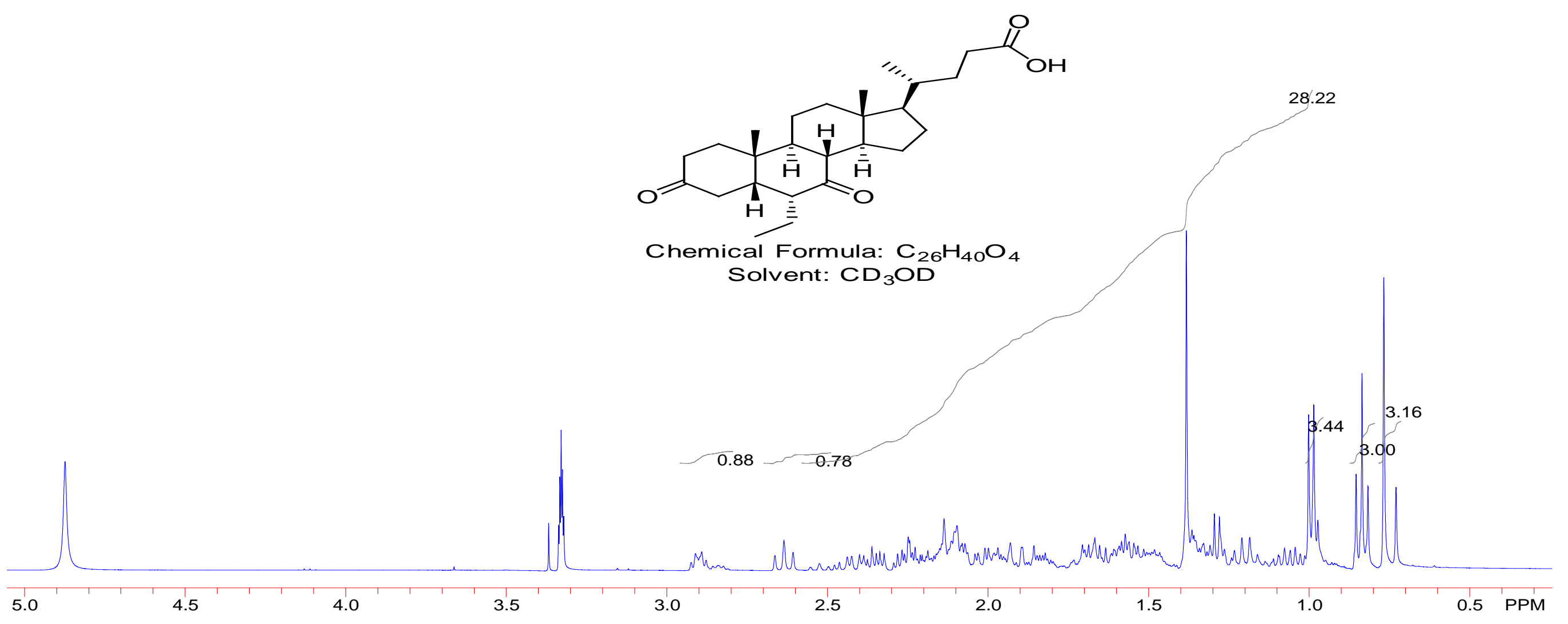

${ }^{1} \mathrm{H}$ NMR (400 MHz, CD $\left.\mathrm{CD}_{3} \mathrm{OD}\right) \delta$ 2.82-2.92 (m, 1H), $2.64(\mathrm{t}, J=11.2 \mathrm{~Hz}, 1 \mathrm{H}), 1.02-2.48(\mathrm{~m}, 25 \mathrm{H}), 1.38(\mathrm{~s}, 3 \mathrm{H}), 0.99(\mathrm{~d}, J=6.4 \mathrm{~Hz}, 3 \mathrm{H}), 0.84$ (t, $J=7.2 \mathrm{~Hz}, 3 \mathrm{H}), 0.77$ (s, 3H). 


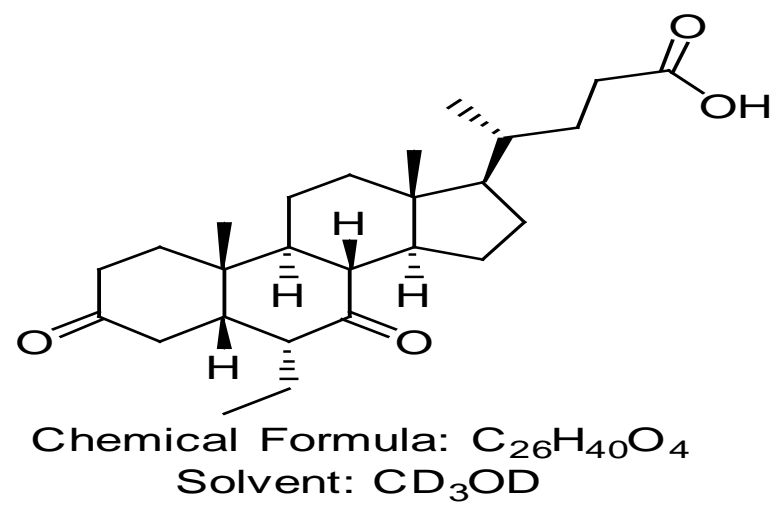

$77 \pi\|\|\|,\| \pi \|$

200

${ }^{13} \mathrm{C}$ NMR $\left(100 \mathrm{MHz}, \mathrm{CD}_{3} \mathrm{OD}\right) \delta$ 212.87, 211.51, 176.25, 54.48, 51.84, 51.59, 49.33, 48.38, 43.13, 41.98, 38.32, 37.27, 35.59, 35.24, 34.72, 34.58, 30.48, 30.15, 27.45, 23.71, 21.50, 21.23, 17.97, 17.00, 10.66, 10.25.

\section{S-55. ${ }^{13} \mathrm{C}$ NMR spectrum of Imp-7}




\section{Mass Spectrum SmartFormula Report}

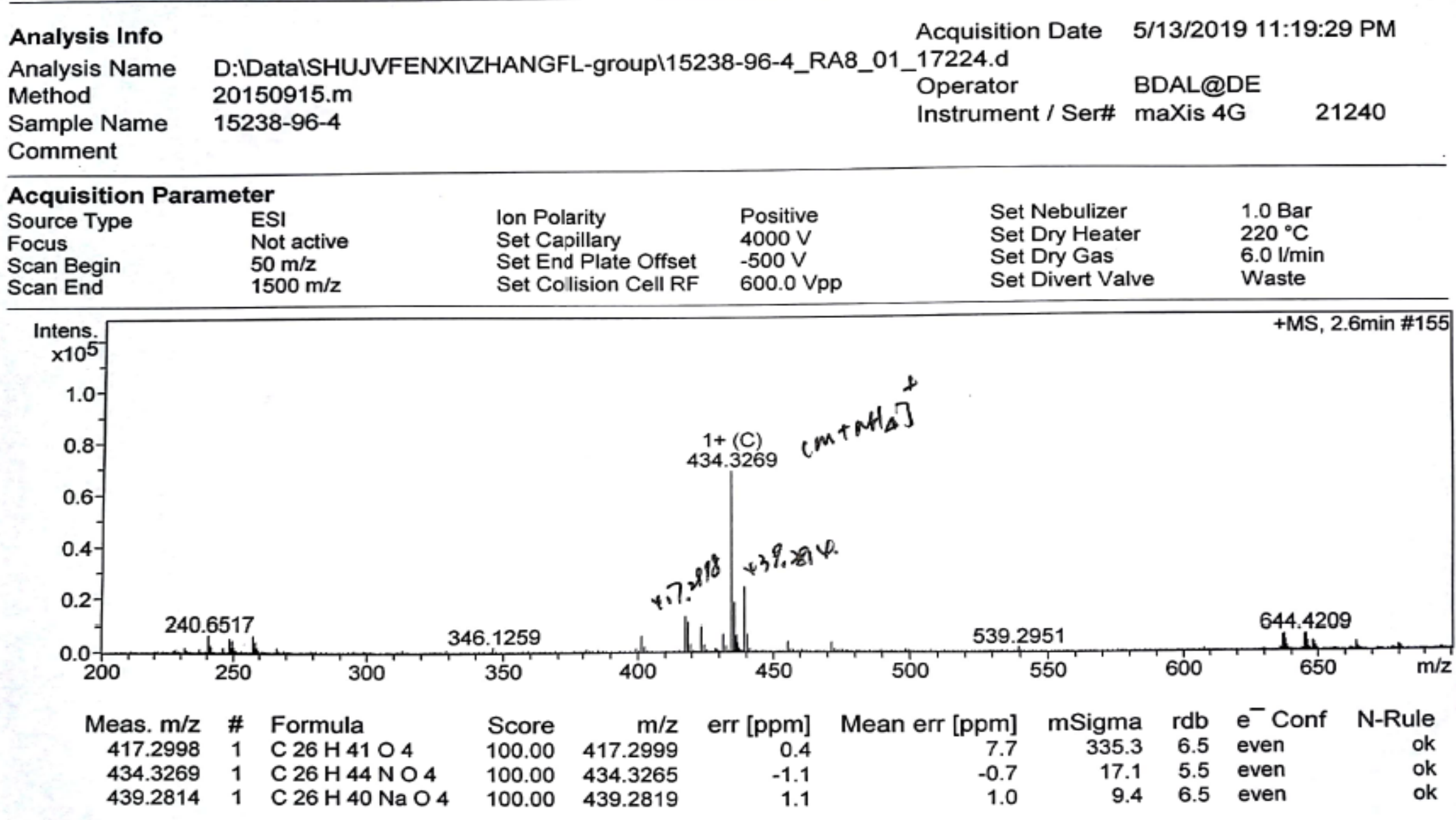

HRMS m/z [M+NH$]_{4}^{+}$Calcd for $\mathrm{C}_{26} \mathrm{H}_{44} \mathrm{NO}_{4}$ : 434.3270; found: 434.3269 .

HRMS m/z [M+Na] Calcd for $\mathrm{C}_{26} \mathrm{H}_{40} \mathrm{NaO}_{4}$ : 439.2824; found: 439.2819 .

\section{S-56. HRMS spectrum of Imp-7}


$\sqrt{ }$

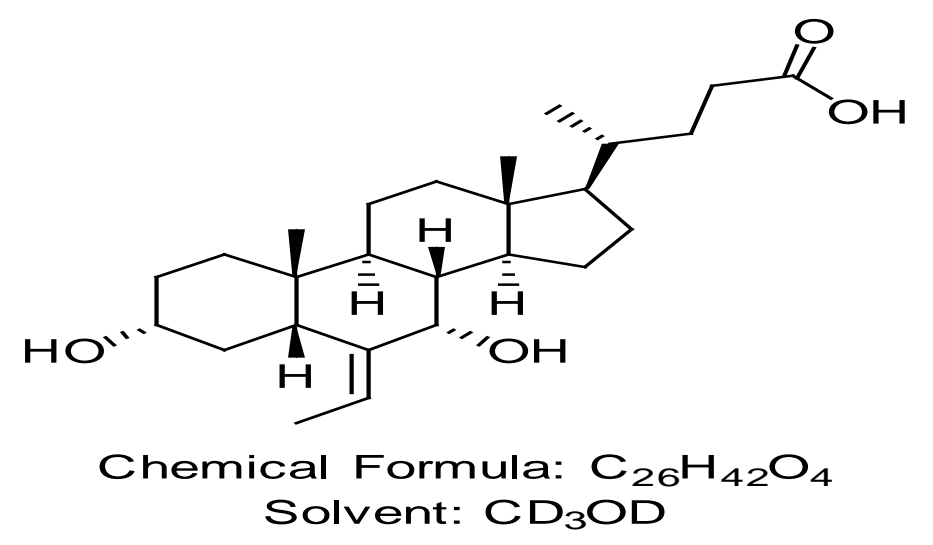

Solvent: $\mathrm{CD} \mathrm{D}_{3} \mathrm{OD}$

1.00

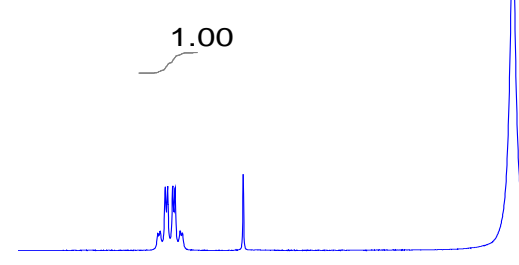

6

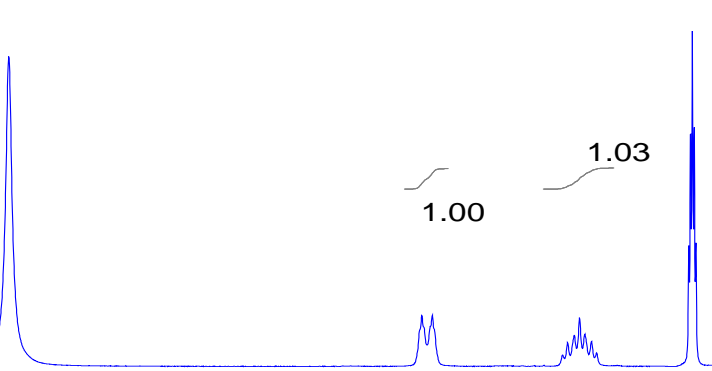

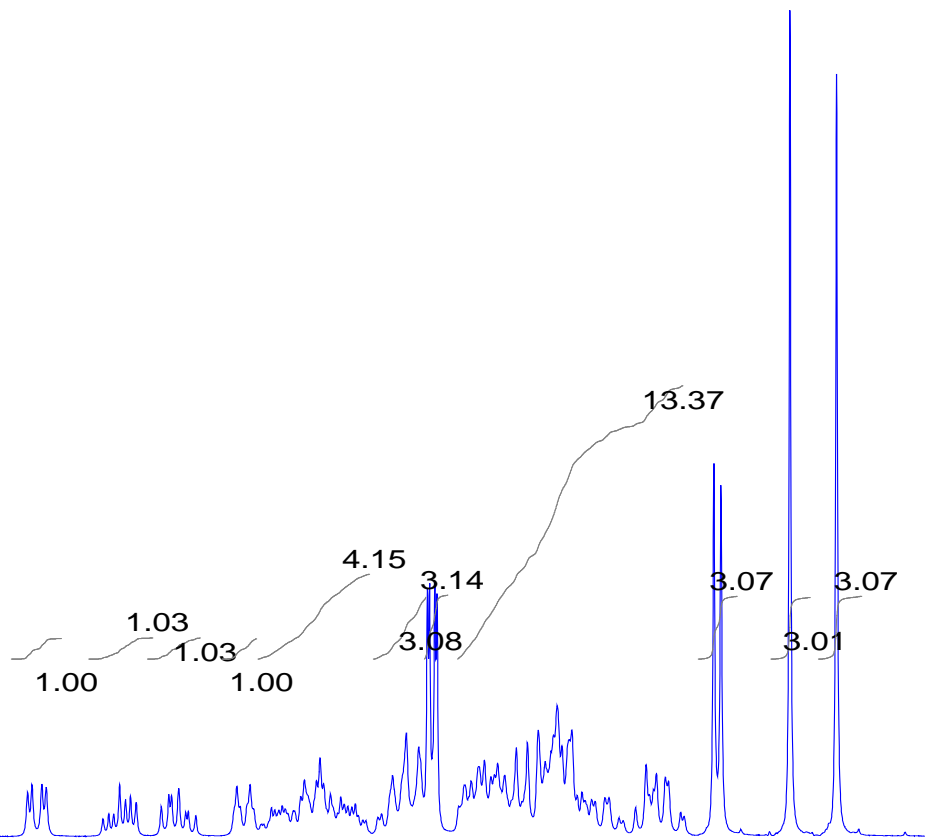

${ }^{1} \mathrm{H}$ NMR (400 MHz, CD $\left.3 \mathrm{OD}\right) \delta$ 5.65-5.71 (m, 1H), $3.94(\mathrm{~d}, J=9.6 \mathrm{~Hz}, 1 \mathrm{H}), 3.55-3.62(\mathrm{~m}, 1 \mathrm{H}), 2.55(\mathrm{dd}, J=4.0 \mathrm{~Hz}, 13.2 \mathrm{~Hz}, 1 \mathrm{H})$, 2.32-2.39 (m, 1H), 2.18-2.26 (m, 1H), 2.32-2.39 (m, 1H), 2.07 (dt, $J=3.2$ Hz, 12.4 Hz, 1H), 1.79-2.01 (m, 4H), 1.67-1.77 (m, 3H), 1.64 (dd, $J=2.0 \mathrm{~Hz}, 6.8 \mathrm{~Hz}, 3 \mathrm{H}), 1.07-1.58$ (m, 13H), 0.99 (d, $J=6.4 \mathrm{~Hz}, 3 \mathrm{H}), 0.82$ (s, 3H), 0.72 (s, 3H).

\section{S-57. ${ }^{1} \mathrm{H}$ NMR spectrum of Imp-8}



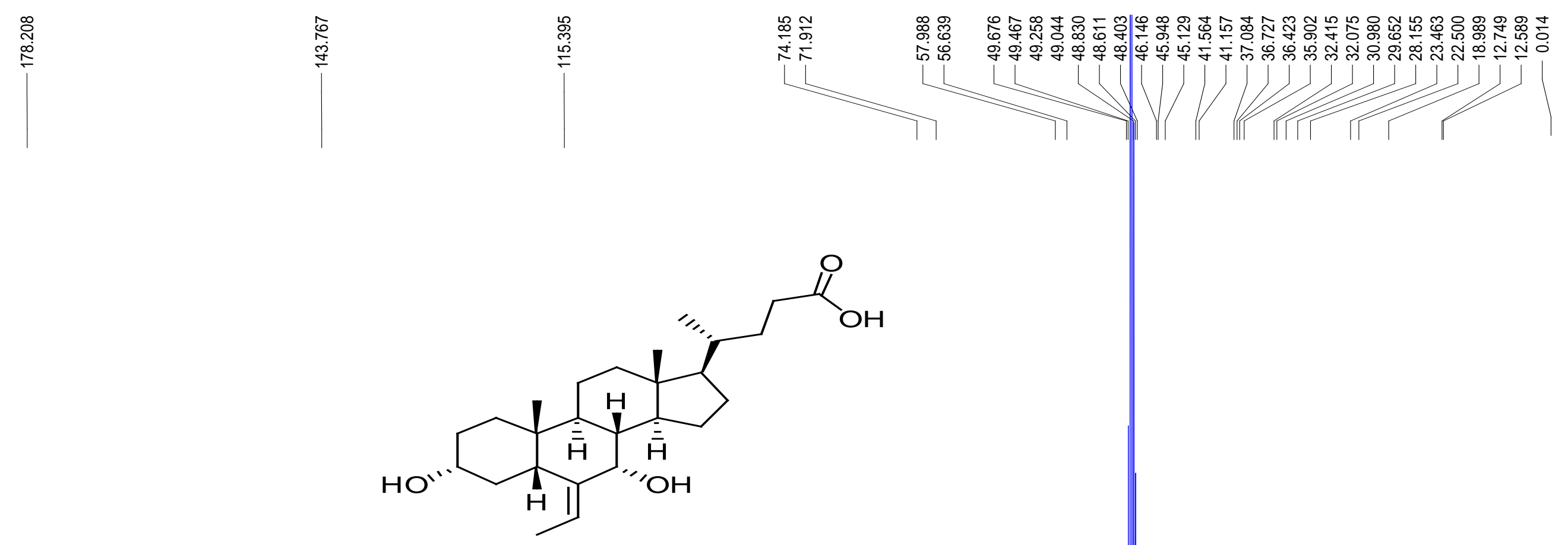

Chemical Formula: $\mathrm{C}_{26} \mathrm{H}_{42} \mathrm{O}_{4}$ Solvent: $\mathrm{CD}_{3} \mathrm{OD}$

${ }^{13} \mathrm{C}$ NMR $\left(100 \mathrm{MHz}, \mathrm{CD}_{3} \mathrm{OD}\right) \delta$ 178.21, 143.77, 115.39, 74.19, 71.91, 57.99, 56.64, 46.15, 45.95, 45.13, 41.56, 41.16, 37.08, 36.72, 36.42, $35.90,32.42,32.08,30.98,29.65,28.16,23.46,22.50,18.99,12.75,12.59$.

\section{S-58. ${ }^{13} \mathrm{C}$ NMR spectrum of Imp-8}




\section{Mass Spectrum SmartFormula Report}

Analysis Info

Analysis Name

Method

Sample Name

D:IDatalSHUJVFENXIVHANGFL-groupl15238-72- Acquisition Date

Comment

20150915.m

$15238-72-6$

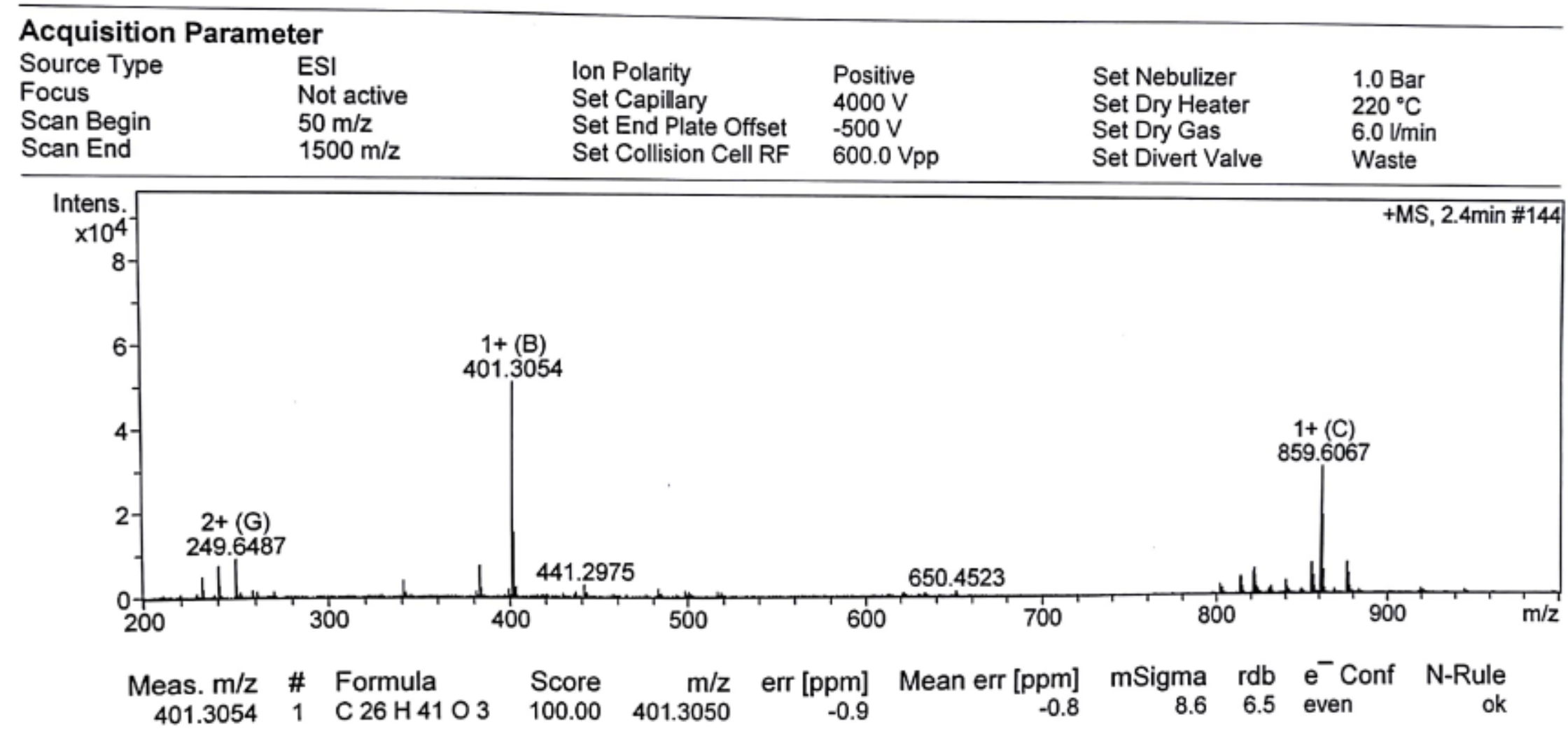

HRMS m/z [2×M+Na] $]^{+}$Calcd for $\mathrm{C}_{52} \mathrm{H}_{84} \mathrm{NaO}_{8}$ : 859.6064; found: 859.6067 .

\section{S-59. HRMS spectrum of Imp-8}




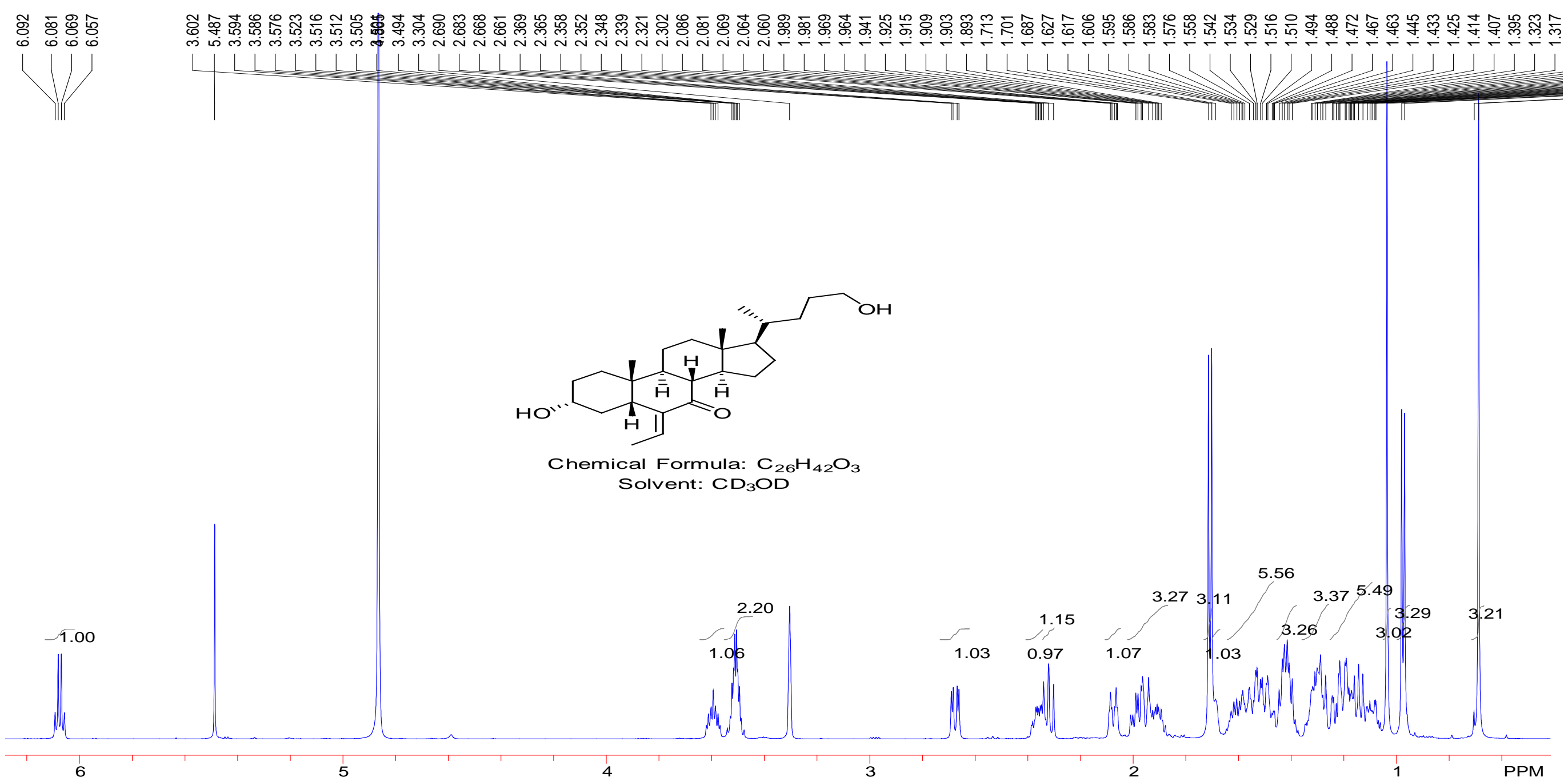

${ }^{1} \mathrm{H}$ NMR (600 MHz, CD $\left.3 \mathrm{OD}\right) \delta 6.08$ (q, $\left.J=7.2 \mathrm{~Hz}, 1 \mathrm{H}\right), 3.59$ (hept, $\left.J=4.8 \mathrm{~Hz}, 1 \mathrm{H}\right), 3.48-3.54$ (m, $\left.2 \mathrm{H}\right), 2.68(\mathrm{dd}, \mathrm{J}=13.2 \mathrm{~Hz}, 4.2 \mathrm{~Hz}, 1 \mathrm{H})$, 2.35-2.38 (m, 1H), 2.32 (t, $J=11.4 \mathrm{~Hz}, 1 \mathrm{H}), 2.08$ (dt, $J=13.2 \mathrm{~Hz}, 3 \mathrm{~Hz}, 1 \mathrm{H}), 1.89-2.00(\mathrm{~m}, 3 \mathrm{H}), 1.71(\mathrm{~d}, J=7.2 \mathrm{~Hz}, 3 \mathrm{H}), 1.69(\mathrm{~m}, 1 \mathrm{H})$, 1.46-1.65 (m, 5H), 1.39-1.45 (m, 3H), 1.27-1.35 (m, 3H), 1.06-1.24 (m, 5H), 1.04 (s, 3H), 0.96 (d, J = 6.6 Hz, 3H), 0.69 (s, 3H).

\section{S-60. ${ }^{1} \mathrm{H}$ NMR spectrum of Imp-9}




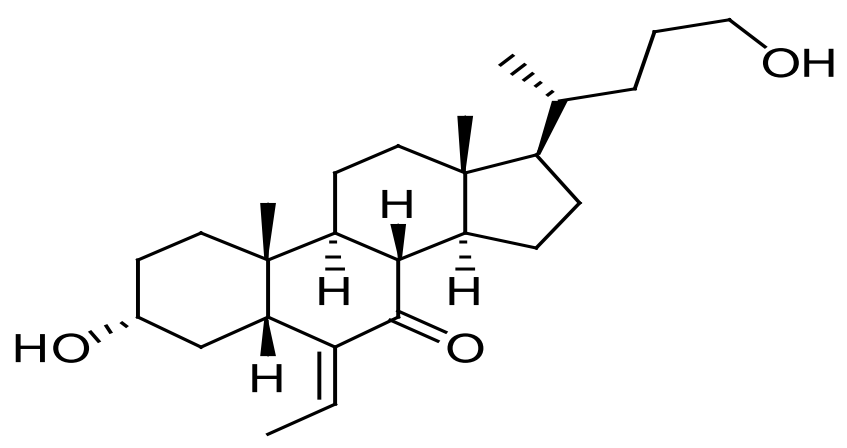

Chemical Formula: $\mathrm{C}_{26} \mathrm{H}_{42} \mathrm{O}_{3}$ Solvent: $\mathrm{CD}_{3} \mathrm{OD}$

${ }^{13} \mathrm{C}$ NMR $\left(150 \mathrm{MHz}, \mathrm{CD}_{3} \mathrm{OD}\right) \delta 207.64,145.38,130.34,70.96,63.55,56.18,52.03,50.18,46.88,44.66,40.74,40.32,38.37,36.87,35.77$, 35.41, 33.24, 30.46, 30.28, 29.53, 27.03, 23.24, 22.45, 19.35, 12.75, 12.49.

\section{S-61. ${ }^{13} \mathrm{C}$ NMR spectrum of Imp-9}




\section{Mass Spectrum SmartFormula Report}

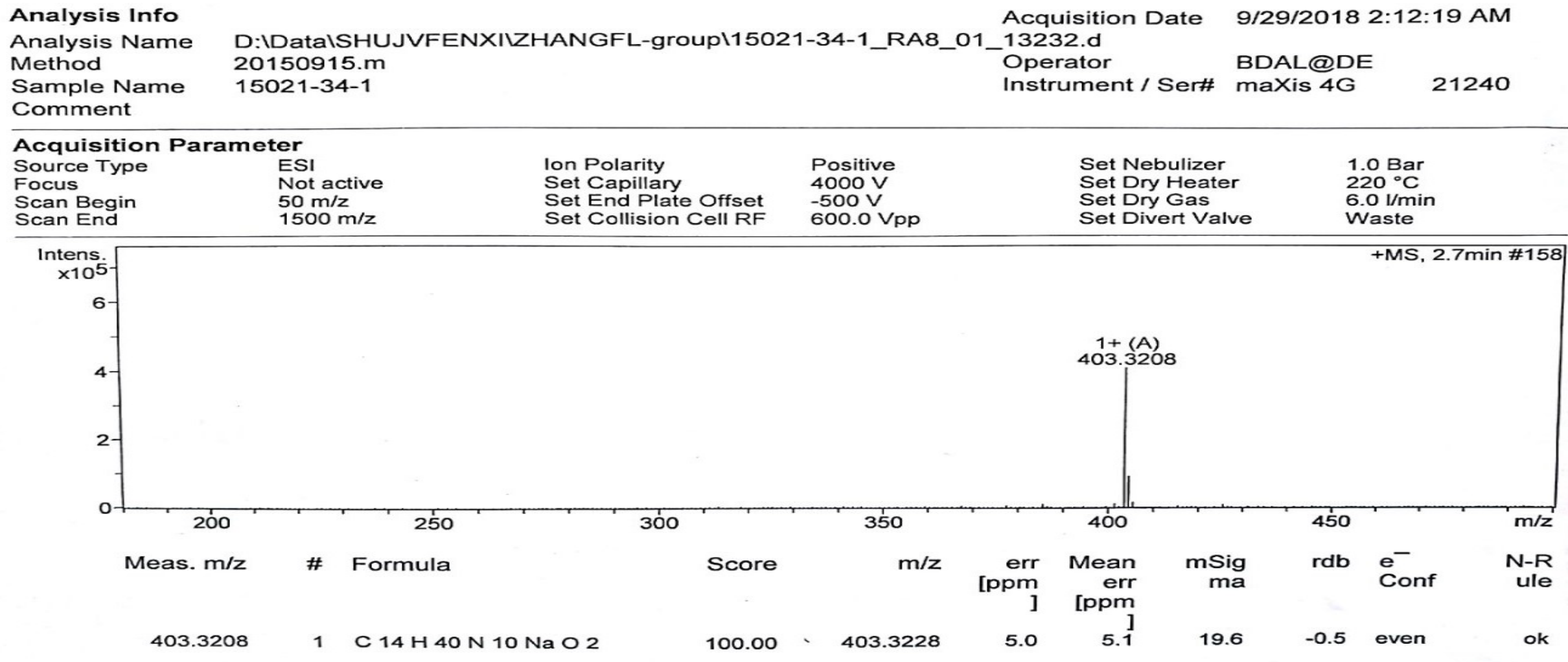

HRMS m/z [M+H] $]^{+}$Calcd for $\mathrm{C}_{26} \mathrm{H}_{43} \mathrm{O}_{3}$ : 403.3212; found: 403.3208 .

\section{S-62. HRMS spectrum of Imp-9}




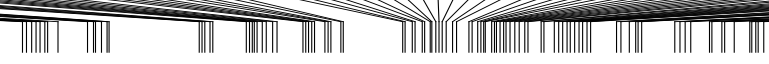

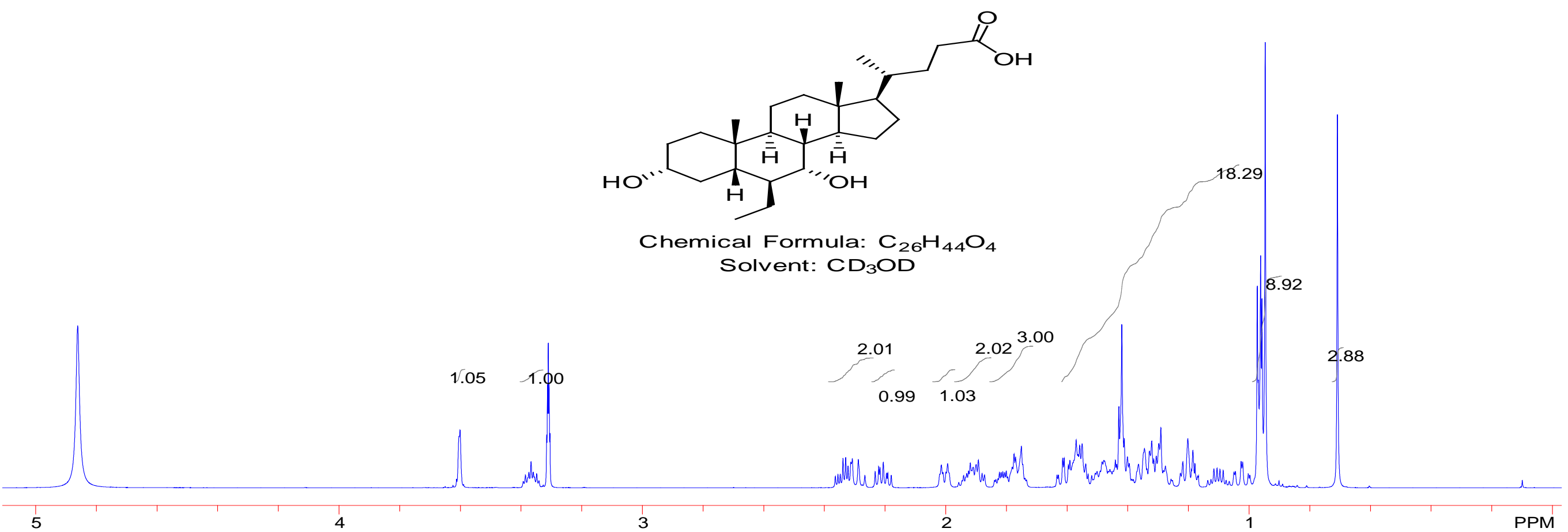

${ }^{1} \mathrm{H}$ NMR (600 MHz, CD $\left.{ }_{3} \mathrm{OD}\right)$ 8 3.60-3.61 (m, 1H), 3.35-3.39 (m, 1H), 2.27-2.36 (m, 2H), 2.18-2.23 (m, 1H), $2.00(\mathrm{dt}, J=3 \mathrm{~Hz}, 12.6 \mathrm{~Hz}$, 1H), 1.87-1.95 (m, 2H), 1.73-1.84 (s, 3 H), 0.99-1.63 (m, 18H), 0.95-0.97 (m, 9H), 0.71 (s, 3H).

\section{S-63. ${ }^{1} \mathrm{H}$ NMR spectrum of Imp-10}




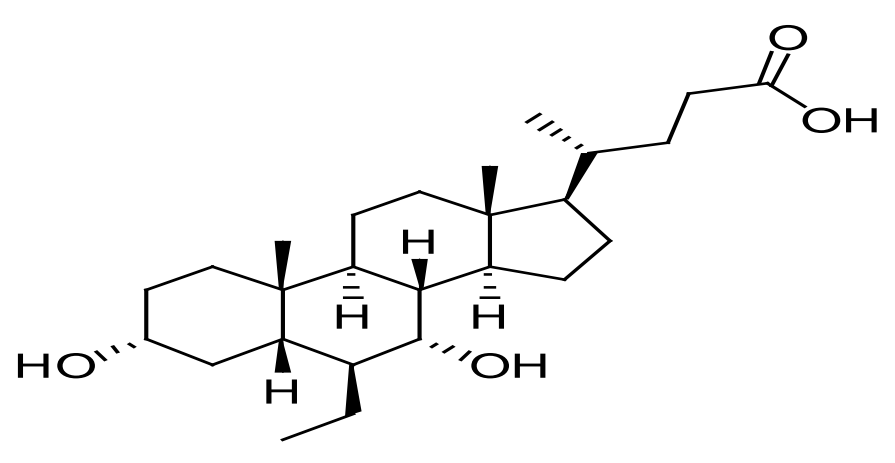

Chemical Formula: $\mathrm{C}_{26} \mathrm{H}_{44} \mathrm{O}_{4}$ Solvent: $\mathrm{CD}_{3} \mathrm{OD}$

${ }^{13} \mathrm{C}$ NMR (150 MHz, $\left.\mathrm{CD}_{3} \mathrm{OD}\right) \delta$ 178.19, 72.78, 72.66, 57.39, 52.65, 51.35, 47.53, 43.67, 42.27, 40.98, 37.47, 37.28, 36.78, 36.75, 34.04, 32.34, 31.99, 30.99, 29.59, 29.21, 26.15, 24.80, 21.58, 18.82, 14.49, 12.14 .

\section{S-64. ${ }^{13}$ C NMR spectrum of Imp-10}




\section{Mass Spectrum SmartFormula Report}

Analysis Info

Analysis Name

Method

D:IDatalSHUJVFENXIIZHANGFL-groupl15238-71-3_RB6_01_17438.d
20150915.m

Acquisition Date 5/28/2019 11:09:41 PM

Sample Name

15238-71-3

Operator

Instrument / Ser\# maXis $4 G$

21240

\section{Acquisition Parameter}

Source Type ES

Focus Not active

Scan Begin $\quad 50 \mathrm{~m} / \mathrm{z}$

Scan End

$1500 \mathrm{~m} / \mathrm{z}$

Ion Polarity

Set Capillary

Set End Plate Offset

Set Collision Cell RF

Negative
$4000 \mathrm{~V}$
$-500 \mathrm{~V}$
$350.0 \mathrm{Vpp}$

Set Nebulizer

Set Dry Heater

Set Dry Gas

Set Divert Valve

1.0 Bar

$220^{\circ} \mathrm{C}$

. $\mathrm{V} / \mathrm{min}$

Intens.

$\mathbf{x} 10^{5}$

1.5

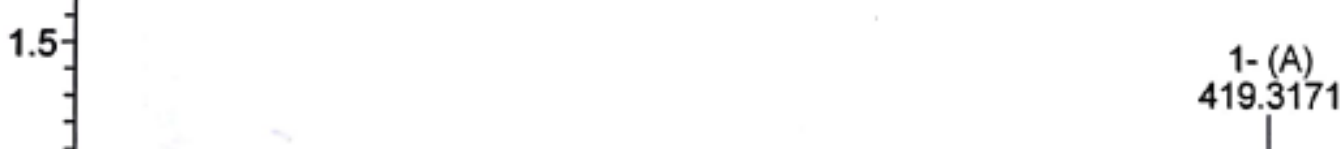

1.0

0.5

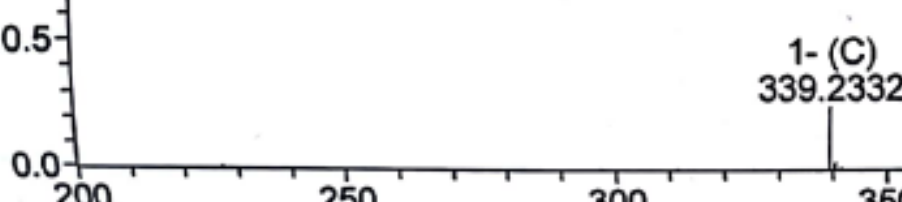

250

300

Score

500

550

$-M S, 3.7 \mathrm{~min} \# 220$

Meas. $\mathrm{m} / \mathrm{z}$

100.00 419.3167

$1 \mathrm{C} 26 \mathrm{H} 43 \mathrm{O} 4$

$-0.9$

$\begin{array}{rr}\text { Mean err [ppm] } & \text { mSigma } \\ -0.9 & 99.9\end{array}$

$99.9 \quad 5.5$ even

N-Rule

HRMS m/z [M-H] $]^{-}$Calcd for $\mathrm{C}_{26} \mathrm{H}_{43} \mathrm{O}_{4}$ : 419.3167; found: 419.3171 . 


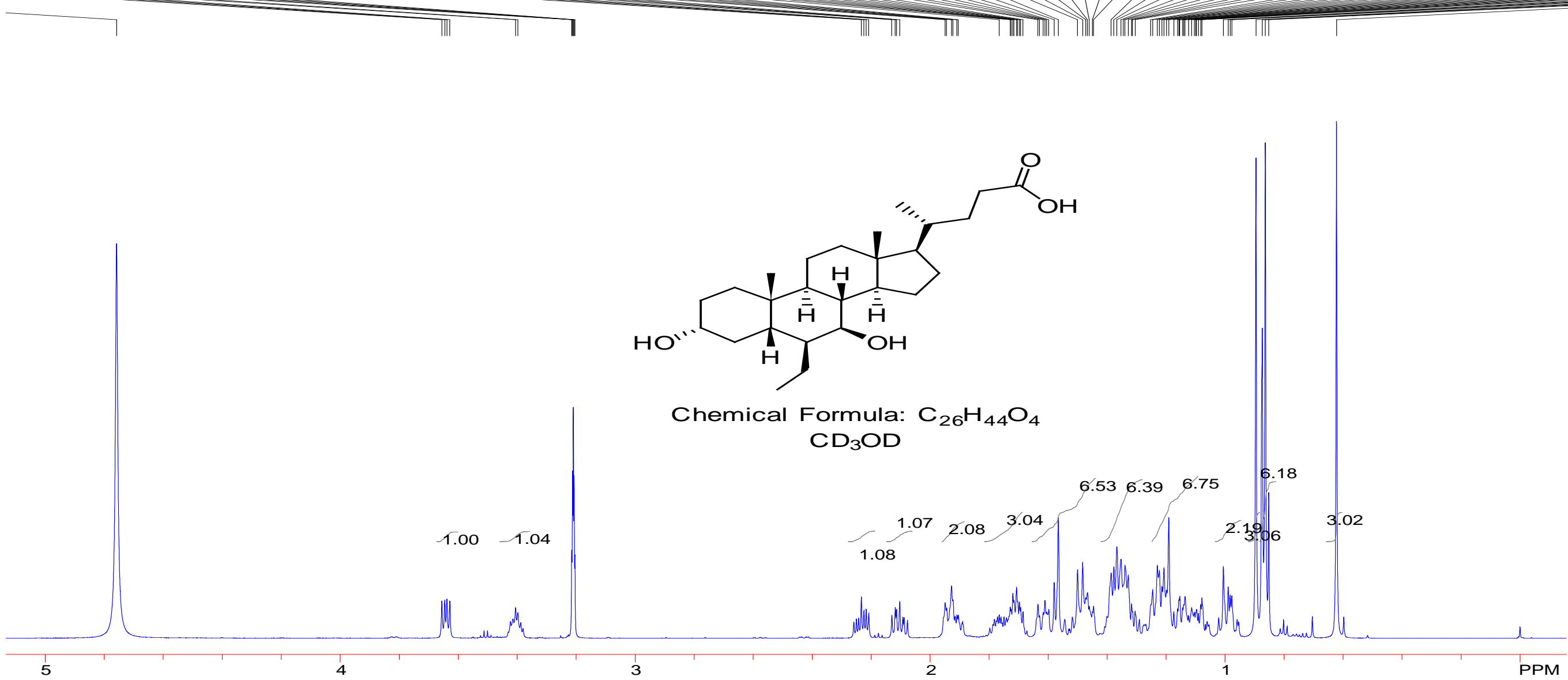

${ }^{1} \mathrm{H}$ NMR (600 MHz, CD $\left.3 \mathrm{OD}\right) \delta 3.64$ (dd, $\left.J=6 \mathrm{~Hz}, 10.2 \mathrm{~Hz}, 1 \mathrm{H}\right), 3.38-3.43(\mathrm{~m}, 1 \mathrm{H}), 2.21-2.26$ (m, $\left.1 \mathrm{H}\right), 2.08-2.13(\mathrm{~m}, 1 \mathrm{H}), 1.89-1.95$ (m, 2H), 1.67-1.79 (m, 3H), 1.45-1.64 (m, 6H), 1.27-1.40 (m, 6H), 1.06-1.25 (m, 6H), 0.95-1.02 (m, $2 \mathrm{H}), 0.90$ (s, 3H), 0.85-0.90 (m, $6 \mathrm{H}), 0.62$ $(\mathrm{s}, 3 \mathrm{H})$.

\section{S-66. ${ }^{1} \mathrm{H}$ NMR spectrum of Imp-11}



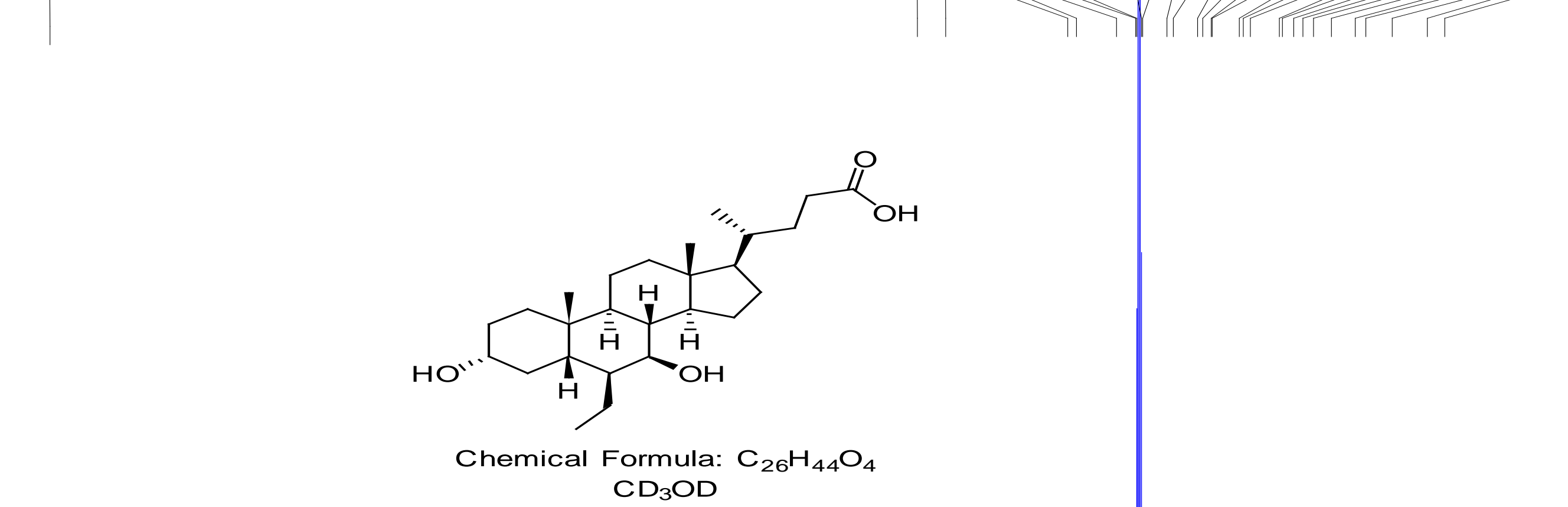

${ }^{13} \mathrm{C}$ NMR (150 MHz, $\left.\mathrm{CD}_{3} \mathrm{OD}\right) \delta$ 178.17, 75.31, 71.94, 57.47, 56.43, 51.69, 45.70, 44.95, 42.06, 41.47, 40.44, 40.35, 37.12, 36.65, 35.82, 32.38, 32.02, 30.66, 29.59, 28.31, 26.19, 23.37, 22.12, 18.99, 14.84, 12.76 .

\section{S-67. ${ }^{1} \mathrm{H}$ NMR spectrum of Imp-11}




\section{Mass Spectrum SmartFormula Report}

Analysis Info

Analysis Name

Method

Sample Name

Comment

\section{Acquisition Parameter}

Source Type

Focus

Scan Begin

Scan End

Set Capillary

Set End Plate Offset

Set Collision Cell RF

Negative

$4000 \mathrm{~V}$

$350.0 \mathrm{Vpp}$

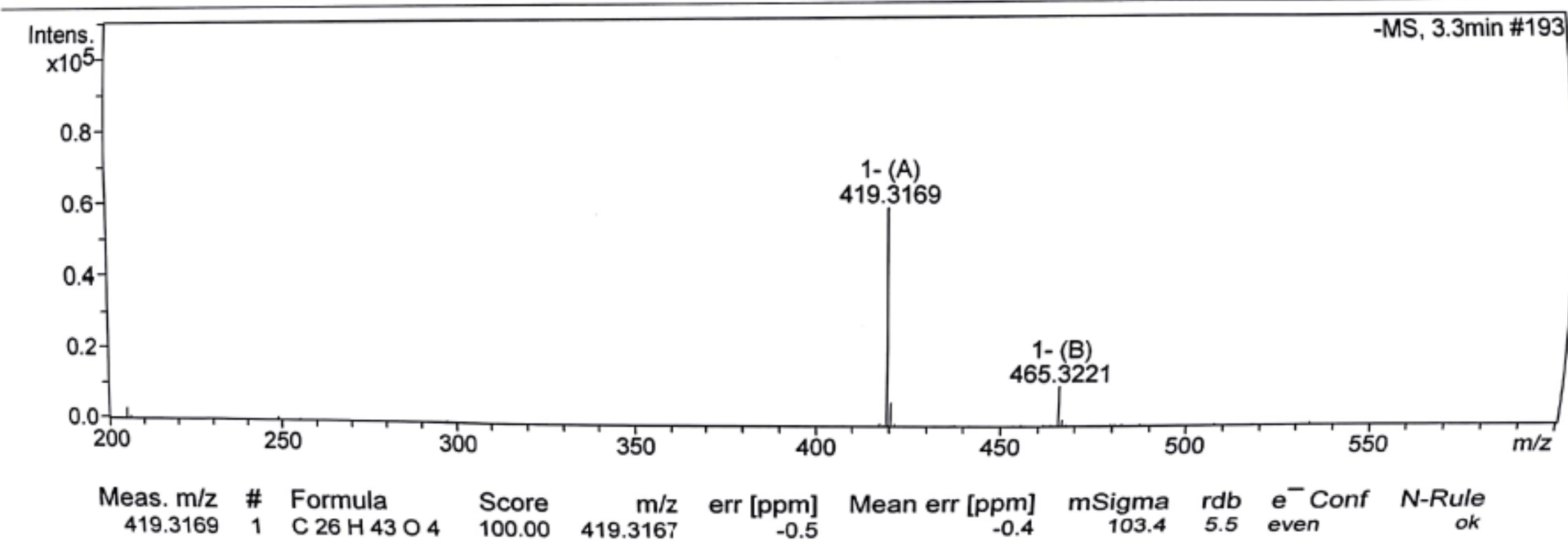

Acquisition Date $\quad 5 / 28 / 2019$ 11:02:12 PM

Operato BDAL@DE

Instrument/Ser\# maXis 4G

21240

HRMS m/z [M-H] ${ }^{-}$Calcd for $\mathrm{C}_{26} \mathrm{H}_{43} \mathrm{O}_{4}$ : 419.3167; found: 419.3169 . 


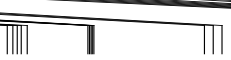
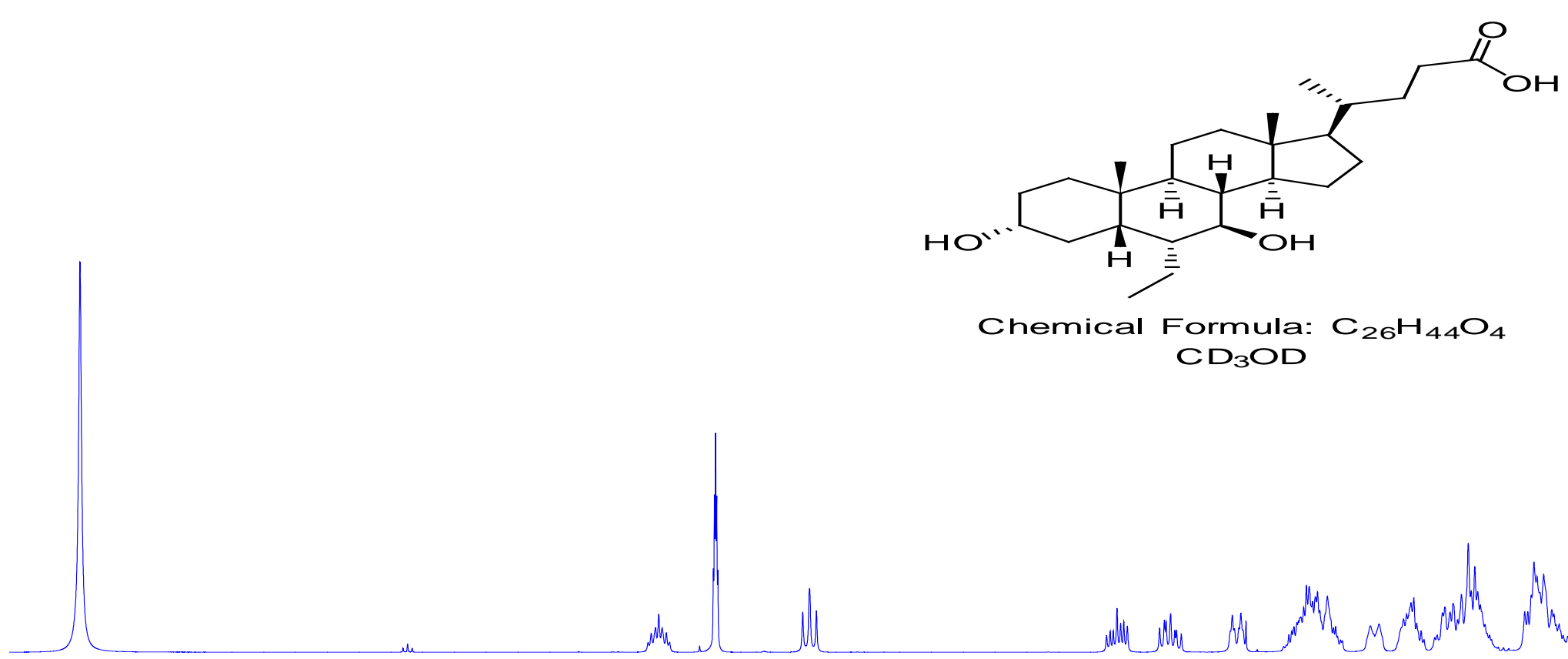

3

${ }^{1} \mathrm{H}$ NMR (600 MHz, CD $\left.\mathrm{OD}\right) \delta$ 3.32-3.37 (m, 1H), $2.98(\mathrm{t}, J=10.2 \mathrm{~Hz}, 1 \mathrm{H}), 2.21-2.26(\mathrm{~m}, 1 \mathrm{H}), 2.08-2.13(\mathrm{~m}, 1 \mathrm{H}), 1.94(\mathrm{dt}, J=3.6 \mathrm{~Hz}$ 12.6 Hz, 1H), 1.68-1.81 (m, 5H), 1.59-1.61 (m, 1H), 1.48-1.53 (m, 2H), 1.29-1.46 (m, 6H), 0.94-1.24 (m, $10 \mathrm{H}), 0.86(\mathrm{~d}, J=6.6 \mathrm{~Hz}, 3 \mathrm{H})$, 0.85 (s, 3H), $0.76(\mathrm{t}, J=7.2 \mathrm{~Hz}, 3 \mathrm{H}),, 0.62(\mathrm{~s}, 3 \mathrm{H})$. 


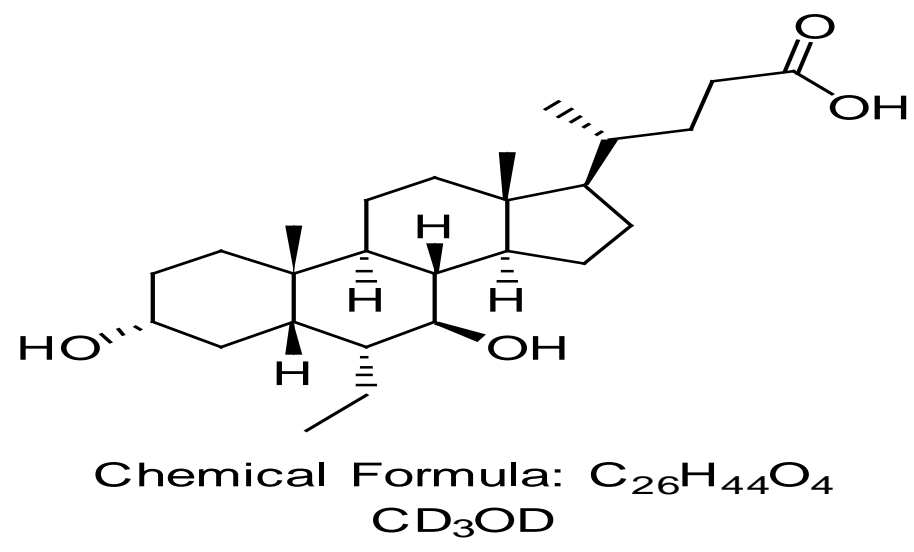

$$
\mathrm{CD}_{3} \mathrm{OD}
$$

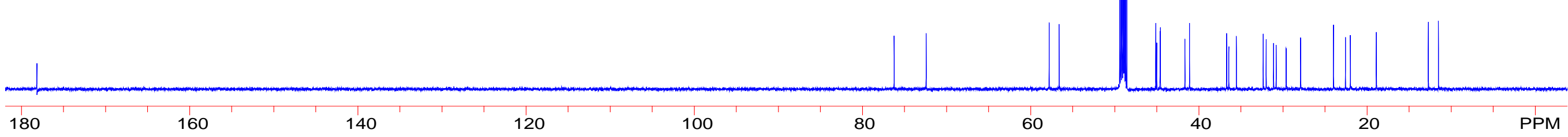

${ }^{13} \mathrm{C}$ NMR (150 MHz, $\left.\mathrm{CD}_{3} \mathrm{OD}\right) \delta$ 178.16, 76.23, 72.43, 57.81, 56.63, 45.14, 45.03, 44.63, 44.59, 41.67, 41.13, 36.71, 36.46, 35.56, 32.37, 32.02, 31.14, 30.83, 29.64, 27.92, 24.02, 22.59, 22.01, 18.92, 12.74, 11.54 .

\section{S-70. ${ }^{1} \mathrm{H}$ NMR spectrum of Imp-12}




\section{Mass Spectrum SmartFormula Report}

\section{Analysis Info}

Analysis Name

Method

Sample Name

Comment
Acquisition Date

D:IDataISHUJVFENXIIZHANGFL-groupl14238-08-1_RA7_01_12939.d 20150915.m

14238-08-1

Operator

Instrument / Ser\# maXis 4G

21240

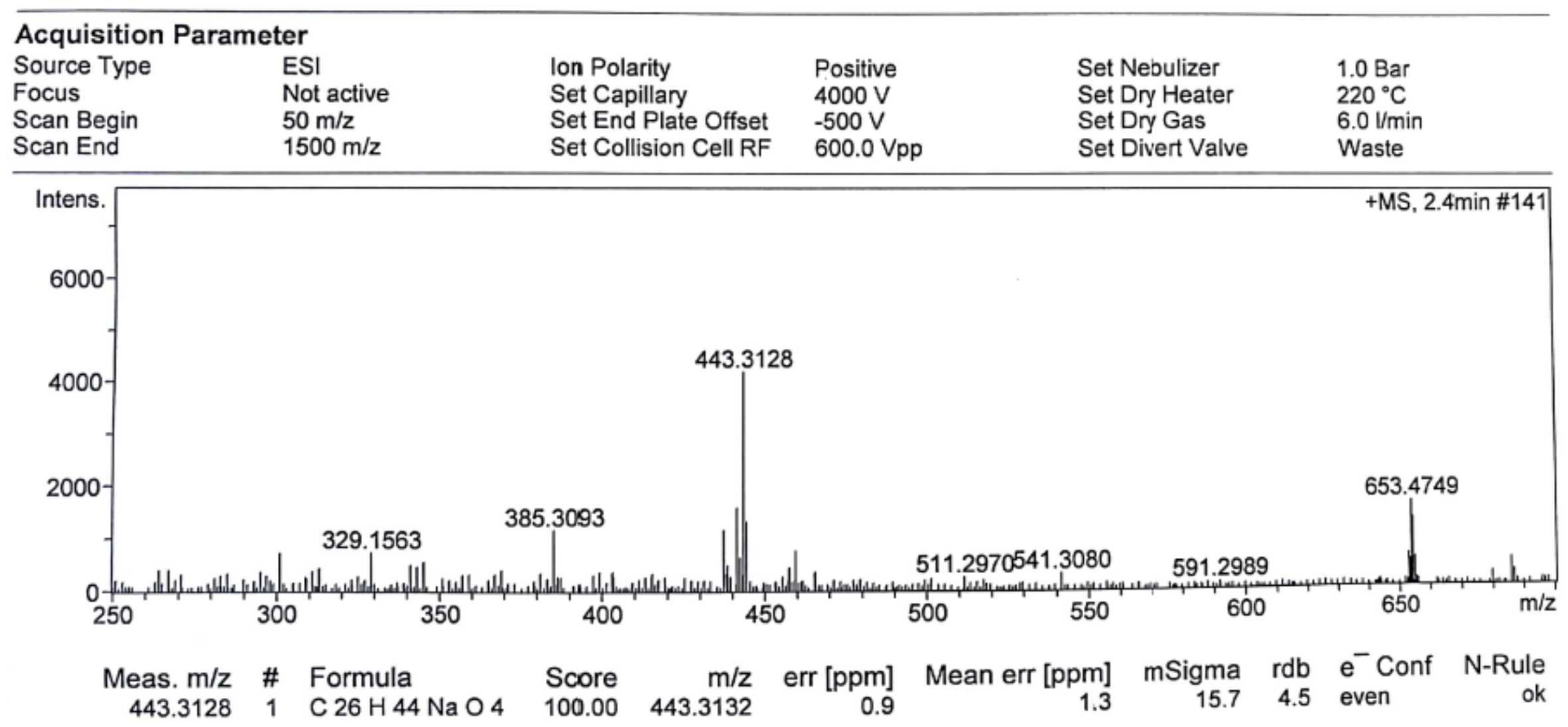

HRMS m/z [M+H] ${ }^{+}$Calcd for $\mathrm{C}_{26} \mathrm{H}_{44} \mathrm{NaO}_{4}$ : 443.3137; found: 443.3128 .

\section{S-71. HRMS spectrum of Imp-11}




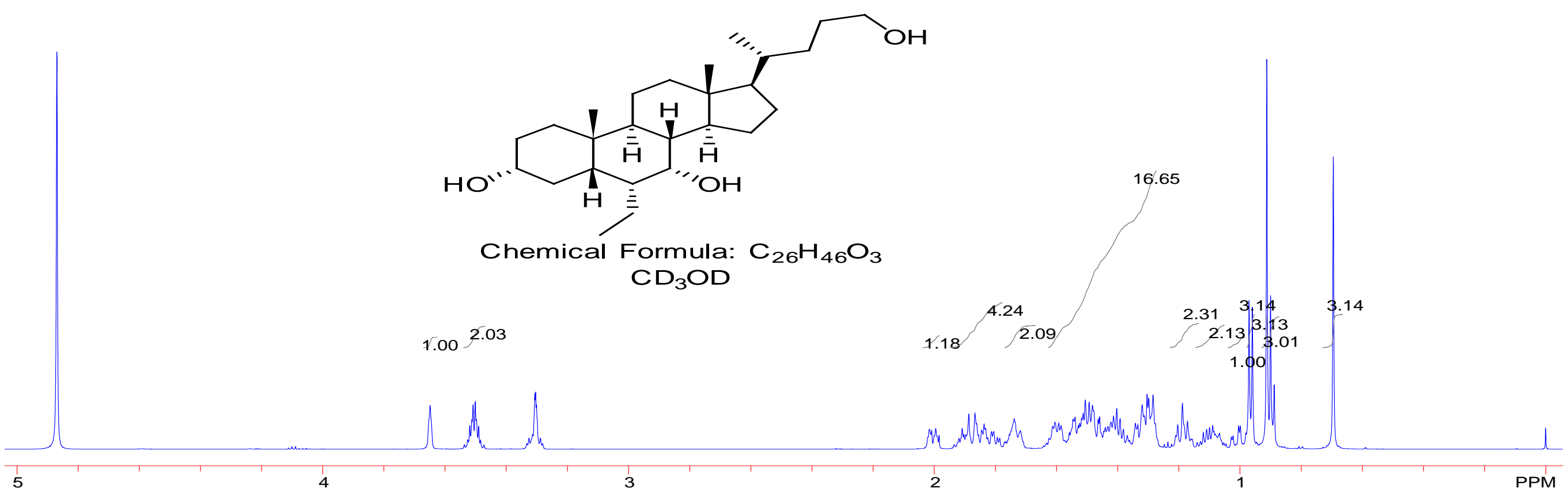

${ }^{1} \mathrm{H}$ NMR (400 MHz, CD $\left.3 \mathrm{OD}\right)$ 8 3.64-3.67 (m, 1H), 3.47-3.54 (m, 2H), 1.99-2.02 (m, 1H), 1.79-1.92 (m, 4H), 1.72-1.77 (m, 2H), 1.27-1.64 (m, 16H), 1.16-1.21 (m, 2H), 1.07-1.12 (m, 2H), 0.98-1.03 (m, 1H), 0.96 (d, $J=4.4 \mathrm{~Hz}, 3 \mathrm{H}), 0.91$ (s, 3H), 0.90 (t, $J=4.8 \mathrm{~Hz}, 3 \mathrm{H}), 0.69$ (s, $3 \mathrm{H})$. 

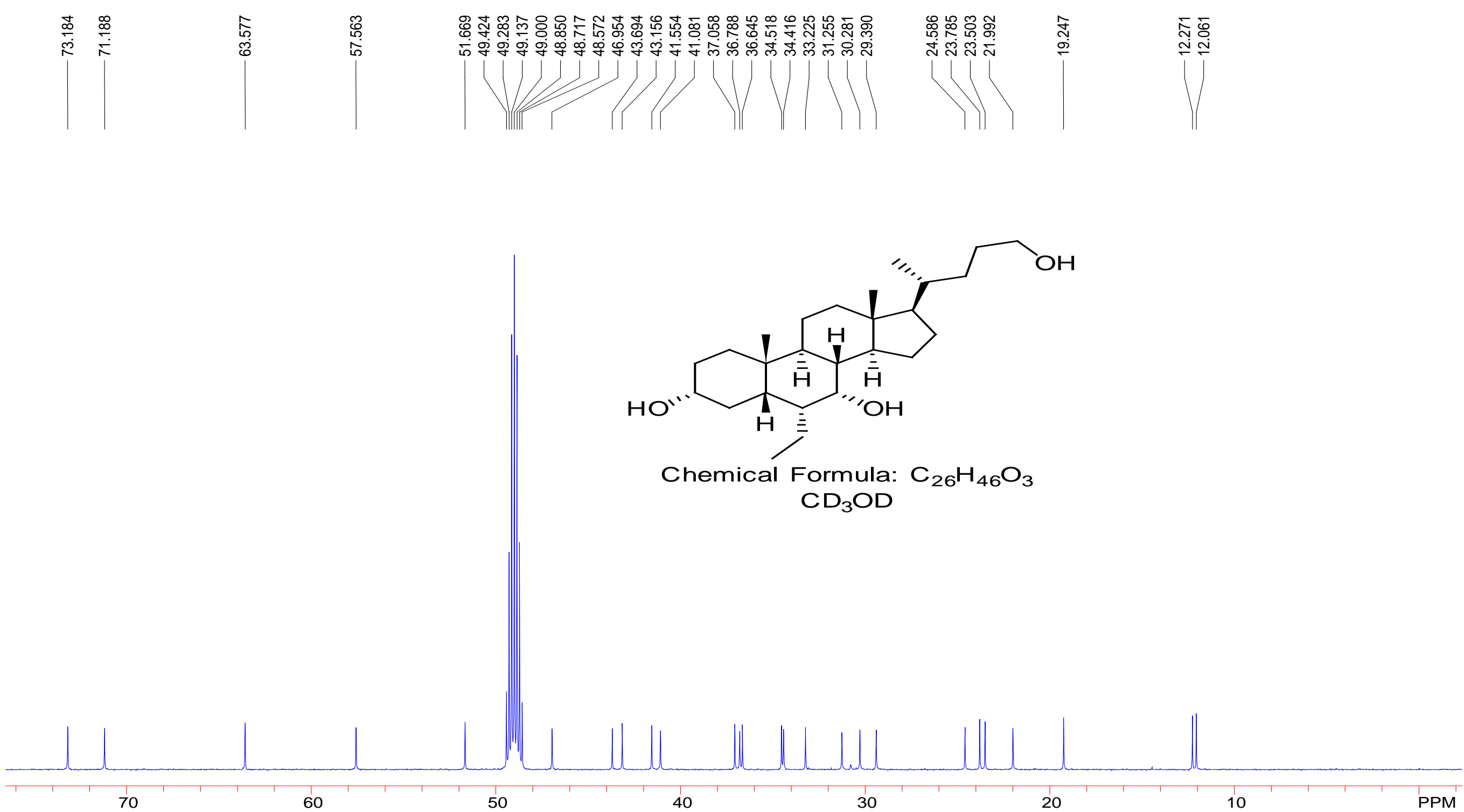

${ }^{13} \mathrm{C}$ NMR (100 MHz, CD $\left.3 \mathrm{OD}\right) \delta$ 73.18, 71.19, 63.58, 57.56, 51.67, 46.95, 43.69, 43.16, 41.55, 41.08, 37.06, 36.79, 36.65, 34.52, 34.42, $33.23,31.26,30.28,29.39,24.59,23.79,23.50,21.99,19.25,12.27,12.06$. 


\section{Mass Spectrum SmartFormula Report}

Analysis Info

Analysis Name

Method

Sample Name

Comment
D:IDataISHUJVFENXIZHANGFL-groupl14238-06-1_RA6_01_12938.d 20150915.m

14238-06-1
Acquisition Date

7/27/2018 7:11:32 AM

BDAL@DE

Instrument / Ser\# maXis 4G

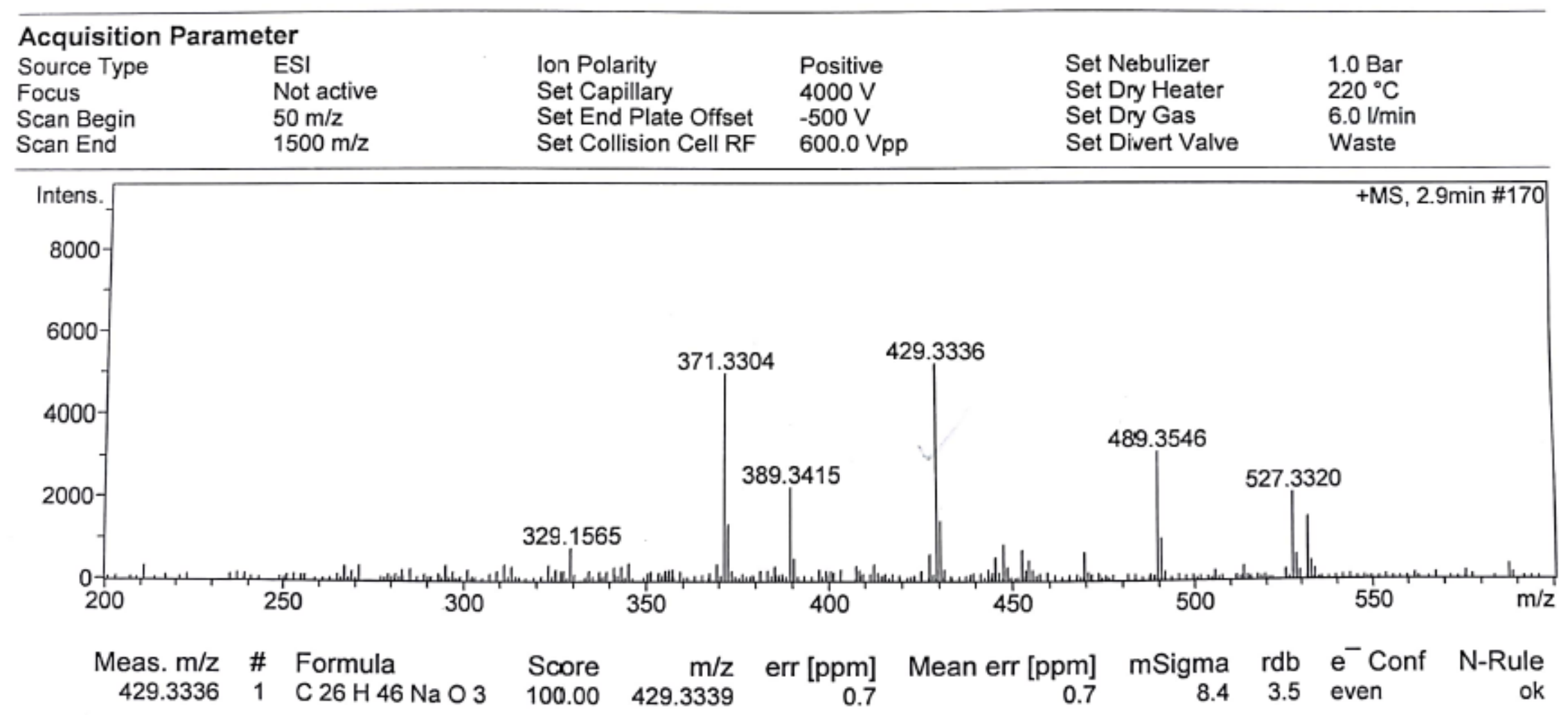

HRMS m/z [M+H] Calcd for $\mathrm{C}_{26} \mathrm{H}_{46} \mathrm{NaO}_{3}$ : 429.3345; found: 429.3336 .

\section{S-74. HRMS spectrum of Imp-13}




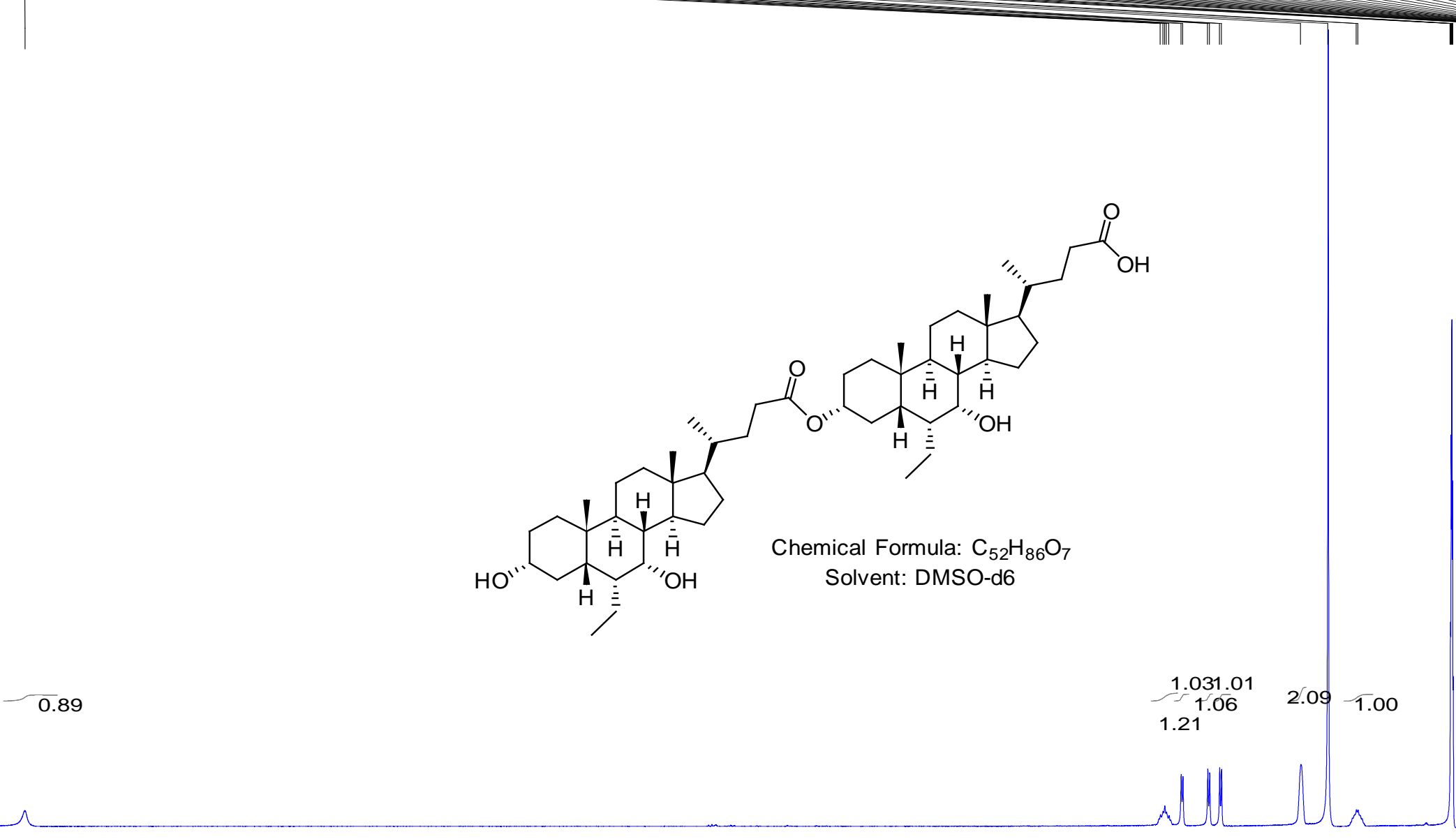

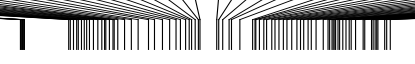

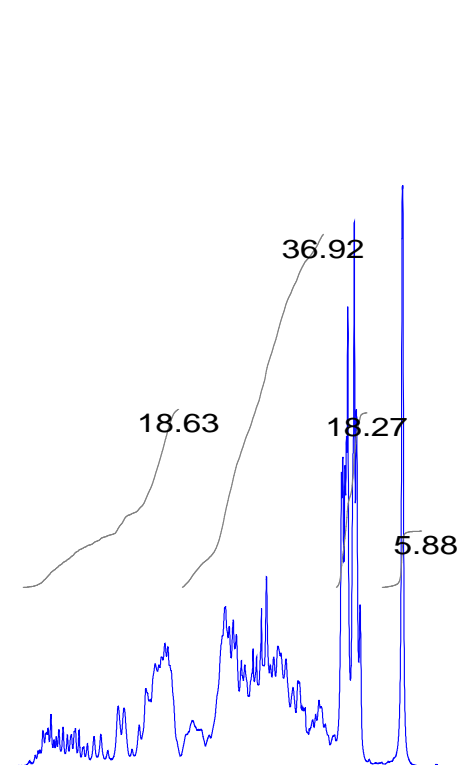

${ }^{1} \mathrm{H}$ NMR (400 MHz, DMSO-d6) $\delta 11.93$ (br, 1H), 4.34-4.43 (m, 1H), 4.28 (d, $\left.J=4.4 \mathrm{~Hz}, 1 \mathrm{H}\right), 4.10$ (d, $\left.J=5.2 \mathrm{~Hz}, 1 \mathrm{H}\right), 4.03(\mathrm{~d}, J=4.8 \mathrm{~Hz}$, 1H), 3.50 (br, 2H), 3.09-3.16 (m, 1H), 1.68-2.30 (m, 18H), 0.92-1.60 (m, 36H), 0.80-0.89 (m, 18H), 0.60 (d, $J=4.8 \mathrm{~Hz}, 0.8 \mathrm{~Hz}, 6 \mathrm{H})$.

\section{S-75. ${ }^{1} \mathrm{H}$ NMR spectrum of Imp-14}




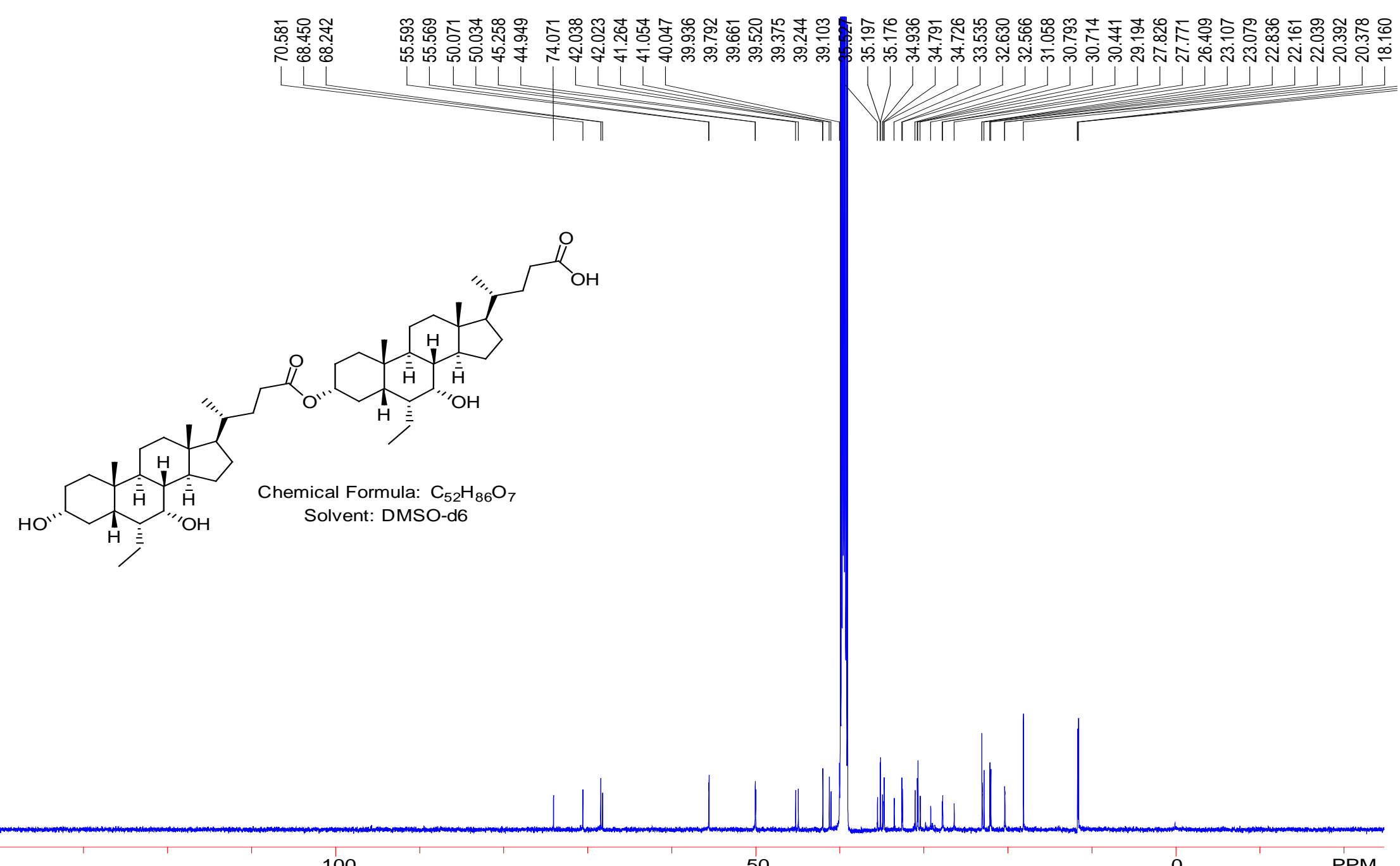

150

100

50

PPM

${ }^{13} \mathrm{C}$ NMR (100 MHz, DMSO-d6) $\delta$ 174.85, 172.67, 74.07, 70.58, 68.45, 68.24, 55.59, 55.57, 50.07, 50.03, 45.26, 44.95, 42.04, 42.02, 41.26, 41.05, 40.05, 35.53, 35.19, 35.18, 34.94, 34.79, 34.73, 33.54, 32.63, 32.57, 31.06, 30.79, 30.71, 30.44, 29.19, 27.83, 27.77, 26.41, 23.11, 23.08, 22.84, 22.16, 22.04, 20.39, 20.38, 18.16, 11.72, 11.68, 11.62 .

\section{S-76. ${ }^{13} \mathrm{C}$ NMR spectrum of Imp-14}




\section{Mass Spectrum SmartFormula Report}

Analysis Info

Analysis Name

Method

Sample Name

Comment
Acquisition Date 5/6/2019 8:52:25 AM

D:IDatalSHUJVFENXIIZHANGFL-groupl15238-71-6_RB7_01_17148.d 20150915.m

15238-71-6

Operator

BDAL@DE

Instrument / Ser\# maXis 4G

21240

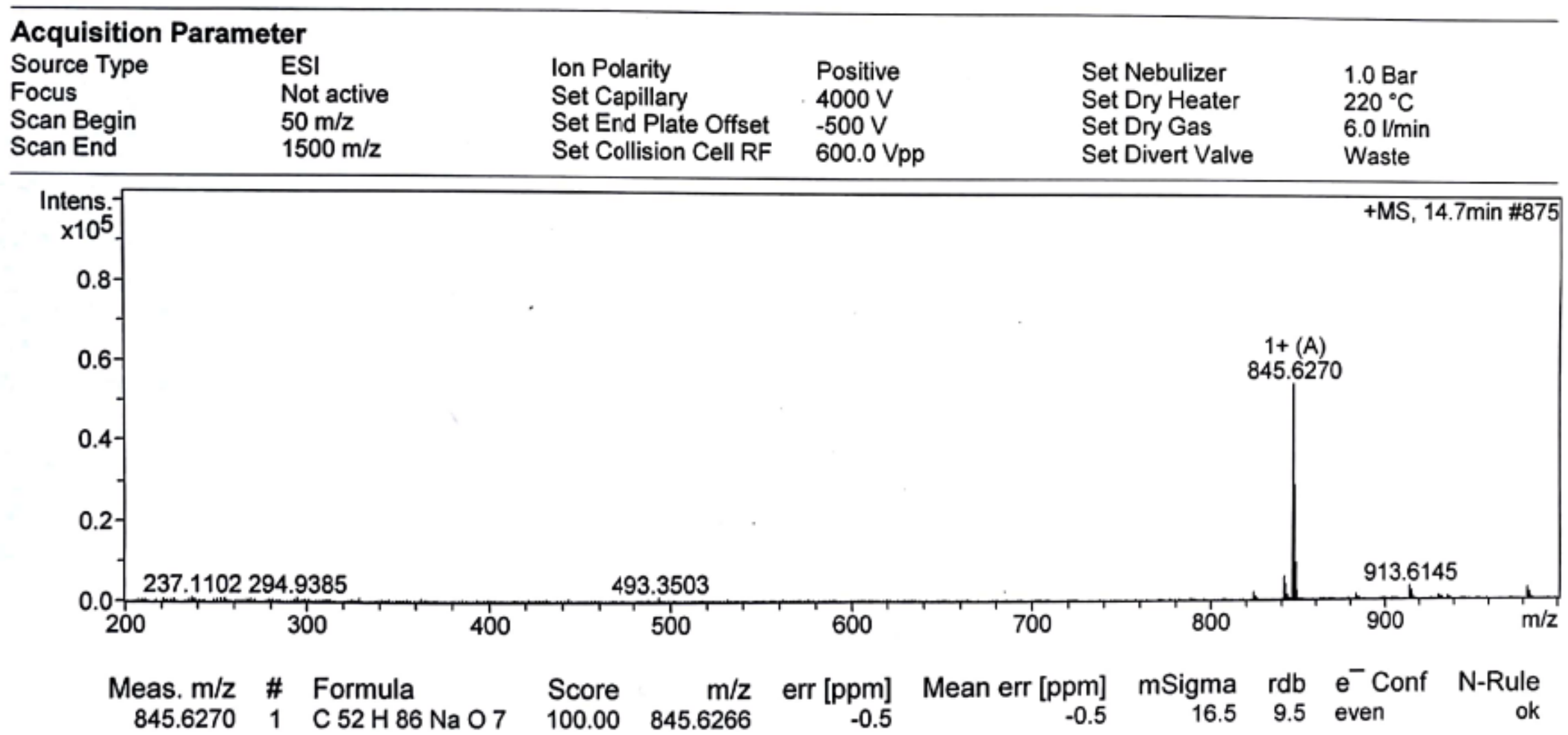

S-77. HRMS spectrum of Imp-14 